University of Louisville

ThinkIR: The University of Louisville's Institutional Repository

Electronic Theses and Dissertations

8-2016

\title{
"This machine kills fascists" : the public pedagogy of the American folk singer.
}

Harley Ferris

University of Louisville

Follow this and additional works at: https://ir.library.louisville.edu/etd

Part of the Rhetoric Commons

\section{Recommended Citation}

Ferris, Harley, "'This machine kills fascists" : the public pedagogy of the American folk singer." (2016). Electronic Theses and Dissertations. Paper 2485.

https://doi.org/10.18297/etd/2485

This Doctoral Dissertation is brought to you for free and open access by ThinkIR: The University of Louisville's Institutional Repository. It has been accepted for inclusion in Electronic Theses and Dissertations by an authorized administrator of ThinkIR: The University of Louisville's Institutional Repository. This title appears here courtesy of the author, who has retained all other copyrights. For more information, please contact thinkir@louisville.edu. 
"THIS MACHINE KILLS FASCISTS":

THE PUBLIC PEDAGOGY OF THE AMERICAN FOLK SINGER

\author{
By \\ Harley Ferris \\ B.A., Jacksonville University, 2010 \\ M.A., University of Louisville, 2012

\begin{abstract}
A Dissertation
Submitted to the Faculty of the

College of Arts and Sciences of the University of Louisville in Partial Fulfillment of the Requirements

for the Degree of
\end{abstract} \\ Doctor of Philosophy \\ in English/Rhetoric and Composition \\ Department of English \\ University of Louisville \\ Louisville, KY
}

August 2016 

"THIS MACHINE KILLS FASCISTS":

THE PUBLIC PEDAGOGY OF THE AMERICAN FOLK SINGER

\author{
By \\ Harley Ferris \\ B.A., Jacksonville University, 2010 \\ M.A., University of Louisville, 2012 \\ A Dissertation Approved on
}

July 19, 2016

by the following Dissertation Committee

Stephen Schneider

Aaron Jaffe

Bronwyn Williams

Jessica Enoch 


\section{DEDICATION}

This dissertation is dedicated to those in my family

who set an example by using their education to educate others-

most especially:

my great-grandfather and namesake, Harley Mitchell (B.A., Beloit College, 1911); my great-uncle, Martin Little (Ph.D., University of Chicago, 1948); and my father, Mike Ferris (M.A., Northwestern University, 2010). 


\section{ACKNOWLEDGEMENTS}

Writing this dissertation has been the most difficult project I have ever attempted, with the possible exception of adequately expressing my gratitude to the numerous people who contributed along the way. It was Derek Hall who hired me as a college dropout and whose encouragement and flexibility allowed me to resume and complete my B.A. Drs. Ray Clines and Sandra Coyle gently nudged me toward Rhetoric and Composition and, along with the outstanding English faculty at Jacksonville University, gave countless hours of their time to support this new direction and career change. The faculty at the University of Louisville likewise deserve my sincerest thanks and appreciation for their enthusiasm and support, as well as key members of this dappled discipline from around the country, including Cindy Selfe and Cheryl Ball for trusting me with responsibilities that made me grow as a teacher, scholar, and human.

I'm immensely grateful to my dissertation committee-Bronwyn Williams, Aaron Jaffe, and Jessica Enoch — for the clarity and insight they brought to this project, thanks to their hours of reading, feedback, conversation, and advice. Thanks also to Mary P. Sheridan for early conversations that both affirmed my direction and sharpened my focus. My highest and most humble thanks goes to my director, Stephen Schneider, whose professional and scholarly example is simultaneously inspiring and intimidating. This dissertation would not have been completed without his assistance, expertise, and camaraderie. 
Saving the most significant for last, I am forever indebted to my family, whose love and faith in me kept me going these past several years. Thanks to Lili and Dave Lauer, who trusted me with their daughter and have cheered us to every victory and encouraged us through every setback. Warmest affection and admiration to my parents, Mike and Bonnie Ferris, for the daily love and unconditional support before and during this entire process through the many phone calls, emails, and visits that buoyed me along the way, and for continuing to be my most ardent fans. Also, I could not be more grateful for or prouder of my sons, Noah, Jonathan, and Dylan, who have brought me more joy than I can describe and who were many times the biggest reason I kept pushing through to the end.

Finally, to my wife, who deserves her own paragraph, I owe my deepest and most heartfelt thanks. Words are inadequate to convey how much this dissertation (and indeed, all of my graduate work) has depended on the unfailing love, trust, and strength she has shown these past six years. Gabi, we made it. 


\section{ABSTRACT \\ "THIS MACHINE KILLS FASCISTS": \\ THE PUBLIC PEDAGOGY OF THE AMERICAN FOLK SINGER \\ Harley Ferris}

June 15, 2016

This dissertation examines the figure of the American folk singer as a public pedagogue engaged in rhetorical action for social change. Through four case studiesWoody Guthrie, Bob Dylan, Ani DiFranco, and Tom Morello- the dissertation examines nearly a century of folk music as a form of activism through these four figures. Each folksinger occupies a unique role in a unique era, requiring each musician to revise the work of their musical forebears to accommodate new cultural and technological environments. Drawing on theories of public pedagogy, rhetorical framing, and media, I argue that an effective use of music in social change depends largely on the relationship between the music, musician, and media. While hundreds of folksingers might have been appropriate to include in this study, these four chart a specific trajectory as each demonstrate a savvy relationship with the technologies that mediate their music, image, and message. This reveals how the ethos of a musician is rhetorically constructed and changes over time in negotiation with the multiple publics in which the musician circulates. Through specific and intentional framing activities, these musicians offer something of a handbook for how activist musicians can most effectively participate in social action in both physical and digital environments. 
TABLE OF CONTENTS

INTRODUCTION




\section{INTRODUCTION}

In 2006, Bruce Springsteen released his fourteenth studio album, We Shall Overcome: The Seeger Sessions, featuring a collection of songs popularized by folk music icon Pete Seeger. While many music critics seemed surprised by Springsteen's apparent change in tone and genre from his previous records, they nevertheless largely praised the album as a celebration of people's music, noting the rich legacies and traditions on which Springsteen was drawing. In one such favorable review, Pitchfork magazine declares,

Like any good folk record, The Seeger Sessions tackles the tangle of war, strife, poverty, and unrest, but does so without sacrificing joy or release (really, the very reasons people began singing in the first place).... Springsteen has a habit of folding current events into his songs without ever being specific enough to limit a verse to a single time and place. Unsurprisingly, that timelessness syncs up perfectly with the centuries-old songs on The Seeger Sessions, and, if nothing else, confirms that Bruce Springsteen was the right (and maybe only) person for this particular gig. (Petrusich)

In folk music, Springsteen found a cultural expression useful for challenging and critiquing current events while simultaneously celebrating the common citizen. In Springsteen, folk music found an authentic, sincere cultural icon capable of conveying the heartache and hope experienced by individuals and communities for the past century in the United States. These two elements-sincere, authentic songs sung by a sincere, authentic singer — highlight an important dimension of what makes folk music valuable as a tactic in collective action. Additionally, they are inextricably linked and inform each 
other: the content of a song suggests certain commitments on the part of the singer, and the perceived commitments of the singer promote specific interpretations of a song. Therefore, in the case of The Seeger Sessions, we reflexively understand both this collection of songs and Springsteen himself as being committed to the same folk tradition as Seeger — one anchored in social protest as much as traditional folk tunes. The album suggests that, because these songs are important to Springsteen, they should therefore be important to us. It implies that Springsteen wants us to not only understand something about these songs, but also about him. After The Seeger Sessions, we are invited to look at the rest of Springsteen's discography with this revised awareness of his commitments, understanding his larger musical project in light of his public persona. To say that Springsteen is "the right (and maybe only) person" to refresh these songs emphasizes the important role Springsteen's ethos plays in persuading the public that these are "good" songs. In other words, as much as folk songs like these are composed and rhetorically situated, so too is a musician's ethos rhetorically constructed to participate in the meaning-making of folk music.

This relationship between a song and its singer is not new, nor is it confined to folk music — surely, opera audiences in the 1700s would have made some judgments about Mozart by his music and vice-versa. But what folk music demonstrates (along with a select group of other vernacular music genres, like punk, hip hop, and to some extent, country) is that the songs demand a kind of performed sincerity and depend on an appropriate demonstration of character if the songs are to be taken seriously and become useful in fomenting social change. This dissertation explores that recursive relationship between folk music and its performers, proposing that American folk singers might best 
be understood as a particular type of public pedagogue who constructs collective action frames through her music and other pedagogical performances. As will be seen through the case studies that comprise the following chapters, these musicians consciously construct visible relationships between their music and their own politically committed personas, such that the music and ethos of a folk singer are equally important in analyzing and understanding the uptake of their songs.

Specifically, these studies investigate Woody Guthrie, Bob Dylan, Ani DiFranco, and Tom Morello, each as prominent artists in unique time periods, and each working on a similar project in the same tradition, drawing from a common musical and cultural heritage. Considering these four musicians as public pedagogues, the following chapters examine music, musicians, and media as a three-part context in which each musician engages in framing activities. As important as the relationship between the music and musician, the ways the musicians leverage technologies to circulate their music - as well as mediation of these musicians themselves - are equally important in enabling, constraining, and defining what their music can say and do.

The rest of this introduction discusses how public pedagogy and framing activities can work together in unique ways that support pedagogical performances through music. Frames represent interpretive schemata that help us orient ourselves in the world around us by providing us with cognitive and cultural cues that structure our behavior. We might understand rhetorical framing as those activities focused on the political and cultural aspects of framing, and on the construction and dissemination of frames through discourse. Finally, after describing various methods of rhetorical framing, this 
introduction concludes with previews of the case studies offered in this project and an overview of the types of framing activities employed by each musician.

Publics, Pedagogy, and Pedagogues

Describing the persuasive functions of songs of protest, R. Serge Denisoff suggests a difference between "rhetorical" and "magnetic" songs, in which magnetic songs draw people toward specific movements or organizations (like a union song) and rhetorical songs attempt to persuade listeners to adopt a certain political perspective (like an anti-war song) (6). Denisoff contends that both types of songs fall under the broad category of "songs of persuasion" and might usefully be understood as protestpropaganda. Although both magnetic and rhetorical songs observe some social problem or condition and build collective identity around values that attempt to shape listeners' attitudes, magnetic songs offer solutions by way of aligning with or participating in an organization. Rhetorical songs, by contrast, do not attempt to offer any type of solution but instead attempt to persuade listeners to adopt the songs' perspectives on the topic at hand. Denisoff's description of protest songs necessarily focuses on the lyrical content, and Ron Eyerman and Andrew Jamison criticize Denisoff's work for failing to take into account the music and performance of protest songs, particularly the embodied act of group singing. They suggest that only focusing on lyrics misses the collective identity, meaning, and memory inherent in the folk tradition (44).

However, these correctives to Denisoff's examination of songs of persuasion still ignore the figure of the folk singer, and such a focus on lyrics and music exclude the relationships between the music, musician, media, and masses. A folk singer's lyrics, music, and image all work together to provide the cognitive cues audiences use to 
assemble meaning, interpreting who a musician is as much as what that musician is saying. This composite understanding of folk singers and their messages is socially constructed, negotiated, and revised over time, and it simultaneously enables and constrains audiences' interpretations of musicians' activities. William Roy observes that the use of music in social movements appears most effective when music-making is regarded as an embedded activity, which highlights the relationship between the songs, the singer, and the movement's participants. Studying protest music for what it does rather than what it is, as Roy indicates, allows us to see how music entrains interaction and constitutes the movement itself (11). This model of meaning-making emphasizes the role of publics and textual circulation in social discourse, but it also creates room for the musician as a public figure to participate in the negotiation process through a unique brand of public pedagogy. More importantly, it permits significantly more valuable study of the rhetorical work of protest songs by attending to both their messages and effects, rather than solely examining the lyrics and music as objects or artifacts.

Over the past few decades, critical theorists including Henry Giroux, Lawrence Grossberg, and Peter McLaren have discussed the more insidious, implicit instruction in popular culture, leading Giroux to coin the phrase "corporate public pedagogy" ("Cultural Studies" 74) to describe the quiet but persistent influence of Hollywood, Disney, popular music, the video game industry, fast food franchises, and other large companies and organizations that drive much of today's entertainment, goods, and services. However, recent scholarly attention to public pedagogy has brought forth new, interdisciplinary methodologies seeking to define the myriad ways in which "the education of the public occurs in public" (Sandlin, Shultz, and Burdick xv). Glenn 
Savage challenges Giroux's "enveloping negativity" toward "capitalist brainwashing" by maintaining that public pedagogy can be as liberating as it may be oppressive, and that rather than using critical pedagogy to "free" the populace, scholars should work to help people both recognize and participate in moments of public pedagogy (108-109).

Likewise, Jake Burdick and Jennifer Sandlin envision public pedagogy as "polyvocal and polymodal discourse," containing the potential for public resistance that is often "performative, improvisational, and tentative" (118-119). For this reason, Burdick and Sandlin suggest that scholars resist applying known methodologies from other areas of education research to public pedagogy, to allow gaps and spaces in knowledge so that, rather than classify an event or experience through extant categories, we should instead "witness" public pedagogy in action and grow into an understanding of its effects and implications. These new approaches to public pedagogy mark an enormous shift in the way we might think about the "spaces, sites, and languages of education and learning that exist outside of the walls of the institution of schools," allowing us to consider how popular culture might then provide opportunities for public pedagogy to also be used as public resistance (Sandlin, Schultz, and Burdick 1).

In the same way that collective action requires a collective, public pedagogy requires a public. Michael Warner observes that publics emerge around public texts, and the circulation of a public text provides a reflexive shaping of interpretation, understanding, and identity for both the text and the public(s) in which the text travels (66). Participants in these publics may then produce more texts - in dialogue with each other and previous texts - but it is nevertheless the circulation of those texts that remains the impetus for publics' emergences. Similarly, Gerard Hauser reasons that "publics do 
not exist as entities, but as processes," because it is the activity of discourse that creates and constitutes a public (64). Therefore, publics are pedagogical insofar as the discussions and generic characteristics of the public texts circulating within and between publics teach participants how to read and comprehend the texts.

Moreover, as publics align with or against texts based on the ideologies inherent in the texts, publics adopt texts in certain ways that constrain textual meaning to resonate with a public's investments. A public then discusses these texts in specific ways, attempting to persuade others to adopt particular values, perspectives, and identities. In this way, publics are also rhetorical. Hauser observes that "intersubjective meanings" the meanings that constitute a collective "we" rather than "I" multiplied - create intersubjective realities: "Public reality comes into being precisely because its meaningfulness is shared among subjects" (67-68). The effect of rhetorically constrained reality, then, has enormous implications for how texts are read, what they mean, and, ultimately, what they are.

In examining the relationship between publics and public figures, Warner argues that the increased circulation of image-based media, coupled with a ubiquitous discourse of consumption, has led to a significant shift in the way publics regard public figures. He explains, "Where printed public discourse formerly relied on a rhetoric of abstract disembodiment, visual media, including print, now display bodies for a range of purposes: admiration, identification, appropriation, scandal, and so on. To be public in the West means to have an iconicity, and this is true equally of Muammar Qaddafi and of Karen Carpenter" (169). Therefore, considering the implications of iconicity and intersubjective meanings in public discourse, these theories offer a way to read public 
figures as public texts, for which the public - much more so than the public figureshapes, constrains, interprets, and in many ways controls who and what a public figure is and says.

If, as critical theorist Henry Giroux claims, films and other media "operate within limits set by the contexts in which they are taken up" (Breaking into the Movies 11), and if we are to consider musicians as a public text, then we can infer that musicianssituated in their various contexts at different times - are similarly constrained by the public's reading of them. Warner says as much, claiming,

It seems inevitable that the world to which one belongs, the scene of one's activity, will be determined at least in part by the way one addresses it. In modernity, therefore, an extraordinary burden of world making comes to be borne above all by style. ... The question of style, at any rate, entails a worry about the nature and duties of the intellectual. (129)

Put another way, the style (and/or genre, medium, mode, or delivery) of a text, situated in the context of a public, directly shapes the way a text can be read and understood. "To publish in a certain venue," Warner argues, "is to orient oneself to its circulation, as a fate" (128). The flipside of the constraining nature of situated contexts, then, is the expectation from individuals that the public pedagogue performs her role in a prescribed way that aligns with the desires and identity of the pedagogue's public.

However, the recursiveness of Warner's model of publics nevertheless allows for intervention on the part of the public figure - in this study, popular folk musicians. Moreover, in order for a public to emerge around a text in the first place, the creation of that text itself assumes an interested audience. Thus a self-selecting public that participates in discourse is in some ways in fact anticipated and summoned by the text(s) it chooses to discuss. This mutual attraction, so to speak, is the resonance that turns audiences into fans, and it again reinforces the essential connections between the music, 
musician, and media. This reciprocal relationship is perhaps best understood as a framing process that involves both the music and the musician's persona as mutually constructed by a musician and the public. As an embedded activity that entrains interaction and organizes participation and mobilization, protest songs are then not so much frames themselves as they represent the activity of framing — again, what music does rather than what music is. Therefore, a musician seeking to build an audience can employ rhetorical framing as interpretive schemata that help perform her public pedagogy.

Folk Music as a Form of Collective Action Frames

Rhetorical framing is a method of signification that highlights certain aspects of a text, event, or situation to propose a specific interpretation. Framing is a common and useful practice in social movement organizations because it allows movement leaders to critique cultural and political texts and events in ways that support their narratives, winning participants to their causes who resonate with and are persuaded by their frames.

David Snow et al. use the term frame alignment to describe the process whereby social movements mobilize participants through demonstrating "congruent and complementary" interests between individuals and the organization (464). If successful, the activity of frame alignment creates a condition called frame resonance, and the degree of success depends on three, interrelated tasks:

(1) a diagnosis of some event or aspect of social life as problematic and in need of alteration; (2) a proposed solution to the diagnosed problem that specifies what needs to be done; and (3) a call to arms or rationale for engaging in ameliorative or corrective action. The diagnostic and prognostic framing tasks are directed toward achieving consensus mobilization. The latter task, which concerns action mobilization, provides the motivational impetus for participation. (Snow and Benford 199) 
Framing processes, then, focus on three elements: injustice, identity, and agency. According to William Gamson, collective action frames should not merely bemoan bad circumstances but should demonstrate injustice within a particular issue. Rather than hardship being caused by misfortune or uncontrollable forces, an effective collective action frame points to specific entities—such as individuals, organizations, movements, governments, and so on —as parties responsible for causing or exacerbating a problem. This assists in a second component of collective action frames: building collective identity. Usually reducible to an "us" versus "them" binary, a collective action frame seeks to align participants into a collective "we," and where the injustice aspect provides context for a particular issue, the identity component contextualizes a particular movement. (For example, seeing the injustice of poor labor conditions helps people understand the issue of workers' rights; viewing oneself as an exploited worker attracts people to join a union.) Finally, in order to support any kind of activity, a collective action frame must offer some agency for a group to feel that something can be done and to provide a mechanism with which to do it (such as a strike to force negotiations, completing the labor example). Gamson argues that all of these elements must be present in order for a collective action frame to be effective and sustainable, otherwise the frame is too weak to persuade participants to join or act (90-100).

As a theoretical lens, framing has become a popular way of analyzing social movements and collective action, but as Robert Benford discusses, its wide uptake has resulted in something of a loose set of definitions and applications. In particular, Benford worries that too much framing analysis fails to distinguish between "frame" as a verb, referring to the activities of interpretation, and "frame" as a noun, referring to the 
boundaries drawn around certain aspects of a text (413). Similarly, Benford suggests that framing analyses too often refer to a static "thing," rather than a dynamic process of "social construction, negotiation, contestation, and transformation" (415). One possible remedy, he proposes, would be to study social movements as they change over time, observing how strategies and tactics evolve and adapt, rather than simply studying a slice in time or activity. Finally, Benford warns against the reification of movements and activities, observing scholarly tendencies to refer to social movements as actors. This, he insists, anthropomorphizes social movements to an extent that overlooks or erases human agency and the role of emotions in collective action frames (418-419).

The use of framing in this project borrows from the above descriptions of collective action frames, primarily drawing on Gamson's three-part structure of injustice, identity, and agency, but also incorporating inquiries into specific actions to make discussions of agency more robust. At the same time, this project also addresses Benford's concerns by focusing not on the artifacts but on the activities of folk musicians within various social movement projects over a period of several decades. Emphasizing the actual frames themselves runs the risk of overlooking how folk singers draw on previous models of framing while also revising framing practices based on changes in culture, politics, and social understanding of issues. What is needed instead is a relational approach to the figure of the folk singer that accounts for the particular performer in a particular time and place with a particular public. Simply, what constituted effective framing strategies for Woody Guthrie, for instance, could not merely be imported into Bob Dylan's work, and what Dylan developed to suit his own time and place would need to be challenged and further revised by Ani DiFranco, and so on. 
In light of the above discussions of process, consensus-building, and mobilization, framing should be understood not as a byproduct of rhetorical action but as a rhetorical act in itself. For each musician covered in this study, their construction of collective action frames is not incidental or occasional but is integral and persistent throughout their creative and critical work. Through lyrics, essays, and interviews, the singers in this study build grievance frames, or injustice frames, that attempt to logically diagnose problems, pointing out how hardships may be linked to malfeasance by responsible parties. By recognizing a shared grievance, the musician has already begun building identification into their collective action frame, drawing on the shared experience as a common interest. However, beyond lyrics or statements, the music itself also participates in the identification process, invoking a common heritage, class, or social status. Additionally, the personas of these musicians—no less composed than their songs—play a significant role in fostering collective identity, too. From Woody Guthrie's work shirt to Bob Dylan's sunglasses to Ani DiFranco's shaved head to Tom Morello's raised fist, each of these musicians use their appearance to signify their commitments and identify with their respective tribes. Whereas their words work largely on a communicative, logical plane, their sounds and images rely heavily on a pre-communicative, affective set of appeals that underpin the public's understanding of what their songs mean.

What remains most difficult to measure is agency, uptake, or success, especially when folk singers are not directly tied to a specific social movement organization. A project like "worker's rights" or "feminism" is simply too large and varied to operate as an individual movement. Certainly, one might consider record sales, concert venue size, career longevity, or celebrity status as indicators of success, but these do not directly 
translate to social change in the way one might consider legislation or voter registration numbers as positive proof of a social movement's success. Instead, the case studies in the following chapters consider the agencies that allow each musician to accomplish their work and provide a means for audiences to participate in collective action, even when that action is simply singing along.

Framing reveals its pedagogical dimensions in four ways, identified by Snow et al. as four types of frame alignment processes: frame amplification, frame transformation, frame bridging, and frame extension (467). These four processes offer different ways of accomplishing the same purpose, which is the mobilization of participants, and yet they remain distinct in their pedagogical methods, based on the relationships between the pedagogue, the public, and the text. These processes are also flexible and overlap at various points, and they are intensely pedagogical and rhetorical processes that are common and recognizable enough to be internalized or overlooked in social movement activities. As methods of public pedagogy, they offer a more flexible framework that allows more robust inquiry over time, such as over the course of an artist's career, rather than simply examining each of an artist's texts in isolation. What they provide, in fact, is a way of viewing a musician's creative and critical output as an entire project, and the many and varied performances that comprise a career can be measured against the projects of musicians who came before and those who follow. Focusing on these four strategies as specific framing activities - rather than simply describing the frames themselves - helps avoid the pitfalls noted by Benford while also providing something a bit more practical in terms of reproducible strategies rather than merely observing uniquely situated phenomena. 
(Re)Framing the Folk Singer

The case studies in this dissertation were chosen to tell a specific narrative about how folk singers have enacted public pedagogy throughout the shifting technological and cultural landscapes over the last century. The commitments of each are largely the same- empowering and giving voice to the marginalized, condemning systemic violence and oppression, and promoting equity and respect among all people — but their methods necessarily changed to suit their own times and places. What these four case studies offer is a kind of genealogy or trajectory, rather, in which each musician builds on previous work and points to the future through adapting the model of public pedagogy that was largely crafted by Guthrie, arguably the first folk music superstar. As each musician deconstructs and reconstructs what it means to be a public pedagogue, technology appears to be significantly responsible for reasons the previous model of public pedagogy needed updating.

Although there were notable folk singers before Woody Guthrie, none had achieved the level of popular and critical success he realized. Guthrie typified the American folk singer through his music, clothing, quips, and cross-country travel. $\mathrm{He}$ modeled musical activism by participating in causes for farm workers and impoverished people throughout the country. During this time, the recording industry began to develop a catalogue of folk musicians and recordings, and, along with radio broadcasts, brought folk music to a wide and diverse audience. Guthrie's songs spoke of poverty, migration, labor, and anti-fascism, and his music and persona not only inspired but in many ways set the mold for folk singers to follow by cementing in the public memory what a folk singer was all about. Through radio, Guthrie honed his Okie persona, earning the trust of the 
listening public with the implicit message, "I'm one of you." Visually, Guthrie wore working-class clothes, bore the look of a man hardened by hopping trains, and announced through a sticker on his guitar, "THIS MACHINE KILLS FASCISTS.” Collectively, the sounds and images of Guthrie performed essential pedagogical functions, and the media of radio and newspapers allowed for the rapid circulation of his rhetorical frames. When he sang about the difficult life of migrant workers and the hard time they were given by the bankers who took their homes, he clarified the

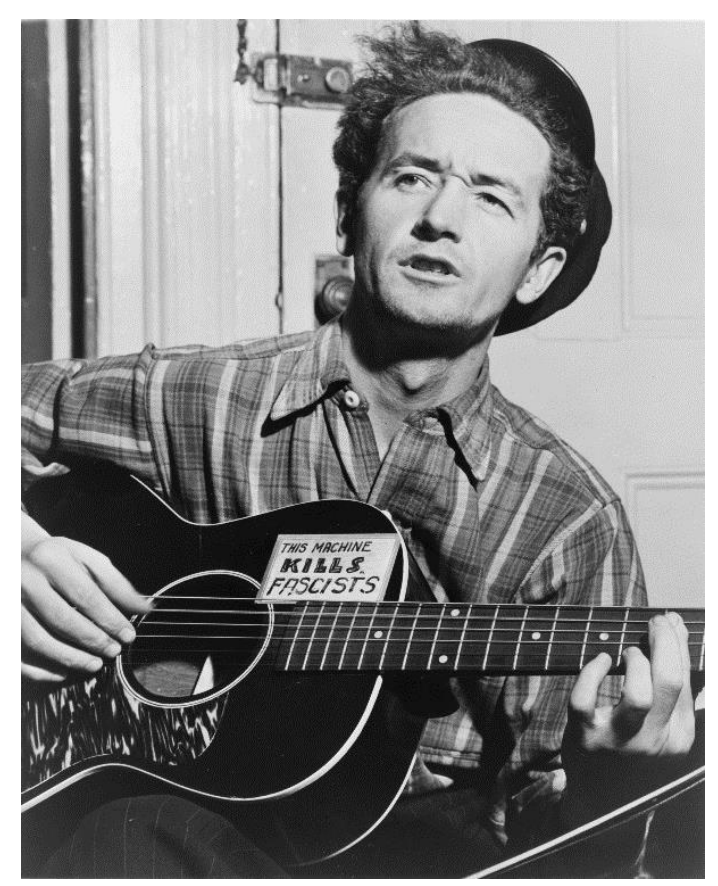

Figure 1: Woody Guthrie, seated, singing and playing guitar / photo by $\mathrm{Al}$ Aumuller.

reasons for why those workers struggled. In frame amplification, social movement organization leaders gain support for their cause through "the clarification and invigoration of an interpretive frame that bears on a particular issue, problem or set of events" (Snow et al. 469). Returning to the same themes again and again, Guthrie employed frame amplification as he connected the characters and events in his songs and stories to the values and beliefs of his audiences, effectively teaching them about their situation and supporting participant mobilization by raising the visibility and importance of their circumstances.

Near the end of Guthrie's life, folk music saw an enormous revival, producing many new performers in the genre, but perhaps none as prominent as Bob Dylan. Dylan took the folk world by storm, dubbed both savior and spokesman by popular media. 
However, despite Dylan's supersonic rise to folk fame, his tenure as a folk artist was relatively short lived, turning as he did to electric guitar and rock and roll. In considering Dylan as a public pedagogue, one must wrestle with Dylan's ostensible reluctance to being a champion of causes or any other kind of prophet or people's hero. Whereas Guthrie used his music and persona together as the vehicle for his framing work, Dylan became keenly aware of how the mediatedness of his image obfuscated any true understanding of who he was. Rather than rejecting televisual technologies, however, Dylan embraced them, using film and television as ways of demonstrating again and again how little truth could be conveyed through the media.

As much as Guthrie crafted his consistent persona to say, "I'm one of you," Dylan repeatedly tried on new hats as if to say, to use the title of one of his songs, "I'm not there." This recasts much of his capriciousness as less antagonistic and more purposeful, and Dylan's pedagogical framing takes on new significance, particularly alongside some of his contemporaries like Andy Warhol, Marshall McLuhan, and The Beatles. Dylan began his career closely emulating Guthrie, but when he rocked the folk world by going electric, he employed a new strategy in frame transformation, which "may not resonate with, and on occasion may even appear antithetical to ... extant interpretive frames" (Snow et al. 473). Put another way, Dylan told his confused audiences, "You're looking at this all wrong." Although he abandoned Guthrie's model of rhetorical framing, he was no less calculating or pedagogical in his relationship to the public. Between Guthrie and 
Dylan, enormous shifts in technology and culture had occurred, and a new era demanded a new interpretive schema. Thus, demonstrating frame transformation, Dylan can be seen as retaining many of the same commitments as Guthrie — can even be considered remaining completely

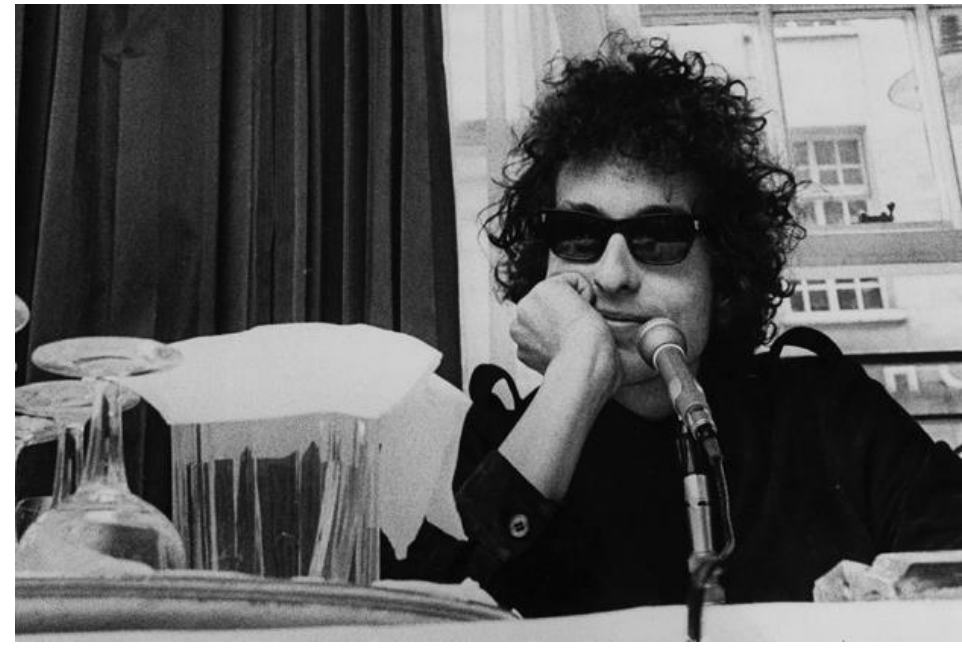

Figure 2: Bob Dylan in dark sunglasses, smirking and silent at a press conference / photo by Fiona Adams sincere and authentic as he adopted new personas - but he saw a need to update the way audiences understood their relationships to him and his material. Ultimately, Dylan's project in part exposes folk music in the 1960s as something very far afield from what Guthrie helped create, and it is quite possible that in leaving folk music behind, Dylan helped save the most important parts of it.

Near the end of the 1980s, when folk music was the farthest from most audience's minds, Ani DiFranco released her first album through her own independent record label. Only 18 years old, DiFranco wove elements of punk, rock, hip hop, and jazz into folk music, helping to put the alt-folk genre on the musical map. Touring extensively, DiFranco connected with her audiences across North America, quickly becoming a feminist icon for her views and efforts backing various causes and campaigns, including abortion rights and LGBT issues. In 1996, she was invited to participate in a concert celebrating the opening of the Woody Guthrie archives in New York, where she took the stage with other notable musicians including Billy Bragg, Arlo Guthrie, Ramblin' Jack Elliot, and Bruce Springsteen, cementing her place in the folk music camp. As a female 
and queer feminist, DiFranco radically revises the Guthrie model while also taking into account Dylan's lessons on media and corporate capitulation. Rather than rejecting attempts to be understood, however, DiFranco decided that she could remain true to her commitments if she built her own subaltern publics. When she first appeared on the folk scene, sporting a shaved head and combat boots, she signaled that she was not a part of the dominant culture. Rather than follow Guthrie's proclamation of "I'm one of you," she instead asks a question, "Are you one of us?"

Frame bridging links two or more existing “ideologically congruent but structurally unconnected frames regarding a particular issue or problem" (Snow et al. 467). For DiFranco, who appears to have made her life's work all about

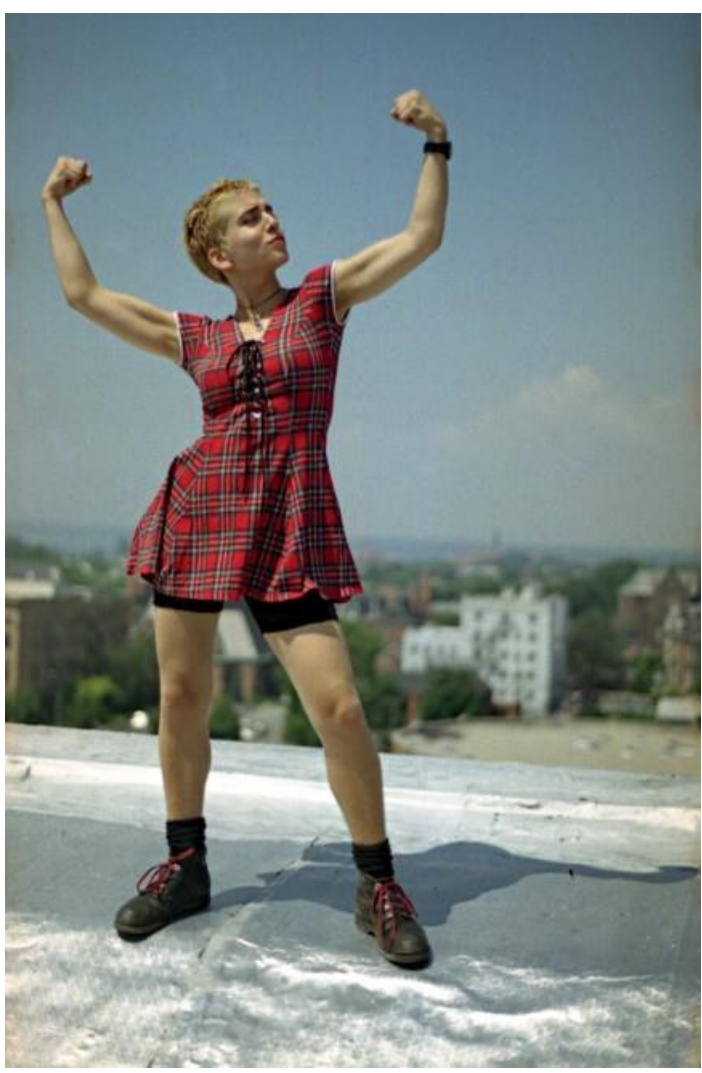

Figure 3: Ani DiFranco, flexing muscles, standing on a rooftop overlooking a city / photo by Scot Fisher

demonstrating how patriarchy lies at the root of all of society's evils, frame bridging is an ideal type of frame alignment for reaching audiences who do not identify with feminism but who would be open to supporting complementary causes. Similarly, frame bridging is an effective process for showing feminists—DiFranco's "tribe," as she calls them-how other issues outside the immediate purview of feminism are likewise worthy of their attention. Certainly, DiFranco also employs frame amplification in ways similar to Guthrie, and her career is punctuated with moments of frame transformation in line with her queer identity and agenda. But DiFranco appears to draw on both Guthrie and Dylan 
equally in a new way, again because of shifts in technology and culture, and she is thus able to reconcile the two through frame bridging. Because of advances in recording technology, cable television, and the ability to communicate directly with her fans through the Internet, DiFranco has been able to fully sustain her own career and leverage those technologies in the promulgation of her rhetorical frames.

As a member of Rage Against the Machine, Tom Morello pioneered a new style of playing electric guitar as the band launched their unique brand of activist rap-metal, taking up both local and global issues of politics, economics, and race. Morello is also a part of the Axis of Justice, a collective of musicians who acknowledge and promote activist work around the world. After the breakup of Rage Against the Machine, Morello joined Audioslave, a popular but largely apolitical band. Frustrated by the lack of activism with Audioslave, Morello decided to

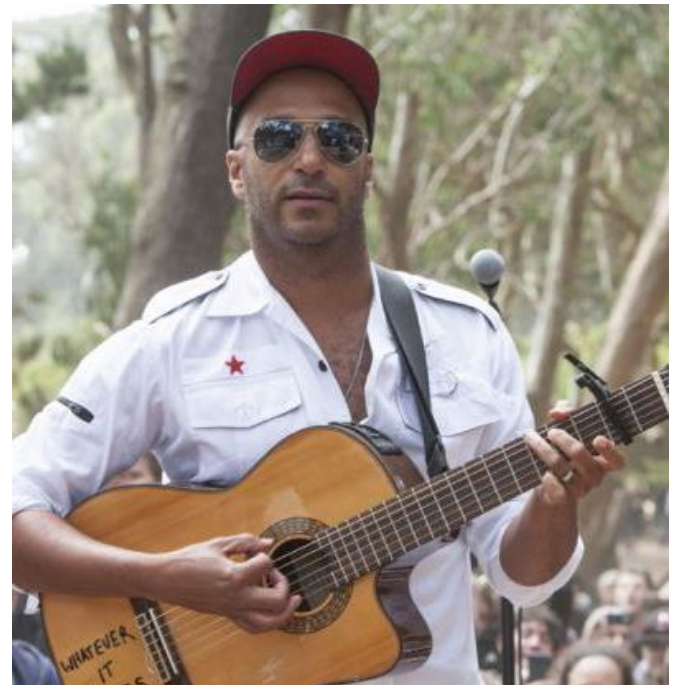

Figure 4: Tom Morello, facing the camera and playing guitar at an outdoor venue / photo by Tom Tomkinson take up an acoustic guitar and start singing folk songs, beginning with the songs of Woody Guthrie and Phil Ochs. Seeing an immediate resonance with his audiences in a more intimate way than ever possible with his previous music, Morello began to write, perform, and record original folk music for a new generation, taking the moniker, "The Nightwatchman." Although his new style of music changed the venues in which he would appear, the introduction of YouTube, Twitter, and other Web 2.0 technologies put him in touch with his fans in newly immediate and direct ways. Moreover, his adoption 
of folk music granted him and his music a new level of portability, allowing him to travel directly to any site that he felt warranted attention. Calling himself "the black Woody Guthrie," Morello probably most closely resembles Guthrie's model of public pedagogy of all the musicians studied, from the songs and style of his music to even his physical appearance, typically performing in either a plain t-shirt or a quasi-military shirt and an International Workers of the World ball cap. Also like Guthrie, he has inscribed his numerous guitars with various messages, such as "ARM THE HOMELESS" and “WHATEVER IT TAKES.” And yet, despite his obvious emulation of Guthrie, Morello seems to draw his attention to his image from Dylan (as well as many choice words about corporate media). Also, like DiFranco, Morello has started his own record label, Firebrand Records, to retain complete control of his music and avoid participating in the corporate corruption of commercial record labels. He frequently reminds audiences and interviewers that he is a union member, and that despite his fame and financial success, he is as committed to the people as he ever was, echoing Guthrie's assertion, "I'm one of you."

Morello clearly exhibits the Snow et al.'s final framing activity, frame extension, which is a process of "extend[ing] the boundaries of its primary framework so as to encompass interests or points of view that are incidental to its primary objectives but of considerable salience to potential adherents" (472). When Morello turned to folk music, he demonstrated a type of frame extension that connected protest songs from the 1920s and 1930s with present-day issues, like the Wisconsin Teacher Union battle in 2012. Morello has had tremendous success mobilizing individuals through social media, suggesting that the rapid increase of textual circulation brought about by radio continues 
to accelerate through each new age of technological innovation, and that Web 2.0 appears to be an extremely effective set of channels for distributing rhetorical frames.

What these four case studies demonstrate together is a consistent process of constructed meaning-making throughout a shifting cultural, political, and technological milieu. Understanding how music and shifting media spaces participate in the construction of a musician's persona provides a means for understanding how a folk singer can function as an agent in the process of protest and social change. 


\section{WOODY GUTHRIE}

The 1940s were a frustrating time for progressive Americans. The economic and social gains made by labor unions and Franklin Delano Roosevelt's "New Deal” had been tempered by price freezes during World War II, and mass unemployment of returning veterans presented an enormous concern that the country might slide back into economic depression. The implications of the war-ending atomic bombs cast a shadow over the consciences of many, and Harry S. Truman's plans to contain the Soviet Union and rebuild Europe forecasted the Cold War. Relations between Congress and the president had become greatly strained, with Congress rejecting Truman's "Fair Deal" proposals and overriding many of his vetoes of their legislation. As commodity prices were restored after the war but labor wages were not, workers' strikes abounded, leading both politicians and the public to call for a moratorium on striking. Morale was low, and by the time Truman ran for re-election in 1948, his approval ratings had plummetedonce as high as $82 \%$, down to $32 \%$.

When Roosevelt's previous vice-president, Henry A. Wallace, joined the U.S. presidential race in 1948 for the Progressive Party, he gained the support of not only many labor groups, but also the folk music community, who had been active participants in the labor organizing efforts for decades. This support included an official endorsement from People's Songs, a folk music organization co-founded by Pete Seeger. Archivist and folklorist Alan Lomax sat on the board of directors for the organization and assumed the 
role of planning the music for Wallace's campaign, tapping the talents of Seeger and Woody Guthrie, among others, to write songs that would rally voters. Wallace, who had also gained public support from the Communist Party, faced severe criticism and accusations throughout his campaign for his alleged communist ties and ultimately failed to gain a single electoral vote in the election. Wallace's abysmal failure led many folk musicians to question whether folk music in general was still an effective tool for social action. Guthrie, however, emphasized a significant distinction, insisting that it was not the genre of music but its poor implementation that failed the campaign. In a sharp, seven-page letter to the organization, Guthrie leveled a scathing critique at Lomax and People's Songs to indicate his opinion that the election was effectively decided by its (mis)use of music:

How much of the Progressive Party blowup and letdown is due to the failure of our songs? I say that the songs stood at the head of the list in attracting (for close inspection) some of the largest audiences ever ganged together to listen to the words, facts, prophecies, and freedom words of our artists and of our candidates; our songs then, must sure stand up first to be counted, first to be taken apart nut by nut and bolt by bolt, first to be looked at under the most critical microscope that we can find to use. (Kaufman 141)

Guthrie argues that it was the music that initially grew support for Wallace, speaking to the organizing power of folk music. Wallace's rallies indeed attracted large numbers, including a 48,000-strong event at Yankee Stadium. The reality of Wallace's loss, however, reveals a lack of mobilization, leaving Guthrie to question why those whom he believed were invigorated by the music were nevertheless unmotivated to vote for Wallace on Election Day. Of the songs used during the campaign, printed in a songbook titled "Songs for Wallace," Guthrie singled out "I’ve Got A Ballot" as a particularly offending number. Set to the tune of the traditional song, "I've Got A 
Sixpence," with lyrics by Yip Harburg, "I've Got A Ballot" is unique among the collection in that it specifically addresses the act of voting, rather than simply raising support or building enthusiasm for Wallace. Folk singer Oscar Brand recorded the song, which begins with the following lines:

I've got a ballot, a magic little ballot

I've got a ballot, and it means my life

It means freedom from want

It means freedom from fear

And all the dreams we shared with F.D.R.

The Republicans, they grieve me

The Democrats deceive me

But I've a brand new party, believe me

As we go rolling up the vote

A cheerful tune with a lively tempo, the music of "I've Got A Ballot" indeed feels appropriate for a campaign rally in 1948, but Guthrie disparages the song as a contrived attempt that completely misses its mark. In his critique, he blames the song's lyrics and, more importantly, the musical director, Alan Lomax.

How a man with such a long road of sensible travels behind him, Alan Lomax, could expect such a shallow jingly and insincere number as 'I've Got a Ballot' to touch the heartstrings and conscience of the hard-hit masses, is a problem beyond me. I never did hear a living human being call his vote a 'magic little ballot.' People I have seen call their vote a number of things, none of which are nearly as cutiepie, as highly polite, as flippant, as sissy nor effeminate as this song. (Kaufman 141)

In this brief passage, Guthrie's insight is sharp and significant. Far from merely disparaging their song choices, Guthrie reminds Lomax and company that, despite their thorough knowledge of folk music, they were greatly out of touch with the folk behind the music, the "hard-hit masses" who failed to resonate with the campaign's songs. His diatribe suggests their audience were both more intelligent and more disaffected than People's Songs understood, and, while too simple an explanation and impossible to 
quantify, Guthrie seems to assert that the masses filtered their assessment of Wallace through the campaign's music. ${ }^{1}$ His letter implicitly reminds his colleagues the reason they welcomed him into their circle in the first place: his resonance with and unswerving support of average people. Guthrie's confident rebuke suggests that he knew the common citizen better than they did. Certainly, by 1948, Guthrie's country rambler reputation and his Okie persona had been well established and highly circulated, and he demonstrated his connection to the commoners through the songs he sang, the ballads he wrote, the stories he told, the way he spoke, the clothes he wore, and the ideals he championed.

More significantly, Guthrie's letter affirms the persuasive power of music and reveals his belief that, despite Wallace's poor showing, folk songs are nevertheless capable of playing a supremely important role in mobilizing voters and, more broadly, educating and persuading the public. Guthrie marvels at Lomax's ability to miss the mark so entirely despite the folklorist's "long road of sensible travels," chastising Lomax for failing to grasp what folk music is and how it functions. By pointing out the problems with the Lomax-penned "I've Got A Ballot," Guthrie offers a theory of what effective folk music should be and do.

By calling the song "shallow," Guthrie indicts the song for falling back on platitudes and failing to connect with the masses' concerns. A "magic little ballot" that can make "a little home for kids and wife" indeed sounds like magic, not the hard work of radical change, and for Guthrie, whose own lyrics are frequently deeply grounded in the grit and grime of reality, the trite expression of a "magic little ballot" does nothing to

\footnotetext{
${ }^{1}$ Sheridan, Ridolfo, and Michel discuss a film theory term, "synchresis," as an effect of juxtaposing sound and image that "rests on our ability to receive information through two separate channels simultaneously and our ability to fuse or synthesize that information into a single message" (5).
} 
convey any sense of how radical politics works. The final lyric of the song reads, "Happy is the day when the people get their way / We'll go rolling up the vote" (Harburg). The penultimate line sounds positive and might feel or even be true, but it offers nothing more than telling listeners that they'll be happy if their candidate wins. This is, of course, true for any voter, not just Wallace voters. The lack of specificity-identifying any issues, characteristics, or demographics - keeps the song shallow instead of connecting or resonating with the specific people the song was meant to motivate.

Guthrie then uses the term "jingly," directly invoking the commercial trappings of the music industry specifically and capitalism generally. Sonically, a "jingle" suggests a small, insignificant item, like coins or keys, greatly diminishing the potential magnitude of a large social and political revolution that the Wallace campaign hoped to achieve. As a genre, a jingle is a brief musical composition designed to sell a product and is thus a tool of capitalism. Elsewhere in his letter, Guthrie notes artists who toned down their politics for "the simple jingle of a palmful of coins" (Kaufman 141). Through this comment, Guthrie seems to align "I've Got A Ballot" with weak politics in the name of personal gain, and he implies that listeners are savvy enough to recognize the manipulation of selling, rather than the conviction of truth in song. Thus the jingly nature of this song betrays a concocted, contrived little ditty, rather than an authentic, artistic expression that resonates with the working class.

Perhaps most harsh, however, is Guthrie's calling the song insincere, effectively questioning the integrity of Lomax, the performers, and, by extension, Wallace. In the first verse, the lyrics assert that this magic little ballot "means my life," "freedom from want," and "freedom from fear." The progressives, workers, communists, and others who 
supported Wallace's policies and ideas were surely under no delusion that a Wallace presidency would magically save their lives, give them everything they needed, or remove any fear or concerns they might otherwise feel. However, this song seemed to promise that a Wallace victory meant a utopian future, which would be interpreted at best as naïve and at worst as promising something that no president could ever guarantee to deliver. In his own songs, Guthrie regularly accused politicians, bankers, police, and presidents of being insincere by pointing out their own inconsistencies between word and deed. Referring to "I've Got A Ballot" as such, then, aligns the leaders in Wallace's failed campaign with the same culprits they intended to oppose, and Guthrie again assumes that the people were aware and experienced enough to see this.

A deep, authentic, sincere song is what Guthrie argues was needed, and instead, he concludes, the campaign offered the people a vapid, contrived tune that entirely missed the mark. Guthrie sums up his indictment of "I've Got A Little Ballot in the final line of the letter's excerpt above: "People I have seen call their vote a number of things, none of which are nearly as cutiepie, as highly polite, as flippant, as sissy nor effeminate as this song" (Kaufman 141). These final adjectives reveal a masculine approach that Guthrie took in nearly everything he did—a direct, forceful, and distilled perspective that examines and exposes problems while calling for strength, pride, and solidarity. And while it might seem counterproductive for Guthrie to attack his friends and colleagues in this manner, Guthrie's letter emphatically demonstrates his belief that folk music is indeed capable of doing serious political work, and that he himself understands how it operates. 
Guthrie's insight in this letter is but one example in an entire career spent demonstrating the social, pedagogical, and rhetorical functions of folk music. As a musician, Guthrie penned thousands of songs that would heavily shape the genre and canon of American folk music, weaving themselves into the fabric of American consciousness. As a writer, Guthrie's stories, poems, polemics, quips, and criticisms simultaneously entertained and educated the general public on a number of topics, based on his own experiences traveling the nation as well as drawing from current events. As an activist, Guthrie participated in numerous rallies, protests, and strikes, both musically and bodily, using his music and messages to deliver powerful insights that praised American ingenuity and championed egalitarian ideals while decrying policies, institutions, and attitudes that worked against common citizens. In short, Woody Guthrie became a folk hero who in turn pointed out the heroics of the oppressed, and his legacy not only in American folk music but in American culture at large cannot be understated. His conscious approach to his craft created a template that countless musicians would emulate, and he remains the quintessential American folk singer, forebear to both the singer-songwriter and the activist musician. This chapter describes how Guthrie harnessed the rhetorical features of folk music through the construction of collective action frames, consciously crafted his public identity and ethos to present an authentic persona, and utilized current technologies of his day to play the role of a critical public pedagogue, enacting a specific kind of rhetorical education through his pedagogical performances. 
The Rhetorical Features of Folk Music and Collective Action Frames

Guthrie's critique of "I've Got A Ballot" presents an argument by negation, but his own songwriting can be examined as a positive example of his theories about how folk songs can be rhetorically effective. Furthermore, they demonstrate how Guthrie used his songs to construct collective action frames, and in so doing, he positioned himself as a public pedagogue. Among the collection of "Songs for Wallace" was Guthrie's own "Wallace-Taylor Train," adapted from his earlier union song, "Farmer-Labor Train," when Senator Glen Taylor was named as Wallace's running mate. In comparison to "I've Got A Ballot," the contrast between the two songs' lyrics is noteworthy, as Guthrie fills his verses with concrete imagery and characterizations, as well as a significant difference in the scale of the movement, represented both sonically and visually in the following excerpts:

From the high Canadian Rockies to the land of Mexico City and the country, wherever you may go Through the wild and windy weather, the sun and sleet and rain Comes a-whistlin' through the country this Wallace-Taylor train

Listen to the jingle and the rumble and the roar She's rollin' through New England to the West Pacific shore It's a long time we've been waitin', now she's been whistlin' 'round the bend

Roll on into Congress on that Wallace-Taylor train

There's lumberjacks and Teamsters and sailors from the sea There's farmin' boys from Texas and the hills of Tennessee There's miners from Kentucky, there's fishermen from Maine Every worker in the country rides that Wallace-Taylor train

This train pulled into Washington a bright and happy day When she steamed into the station, you could hear the people say: "There's that Wallace-Taylor Special, she's full of union men Headin' onto White House on the Wallace-Taylor train." 
Guthrie's own use of the word "jingle" notwithstanding, the contrast between these two songs is remarkable. Rather than the "magic little ballot," Guthrie depicts the campaign (and by extension, voting for Wallace) as a loud, puffing locomotive, crowded with "folks of every color" who are "ridin' side by side." The narrative of the song describes numerous types of people from all across the country, united in purpose and working toward progress by participating in the democratic process, represented metaphorically by the train arriving in Washington. Guthrie's description praises the laborers as hard workers, and he esteems the "wheat fields," "orchards," and "lowing cattle range" as honorable sites of work. And, just as a train is a perfectly reasonable, tangible way of traveling from these locales to Washington, the song suggests that voting in the interests of these hard working people is a logical way to affect change for the greater good. By contrast, a magic little ballot that grants freedom from want and fear seems childishly fantastic and incredibly far-removed from reality.

"Wallace-Taylor Train" provides several insights into the rhetorical dimensions of folk songs. Oscar Brand argues that folk music's sincerity and power lies in its "simple noise," which he defines as "the result of an artless, unself-conscious quality in the music and lyrics" (10). He further explains that "[f]olk song calls the native back to his roots and prepares him emotionally to dance, worship, work, fight, or make love in ways normal to his place" (51). Echoing Brand, Agnes De Mille also observes that folk music's simplicity is its main attraction and usefulness in modern culture: "Folk songs . . . mirror most closely the will and essence of any group, not, to be sure, the great art songs which of their nature are unique, but the lesser and more homely ballads which are typical and which, because they reflect pervasive and common emotion, are remembered and kept" 
(n.p.). Guthrie's particular brand of folk music exemplifies this simple noise and embodies (personifies, even) the American working class experience. Within this simple noise of folk music, struggling working class Americans found resonances with the experiences of their forebears, and the familiarity of the sounds and stories in the songs offered a sense of connection, community, and identity that was not commonly represented in the whole of popular music at that time.

William Gamson's tripartite model of collective action frames focuses on injustice, identity, and agency, and "Wallace-Taylor Train" also outlines one example of how Guthrie used framing to organize people. Initially, as "Farmer-Labor Train," this song was Guthrie's call for a political party of farmers and laborers. After several descriptions of hard working conditions and a list of labor jobs, Guthrie depicts this train "rolling onto victory." The question naturally raised is, "Victory over what?" Herein lies Guthrie's injustice frame in this particular song. His implicit argument is that farmers and laborers, whom he positions as the gears who keep America turning, are not getting their due because of a lack of representation in government. By forming a political party and representing themselves, he argues, their working conditions, pay, prospects, and lives will improve. But it is not simply a mistake that they are not represented-their elected representatives overlook or ignore them, and they must therefore represent themselves. When Guthrie changed the lyrics to "Wallace-Taylor" instead of "Farmer-Labor," the only change in the message was to say, "Here are the candidates who will bring justice to the situation."

Guthrie also fosters collective identity in this song by effectively putting all these workers on the same train. He also uses the first-person-plural: "It's a long time we've 
been waitin'." Not only should all workers unite, Guthrie argues, but he considers himself one of them. This act of solidarity says, "You're part of this large group, and our interests are aligned, so let's work together for the benefit of all." Perhaps more significantly, Guthrie uses this opportunity to reinforce his own ethos, effectively saying, "And I'm one of you, too." This is a clear strategy in rhetorical framing that aligns the collective identity with the persona of a leader, and the leader's values then become a kind of guide for understanding the shared values of a group or movement.

In terms of agency, then, the message is clear: vote for Wallace and Taylor. In this song, voting is the agency, or vehicle, through which social change will occur. Or, in the previous iteration of the song, forming a political party to participate in government will bring social change. In either case, Guthrie's message is that the only way to ameliorate the hardships caused by the injustice of non-representation is to become active in the political process - specifically, to form a party or vote for candidates who will support workers. Through frame amplification, Guthrie is able to reinforce the values and beliefs of his audiences through this song, invigorating the interpretive frame through which they understand their situation and see a way forward.

Guthrie's ideas about the rhetorical force of folk music and its aptness as a vehicle for informing and persuading the public did not simply emerge out of his own head or merely from direct experience; rather, by the time of the Wallace campaign, American folk songs had already been playing an important role in protests and political efforts for decades, particularly in labor organization efforts throughout the South. As folk songs circulated, they became familiar, public texts within working class populations, and, taken together, these texts offered a kind of public pedagogy, providing an alternative 
curriculum in history, economics, politics, and literature. The folk understood their heritage, their struggle, their collective goals, and their lived experience in part through their music, and their participation in making music together fostered community engagement on several levels. Aside from the social function of group music-making, folk music offered a way for ordinary people to articulate and respond to the hardship and oppression they felt on a daily basis. Thus folk music proved to be already well-suited to framing activity, and Guthrie became very adept at using framing for pedagogical purposes.

In Pastures of Plenty, a posthumous collection of previously unpublished writings, Guthrie succinctly describes how folk music participates in populist discourse that is both persuasive and educational:

There's several ways of saying what's on your mind. And in states and counties where it ain't any too healthy to talk too loud, speak your mind, or even to vote like you want to, folks have found other ways of getting the word around. One of the mainest ways is by singing. Drop the word 'folk' and just call it real old honest to god American singing. No matter who makes it up, no matter who sings it and who don't, if it talks the lingo of the people, it's a cinch to catch on, and will be sung here and yonder for a long time after you've cashed in your chips. If the fight gets hot, the songs get hotter. If the going gets tough, the songs get tougher. (Guthrie, Marsh, and Leventhal 78)

Beginning with "several ways of saying what's on your mind," Guthrie affirms non-dominant expression, authorizing his listeners to communicate in ways that circumvent the language and communication channels of the powers that be. He acknowledges that many live under a ruling thumb that prevents their engagement in civic activities, but then suggests singing as a historically proven method of sharing information and speaking truth. (For anyone even remotely aware of the history of slave songs and spirituals, this is an entirely familiar concept.) By then replacing "folk" with 
"real old honest to god American singing," Guthrie does several things. First, he actually dismisses the label of "folk music" (which comes from academics and recording companies) and reminds listeners that this music belongs to them. Second, his use of "real" and "honest" are positive adjectives he attributes to his audience. Finally, he makes the entire process a patriotic one, implying that this might even be their civic duty as Americans, effectively rerouting the democratic process from the dominant channels of society through the subaltern. The next sentence is a crash course in writing a political, protest, or topical song - the author and performer are irrelevant (thus defying commercial interests), but the song must be in the voice of the people (unlike "I've Got A Ballot") and easy to sing. If these conditions are met, Guthrie asserts that the song will endure and be useful, suggesting that Guthrie was aware of rhetorical framing, just as he himself drew on previous songs for adaptation to new circumstances. Finally, he reminds the listener that if songs are to convey truth and knowledge, they must rise to the intensity of the rhetorical situation that demands the response.

R. Serge Denisoff explores this concept of rebellion and resistance through the term "Folk Consciousness," which he defines as "an awareness of folk music which leads to the use of the music in an unnatural environment, such as the metropolis, in the framework of social, economic, or political activity" (Sounds of Social Change 106). Similarly, because of the way folk music's formal features disrupt traditionally high class culture music, Oscar Brand asserts that "folk music is a socially acceptable manifestation of rebellion" (54). In this way, folk music, when presented in a modern or postmodern setting is already making a political, rhetorical statement, simply by its presence. The sounds, stories, instruments, clothing, dialect, attitudes, and other accoutrements of the 
folk music tradition resist the dominant narratives of society that claims to have surpassed and improved upon the earlier times and ideals that originally produced such music, and the incongruence created by folk music's out-of-time-ness critiques society's ostensible progress. The fact that people still resonate with folk songs, still identify with the stories and struggles in the lyrics, still feel stirred by the simple noise of the music, harshly condemns any attempt to suggest that the politicians and bankers and warmongers are steering the country correctly. Thus, despite the so-called progress made in the United States by the time Guthrie entered the scene, the popularity of his type of folk music suggests a wide-spread dissatisfaction with the status quo and a nostalgic longing for a more hopeful era. By this definition, then, folk music in the 1930s was an alternative expression of cultural and political criticism as much as it was a celebrated art form.

Denisoff contends that Folk Consciousness first came into existence as a tactic by the Communist Party in American in the 1930s and 1940s, pointing to Karl Marx's notion of "class consciousness," that the first step in liberating the proletariat was helping them become aware of their situation (Sounds of Social Change 107). In various ways, Woody Guthrie publicly performed the role of the proletariat, wearing the clothes, adopting the language, living the life, and telling the stories of working class people everywhere. His participatory approach implicitly argues that he and his audience are one and the same, and thus all are in it together. Guthrie's consubstantive language is built around empathy, a strategy that Bump Halbritter argues relates to Burkean identification. Insofar as persuasion is most effective when a rhetor fosters empathy for her audience, empathy in itself becomes a form of rhetorical action. As Guthrie identifies himself with 
his listeners, he positions himself and the masses as "the good guys." Likewise, his audience should recognize the "villains" he identifies in his songs as the individuals and organizations in their lives who are responsible for their oppression (such as bankers, police, politicians, and so on).

Regarding the nature of genres, John Frow discusses the "structure of implication, which both invokes and presupposes a range of relevant background knowledges" to create a kind of "complicity" with the audience (9). Speaking of folk music specifically, Leonard Cassuto similarly points to Adam Smith's statement that "sympathy depends on proximity" (n.p.). Thus, if an audience is unaware of the circumstance being discussed, the song will have little persuasive impact. Conversely, if a singer appears to be unaware of an audience's condition or situation, as Guthrie seems to suggest of Lomax in this chapter's opening analysis, the song will again miss its mark. Guthrie demonstrates an effective use of these concepts in "I Ain't Got No Home," for example, as he sings,

I ain't got no home, I'm just a-roamin' 'round, Just a wandrin' worker, I go from town to town. And the police make it hard wherever I may go And I ain't got no home in this world anymore.

My brothers and my sisters are stranded on this road, A hot and dusty road that a million feet have trod Rich man took my home and drove me from my door And I ain't got no home in this world anymore.

Was a-farmin' on the shares, and I always was poor; My crops I lay into the banker's store. My wife took down and died upon the cabin floor, And I ain't got no home in this world anymore.

I mined in your mines and I gathered in your corn; I been working, mister, since the day I was born. Now I worry all the time like I never did before 'Cause I ain't got no home in this world anymore. 
Now as I look around, it's mighty plain to see

This world is such a great and a funny place to be;

Oh, the gamblin' man is rich an' the workin' man is poor,

And I ain't got no home in this world anymore.

In this song, Guthrie names various jobs in which laborers and migrant farmers would have engaged, and by using the first person, Guthrie symbolically joins them in these menial tasks. Each verse identifies a "villain": the police, a rich man, the banker, "mister" (who owns mines), and the gamblin' man. Although a simply constructed and easily sung tune, Guthrie systematically teaches his audience that their lowly state is not their own fault or even bad luck, but that others are responsible for their hardship, and that hardship has very real and very significant consequences. Guthrie, effectively, is not even saying that he "ain't got no home," but, through the structure of implication, that you, the listener, "ain't got no home.” Guthrie acknowledges the hard labor of workers, identifies the culprits of their suffering, and laments the consequences, and in doing so builds an injustice frame through which his audiences can better understand and articulate their own situation. The repeated final line of verse not only underscores the point - the consequence - but it also invites participation through the consistent musical structure, so that by even the second verse, listeners would be able to join in and sing along, affirming that they, too, "ain't got no home in this world anymore."

The participatory capability of folk music is significant, and its singable, memorable style is essential to its uptake and portability. Additionally, when coupled with its traditional simplicity, folk music also becomes highly adaptable, and new lyrics can often be made up on the spot to suit the present situation. Very often in these scenarios, the musician acts as a public pedagogue, using a song to educate the public on a particular issue and to persuade them to adopt the song's position (Sandlin, O’Malley, 
and Burdick 347), as in the above example. However, lyrics are only half of the rhetorical apparatus of folk song. The music itself is able to perform a unique rhetorical function that words alone cannot. William Roy explains that "music is not a non-social activity in social context but is context in and of itself" (15). As Roy continues, "the mutual synchronizing of sonic and bodily experiences creates a bond that is precommunicative and perhaps deeper than shared conscious meaning" (16). Beyond language, individuals align themselves physically and spiritually with the group, defining group solidarity and identity (Eyerman and Jamison 98). Thomas Turino suggests that "[t]hrough moving and sounding together in synchrony, people can experience a feeling of oneness with other" (2-3). This kind of solidarity through shared experience and community aligns perfectly with Guthrie's desire to strengthen collective identity, and is exemplified in such songs as "The Sinking of the Reuben James," a ballad written about the first U.S. ship sunk by the Germans in World War II. The verses recount the story, but the chorus is simple and repetitive: "Tell me, what were their names, tell me, what were their names? / Did you have a friend on the good Reuben James?" Interestingly, Guthrie's initial draft of the song actually listed the names of all the casualties to honor them, but fellow Almanac Pete Seeger observed that the song would be interminably long and not very singable. Guthrie revised to the current lyrics, and by making the lost seamen nameless, he not only made the chorus instantly singable and memorable but also invited listeners to participate in the eulogy with him, since they could now sing along.

In the final verse, Guthrie unites the entire country under one purpose: to honor the fallen heroes by sharing their story and forging ahead united against Hitler. He sings,

Now tonight there are lights in our country so bright In the farms and in the cities they're telling of the fight 
And now our mighty battleships will steam the bounding main And remember the name of that good Reuben James

As if to demonstrate and document the rhetorical effects of this strategy, Guthrie invited Daily Worker writer Paul William Ryan (under the pen name Mike Quin) to join him in the subways of New York in the weeks following the sinking. Quin writes, "Woody's fingers plunked the strings extra hard and his voice cut through the noise with the story of the Reuben James. Pretty soon other people were joining in on the chorus. And that night, hundreds of men and women went home with those words ringing again and again in their minds: "Did you have a friend on the good Reuben James?" (Kaufman 70).

Topical songs like these-songs that describe situations with which audiences would experience first-hand - are then both pedagogical and rhetorical. They do not simply speak about events and circumstances, but they respond. Sociologist and music critic Simon Frith describes music generally as a byproduct of negotiation between social forces and ideas; the music itself is not the conversation but the result of the conversation, so to speak (ix). In other words, music is one of the available expressions that emerges from and as the symbolic inducement of social cooperation (Hauser 14). Similarly, according to Agnes De Mille, "no folk song ever is successful when it does not suit the prevailing need. It is the answer to a situation, not the cause of it . . It has to do with now-how it feels at the moment while the blood is still fresh, while the wind still blows and the calls ring out. No dust ever settles in a folk song" (n.p.). If considered alongside Lloyd Bitzer's concept of the rhetorical situation, De Mille's description of folk music positions it as a form of rhetorical discourse, effectively interweaving the pedagogical and rhetorical features of these songs. Folk songs provide listeners with information, and listeners, via identification and participation, are able to understand and respond to 
circumstances in their own lives. Each of these descriptions of folk music underscore the highly rhetorical potential inherent in folk songs, particularly when employed during Woody Guthrie's time. Moreover, the way folk songs build collective identity is also very often the way they offer agency; the performances and shared music-making experiences reinforce the collective, and the solidarity among the group participates in the organization and mobilization of participants.

Many of Guthrie's most memorable songs use similar framing methods to recount stories of folk heroes ("Pretty Boy Floyd", “Tom Joad," "Ludlow Massacre”), discuss various sides of war ("Reuben James," "Sally Don’t You Grieve," “All You Fascists Bound To Lose"), make visible oppressive living and working conditions (“So Long, It's Been Good To Know Yuh," "Do Re Mi," "Dust Bowl Blues," "Hard Travelin'”), expose corruption ("Vigilante Man," "The Unwelcome Guest," "Old Charlie Lindbergh,"), celebrate human accomplishment ("Grand Coulee Dam," "Union Maid," "Biggest Thing That Man Has Ever Done"), praise nature ("Roll On, Columbia," "Columbia's Waters," "Oklahoma Hills"), and extoll the virtues of community, dignity, and freedom ("This Land Is Your Land," "Pastures of Plenty," "Born To Win"). Likewise, Guthrie's oftquoted passages from his various writings and commentaries hit these familiar themes again and again. If construed as a complete corpus, Guthrie's creative and critical output comprises much more than a collection of pedagogical and rhetorical ideas, but instead reveal something resembling a curriculum in social justice and civic engagement. In other words, Woody Guthrie's career reveals a model of musical activism that functions as a type of rhetorical education, enacted via public pedagogy with Guthrie performing the role of a critical public pedagogue. 
The Cult of Authenticity, the Critical Public Pedagogue, and Rhetorical Education

Equal parts folk singer and radical activist, Guthrie leveraged his celebrity status to consciously craft a role for himself as a public pedagogue, a type of public intellectual with designs on educating the public through his songs, stories, drawings, letters, and performances. Not only did he created a template for musical activism that many still emulate to this day, he also essentially designed the figure or trope of an American folk singer. Guthrie's music and celebrity status were inextricably intertwined: his songs and stories led his audiences to trust him as a public pedagogue, and his trustworthy image in turn led to wide acclaim and the significant public uptake of his music.

The first person to record Guthrie was Alan Lomax, who was strongly impressed by Guthrie's style and sound. Guthrie and Lomax first met at a benefit concert in New York, and Lomax was immediately taken by the stories and songs of the Western frontier, Dust Bowl migrants, criminals, workers, and injustice. According to Lomax, "His guitar has the sound of a big truck going down the highway with the riders bouncing around in the front seat. It was a new idiom and really, all America really responded to that" ("Oral Histories"). Notably, and perhaps ironically, Lomax describes Guthrie's music in opposite terms from Guthrie's criticism of Lomax's campaign song, lauding Guthrie for his down-home, masculine music, nowhere close to "sissy" or "effeminate." Guthrie offered a musical expression that exuded strength, opportunity, hope, and progress, and as Lomax indicates, "America really responded to that."

Guthrie was not simply a musician but a performer, and his greatest performance was perhaps his Okie persona. This persona contributed greatly to his credibility and 
character through what Benjamin Filene calls the "cult of authenticity," but it was

nevertheless a carefully practiced performance. Filene expands upon this concept:

"Revival audiences ${ }^{2}$ yearn to identify with folk figures, but that identification is premised on difference. Roots musicians are expected to be premodern, unrestrainedly emotive, and noncommercial. Singers who too closely resemble the revival's middle-class audiences are rejected by those audiences as 'inauthentic.' Generally, then, the most popular folk figures - those with whom revival audiences most identify - are those who have passed a series of tests of their 'Otherness." (63)

As Filene observes, identification again plays a key role in the uptake of the successful folk musician, and Guthrie demonstrated a mastery of performing the Okie, which endeared him to working class audiences. A self-professed disciple of Will Rogers, Guthrie patterned his banter and mannerisms around dry humor and wry observations, and he played up both his Oklahoma roots and Dustbowl drawl. During one of Alan Lomax's recordings of Guthrie, Lomax laments his own perceived lack of authenticity, stating, "I didn't grow up in the country. I grew up inside of a brick house. I didn't have that kind of experience-I wish I had" ("Rye Whiskey"). Later in the recordings, Guthrie admits that his persona is at least partially constructed, noting that his father had some wealth when Woody was young, and that he was not one of what Steinbeck called "the Okies" ("Beaumont Rag"). Speaking about those recordings, Moses Asch, another archivist who recorded Guthrie, claimed, "You can hear all the put-on he wanted to give Alan Lomax. This is the actor acting out the role of the folksinger from Oklahoma" (Kaufman 41). Lomax's eagerness to document Guthrie and his songs, as well as

\footnotetext{
${ }^{2}$ Folk music in the 1930s and beyond was already something of its own antecedent genre, drawing on music, stories, and stylings of the past. Guthrie was employing an older style of music, albeit in fresh ways, and thus audiences were resonating with the nostalgia of the genre as much as the message, which contributed to the rhetorical force Guthrie's music. Thus many scholars reason that the wide popularity of folk music during Guthrie's time can be considered a folk revival.
} 
Lomax's regret at not being able to boast a similar authenticity, reflects the hunger in the public at this time for an authentic spokesperson. For the rest of his life, Guthrie's authenticity would be invoked and borrowed as a means of lending credibility to performances, recordings, and events. This would continually serve him well as a rhetorical maneuver to establish trust and authority with his audiences, a necessary precondition of fulfilling the role of a public pedagogue.

Patrick Roberts and David Steiner outline their theory of a "critical public pedagogue" working toward radical democracy, framed as a "servant-leader who traverses the space between the normative sphere of subjective articulation and the political realm of institutional determinacy" (20). The authors further contend that "the critical public pedagogue both serves and leads a source of social, cultural, and political critique. Her pedagogical performances 'speak truth' to the power of free market democracy to structure identity in limited oppressive ways" (26). Furthermore, Roberts and Steiner identify two vital responsibilities: (a) to critique the current limited possibilities toward increasing civic participation, and (b) to "develop critical social agency oriented to the public good," which occurs when individuals understand their relationship to dominant political structures (26).

These concerns appear to be Guthrie's concerns, and his roots proved ideal for the incubation of such a public pedagogue. Named for the U.S. president, Woodrow Wilson Guthrie was born in 1912 in Okemah, Oklahoma. Through a serious of family tragedies in his adolescent years, Guthrie found himself living with only an older brother by the age of fifteen, forced to live with friends during the school year and then travel as a migrant laborer during the summers to make ends meet. His firsthand experiences of 
work, travel, and hardship served as something of a crucible for him, shaping early his attitudes about labor, equity, and humanity. Guy Lodgson notes that Guthrie always carried a perpetual sadness but nevertheless remained a fighter and an optimist, and thus became an outspoken critic of oppression in all forms (xii). Guthrie delighted in all aspects of the human experience, and by the time he reached adulthood, he was hopping trains, singing for his supper, and seeing as much of the country as he possibly could while relaying his travels and encounters through story and song to any who would listen. As he traveled, his talent and charisma earned the support and admiration of many, while his rowdy, often cantankerous spirit reflected the hard-knock life of the increasingly hard-pressed lower classes, resulting in the cultivation of an identity that was equal parts genius and familiar. In short, Guthrie demonstrated an incredible talent while appearing to remain true to his roots.

By 1929 , at age 18 , Guthrie was already busking and performing regularly at dances and gatherings. In addition to penning his own compositions, Guthrie was quickly on his way to becoming a walking, singing encyclopedia of American folk music, soon able to perform hundreds of songs upon request. As he developed his repertoire, Guthrie became less interested in dances and singalongs in favor of more performative presentations in which he could be the center of attention, showcasing his music, humor, and folk wisdom and introducing larger audiences to his worldviews. In the mid-1930s, Guthrie joined the Dustbowl migration to California, eventually landing a radio show with Maxine "Lefty Lou" Crissman on KFVD in Los Angeles, California, in 1937. Thousands of immigrant Okies, many still homeless after their travels, tuned into the Woody and Lefty Lou Show and responded favorably to Guthrie's music and message, 
which reminded them of the home they left and offered temporary reprieve from their daily struggle. His songs and stories resonated deeply within populations who were feeling the crush of the Dustbowl and the Depression, endearing him to them as a member of their community who could also possibly gain the ear of those outside for the sake of improving conditions and fomenting social change. Songs like "So Long, It's Been Good To Know Yuh" and "Do Re Mi" acknowledged and documented the migratory experience of laborers struggle to find sustainable employment in the face of agricultural and industrial hardship, while other songs like "Union Maid" and the murder ballad "Pretty Boy Floyd" lionized members of society that mainstream, dominant culture worked to marginalize.

In "Do Re Mi," Guthrie tells of the "bum blockade," a literal barrier to entry in California for hundreds of thousands of Dustbowl refugees. The California government was concerned that poverty of the migrants would increase the state's burden, and in truth, there were simply not enough jobs for the nearly 6,000 per day who tried to enter the state. As a result, the Los Angeles police chief tasked over 100 police officers with stopping penniless migrants at key points of entry. Guthrie sings,

Lots of folks back East, they say, is leavin' home every day Beatin' the hot old dusty way to the California line 'Cross the desert sands they roll, getting' out of that old dust bowl They think they're goin' to a sugar bowl, but here's what they find Now, the police at the port of entry say "You're number fourteen thousand for today."

Oh, if you ain't got the do re mi, folks, you ain't got the do re mi Why, you better go back to beautiful Texas

Oklahoma, Kansas, Georgia, Tennessee

California is a garden of Eden, a paradise to live in or see But believe it or not, you won't find it so hot If you ain't got the do re mi 
"Do Re Mi" could be the story of countless Guthrie listeners, and these lyrics participate in the kind of work undertaken by a critical public pedagogue, both critiquing the limits placed upon individual citizens and describing their relationship with governing powers. As Guthrie's popularity increased, he was provided with increased opportunities to travel, participating in collective action, visiting depressed areas, and reporting back with a type of alternative news that aimed to tell his listening public the events and troubles that were not getting picked up in mainstream media. Along the way, he encountered organized labor and was immediately impressed by the union way of life. He was particularly taken by the Industrial Workers of the World's use of music to "Fan the Flames of Discontent" (as indicated on the cover of their songbook, which Guthrie would carry around in his shirt pocket). Guthrie discovered that their most effective leaders had also been their most prolific songwriters, perhaps the best known being Joe Hill, whom Guthrie greatly admired. Of musical activism, Hill writes: “A pamphlet, no matter how good, is never read more than once, but a song is learned by heart and repeated over and over. ... Put a few cold, common sense facts into a song, and dress them up in a cloak of humor to take the dryness off of them" (M. Smith 19). The use of music in direct action signals a shift from public pedagogy toward rhetorical education, and Guthrie was able to use his platform a celebrity—and as a critical public pedagogue — to empower his listeners to participate more fully in civic matters.

This specific type of public pedagogy, in which a pedagogue moves beyond education toward empowerment, falls neatly in line with recent scholarship on rhetorical education. Historically, rhetorical education is often traced back to Ancient Greece, in which students were prepared to become engaged, active citizens. As scholars have 
indicated, such education has traditionally been reserved for the privileged - that is, rich, white males (Crowley; Enoch; Glenn et al.; Johnson). However, alternative education programs whose primary aim is to help those silenced and excluded from public spheres to gain voice and inclusion have existed for quite some time. In recent years, attention to these programs has resulted in a flurry of scholarship around the topic of rhetorical education and its emancipatory goals of creating a more egalitarian, empowered citizenry.

In the United States, scholars have examined several rhetorical education programs over the past two centuries, particularly for women, Native Americans, African Americans, and the working class (Enoch; Glenn et al.; Kates; Logan; Schneider). Scholars have also looked to more recent marginalized populations - typically lower socioeconomic communities — with the designs of community engagement and/or service-learning (Ackerman and Coogan; Deans et al.; Flower; Long; Mathieu). In each case, rhetorical educators appear to have employed a multi-pronged approach that attends to literacy, skills-based knowledge, and instruction in direct action tactics, all of which are geared toward increasing the agency and empowerment of students. Jessica Enoch defines rhetorical education as "any educational program that develops in students a communal and civic identity and articulates for them rhetorical strategies, language practices, and bodily and social behaviors that make possible their participation in communal and civic affairs" (7-8). So, in this view, rhetorical education is intensely local, dealing with material concerns and self-representation, and, far from needing to be adapted to fit the purpose, folk music is already tailor-made for such an enterprise. The 
use of music in labor organization, made famous by the likes of Joe Hill, invigorated Guthrie for precisely this reason.

Also during this time of Guthrie's career, he became increasingly convinced that a socialist revolution was required to create the type of equitable society he longed to see. In Hard-hitting Songs for Hard Hit People, Guthrie forcefully declares the intention of the project: "These songs will echo that song of starvation till the world looks level—till the world is level — and there ain't no rich men, and there ain't no poor men, and every man on earth is at work and his family is living as human beings instead of like a nest of rats" (Kaufman 45). This explicit call for the redistribution of wealth foreshadowed Guthrie's excitement about the Communist Party USA, and, although it remains doubtful Guthrie ever signed a membership form, his connection to the party led to the Daily Worker, the CPUSA newspaper, offering him a regular column ("Woody Sez").

Eventually, these associations would narrow his opportunities. Guthrie's radio show was cancelled in 1939 for his early support of Stalin, and when the word "communist" began to strike fear into the heart of America, he lost his membership with the National Maritime Union. Nevertheless, Guthrie maintained his loyalties to the party and the cause, and he is no small part responsible for the common assumption that many folk singers of that era were communists or at least communist sympathizers (which, of course, many were). In search of new opportunities, actor and friend Will Geer invited him to visit New York, where he was immediately discovered by Alan Lomax, with whom he recorded an album titled Dust Bowl Ballads in 1940. The album offered a collection of songs and stories that voiced experiences familiar to many working class people and proved to be a significant step forward for both his fame and public 
perception of him as a public pedagogue. The songs celebrate "the working folks [who] have walked bare handed against clubs, gas bombs, billys, blackjacks, saps, knucks, machine guns, and log chains - and they sang their way through the whole dirty mess" (Kaufman 47). Perhaps emboldened by his observations, Guthrie's songs were getting grittier in their depiction of injustice and violence (such as a depiction of rape and torture in "Union Maid"), and he began to sing more topical songs that discussed war, fascism, labor, and race.

First advising and then joining in 1941 a group of musicians out of New York City, including a young Pete Seeger, Guthrie suggested a name for the band: The Almanacs. Guthrie explains the name: "Well, if you want to know what the weather is going to be, you have to look in your Almanac. And if you want to know when to plant your spuds or what side of the moon to dig 'em in, or when to go on strike, and if you want to know what's good for the itch, or unemployment, or Fascism, you have to look in your Almanac" (Kaufman 67). In naming the group after a familiar instructional guide that would have been indispensable for many in his audience, Guthrie could not be any clearer about his intention to parlay his success into a more active role as a public pedagogue.

The Almanacs were intensely interested in action, both in terms of increasing musical participation among audiences and using folk music in collective action for civil and labor rights. The other members of the group came from more well-to-do families hailing from the East coast, so Guthrie's participation lent a hefty dose of credibility and endorsement to the band. Guthrie and Seeger met constantly to write and revise songs, and together they expanded the work of The Almanacs to include secondary materials 
that could help foster civic engagement among their audiences. This work led to the founding of People Songs Inc., the folk organization that participated in the Wallace campaign. People's Songs held regular meetings, published a weekly newsletter and quarterly bulletin, supported unions and musicians, and, of course, released topical songs and songbooks for use in relevant direct action. The organization collected and published hundreds of songs, and they offered unique services directly to unions: "Do you want to publish a songbook for your members? Write us for help in putting one together. Do you want a song composed especially for your union? Would you like to have phonograph records of your own songs for use in your locals? These are jobs which we are prepared to do" (Kaufman 120). Guthrie saw the new organization as a unionization of folk singers, and he writes excitedly about the activist aims of the organization, again revealing his pedagogical and rhetorical designs: "We are trying not to sell ourselves nor our services over onto the right wing scales and display windows. We are trying to actually fight to rid this world of capitalism amongst artists, performers, and every other place. We are like guns and cannons, we must be polished, oiled, loaded, and loved, to work our best" (Kaufman 122). Pete Seeger agrees, claiming that the founding of People's Songs was a purposeful effort of resisting the "heavy hand of the entertainment monopoly" (Brand 16).

Unfortunately, People's Songs would be a short-lived enterprise. After World War II, social and political changes slowly took a toll on People's Songs and folk music in general. The Communist Party was changing, the Red Scare was beginning, and a conservative Congress pushed hard against labor organization and civil rights efforts. The failed Wallace campaign in 1948 bankrupted the organization, and The Almanacs 
disbanded. Seeger went on to form The Weavers, and Guthrie again struck out on his own.

While the publications produced by People's Songs indeed outlined specific strategies including how to demonstrate and organize, as well as providing resources to connect with others, these were secondary to the larger mission of employing folk music as a strategy in itself. This reinforces the music as the primary means of rhetorical action, and as such, the songs simultaneously provide and enact rhetorical education. Lyrically, the songs work toward empowerment through their pedagogy_describing the reality of oppression, equipping listeners with language to understand and articulate their situations, and illuminating the relationships in society between oppressed populations and the dominant powers that maintain their oppression. Musically, via participation, folk songs gave the people something to $d o$. Music provided a means of action, and the rebellion and resistance described by Denisoff, Brand, and others earlier in this chapter became tools that citizens could wield personally. So, while the explicit instructions provided in the literature produced by Guthrie, Seeger, and the rest of the organization are perhaps more obvious representations of rhetorical education, it must be understood that folk music was always the engine that powered their action and provided the most significant, sustained energy in their activism. And at the center, directing the curriculum, was Guthrie, now solidly established in popular culture as a public pedagogue.

He was not without his contradictions, however; many who knew him were aware of his tendency to drink heavily, get into fights, his occasional and sudden abandonment of his wives and children, and eventually his physical and mental decline from Huntington's chorea. The Guthrie documentary, This Machine Kills Fascists, offers a 
refreshingly three-dimensional portrait of the musician, as close friend Pete Seeger describes something of a love-hate relationship: “I couldn't stand him when he was around, and I missed him when he was gone.” Similarly, Guthrie's daughter and archivist, Nora, refers to him as a "scoundrel," and both she and her brother, musicianactivist Arlo, make it clear that Woody's intention was always to make money from his music, suggesting that his first band was simply a dance hall band so they could "meet girls" (Gammond). Moreover, Guthrie's attention to cultivating his own persona naturally raises questions about his sincerity. An optimistic perspective might conclude that age and experience played a significant role in reshaping Guthrie's goals over the course of his career. Perhaps more practically, one may conclude that good work can still be done by complicated, imperfect individuals, and that Guthrie's carefully constructed identity was a significant part of his art that also enabled the good work he did accomplish. Regardless of his intentions, sincerity, or contradictions, Guthrie merits attention as a public pedagogue enacting rhetorical education because of how he was received by working class America.

Additionally, Guthrie is on record several times describing the general mission of his work, which leaves little question for how he wished his work to be interpreted. In Born to Win, a collection of Guthrie's poems, essays, and sketches, he declares, I am out to sing songs that will prove to you that this is your world and that if it has hit you pretty hard and knocked you for a dozen loops, no matter how hard it's run you down or rolled over you, no matter what color, what size you are, how you are built, I am out to sing the songs that make you take pride in yourself and in your work. And the songs that I sing are made up for the most part by all sorts of folks just about like you. (223) 
In this quote, Guthrie claims to be about more than creating music for music's sake, that he has a larger, governing goal to which he subjects his art, which is to raise the dignity of beaten down human beings. None of the circumstances he names that might cause a person to feel less than acceptable can be interpreted as a personal failing: misfortune, ethnicity, body type, etc. Turning from sympathy to empathy in a rhetorical move that again invokes Burke's consubstantiation, he collapses the identities between himself and his audience, suggesting that he does not even write his own songs, but that they are instead composed by the individuals whose lives he portrays. Guthrie presents himself as a trusted friend, a member of the community, and an ally for those in need.

\section{Technology and Agency}

As the preceding sections establish, Guthrie's ability to function as a public pedagogue depended heavily on his fame. Quite simply, in order for the public to embrace his music, he and his music had to circulate and be taken up widely to achieve the acclaim he did. His musical talent and the cult of authenticity worked hand-in-hand to build this celebrity status, which in turn animated his public pedagogy and rhetorical education. However, the circulation of his songs, stories, and persona would have been impossible without established and emerging technologies that facilitated his interaction with the public. Guthrie relied heavily on radio, periodicals, and recording to spread his music and message, and these in turn both enabled and constrained the work he could do and, ultimately, the genre of folk music itself.

When Guthrie launched his show on KFVD in 1937, broadcast radio was booming. As radio receivers became available to the majority of rich and poor 
communities alike, small, low-power stations immediately sprang up across the country, bringing programming of all kinds to eager Americans enamored by such a fascinating and near-miraculous new technology. President Woodrow Wilson invested a great deal of energy in all forms of communication technology, and thus the radio quickly picked up government programming, which Franklin Delano Roosevelt famously employed in delivering his Fireside Chats. Sporting events and religious programming were also popular, but music was overwhelmingly the most demanded format. In wealthier cities, companies saw an opportunity for moralizing the listening public via classical music, as Vincent Roscigno and William Danaher explain: "Elite conceptions of modern, industrialized culture often included a docile and compliant workforce, one that reflected the air of classical, sober art, rather than the rowdy and supposedly crude music of southern 'hillbillies"” (29). However, as stations quickly discovered, gaining and keeping listeners was more profitable than attempting to affect their tastes, and a wide variety of indigenous musical styles filled the airwaves, thanks in no small part to listeners' frequent requests.

Through broadcasts of barn dances and shows like the Grand Ole Opry, various forms of folk music could be heard simultaneously throughout the country, delivering the all-important familiarity and simple noise of folk to the growing multitudes of radio listeners. Oscar Brand describes the cumulative nature of familiarity in folk music, suggesting that folk music is always already familiar-in that Americans have experienced such music all their lives - and thus both feeds and increases the hunger for familiar music, which in turn becomes even more familiar (52). In this way, in a manner unavailable to classical music, people feel that certain types of folk music become "their" 
music, and thus the songs take on much greater personal significance to listeners. Consequently, as radio fueled the nation's interest in folk songs, the genre of folk music was both constrained and mobilized; radio technology brought folk music to the masses, but radio programming presented a much narrower definition of what folk music (and many of its contingent subgenres) sounded like than what was being represented in live spaces across America.

Despite this more unifying aspect of radio programming, radio stations in the 1920s and 1930s enjoyed a great deal of autonomy because of their relatively small broadcast ranges. Very few corporations had been granted powerful wattages, and as a result, colleges, small businesses, and independent stations all over America could produce local content, addressing and responding to local listeners. Frequently, musicians would perform over the radio before appearing in a church or music hall, granting unprecedented access to new fans in a wider variety of places. As Roscigno and Danaher emphasize, this affordance played a crucial role in the rise of labor unions across the South, as organizers could speak directly to their workers, followed by musicians participating in rallies and strikes. This joint effort not only proved an effective technique of disseminating information and gathering bodies in spaces, but it also connected local laborers to regional and national concerns (30). This technique would also provide a blueprint for future uses of folk and protest music in collective action, as well as firmly linking folk music with left-wing activism.

Thus through the format of radio and the widespread demand for authentic folk music, Guthrie found a way to combine his musical and political work into one cohesive, marketable package. Over the run of the show (1937-1940), Guthrie worked on his 
critical commentary of contemporary social issues, refining his consciously crafted persona and developing a comfortable rapport with his listening public. He praised laborers and outlaws, condemned corruption, weighed in on current events, and espoused his philosophies on work, fairness, equality, and freedom, and his musical compositions began to reflect this more activist approach to entertainment. Songs produced during these years include "I Ain't Got No Home," "Talking Dust Bowl Blues," "Tom Joad," "Do Re Mi," "Pretty Boy Floyd," and "Vigilante Man." In this way, Guthrie began to transform his role — and by extension, the perceived role of folk singers - into that of a public pedagogue, and his songs, stories, and comments all become useful texts by which the public could be educated to the plight of marginalized people and, more significantly, become empowered and equipped to participate in finding solutions and affecting change.

Guthrie's co-host, "Lefty Lou," left the show in 1938, leaving Guthrie to rebrand it as "Woody, the Lone Wolf," and allowing him to focus even more on social issues. It was actually his boss, Frank Burke, Sr., who suggested Guthrie use some of the show's time to report on local politics and other situations of concern to leftist listeners, such as worker camps, jail conditions, and labor organization efforts. In adding this element to the show, Guthrie further cemented radical politics into American folk music. As the story goes, Burke is said to have suggested to Guthrie, "You might even consider getting yourself arrested" (Kaufman 6). This attitude and the news coverage on the show earned the respect of Guthrie among thousands of listeners, and thus he was able to go visit the sites of interest and be welcomed into the midst of populations who would otherwise have distrusted outsiders. These visits fueled his writing and intensified his mission, 
turning to a wider set of forms for his expression. In one episode after visiting migrant workers' camps in California, Guthrie wrote and read a poem on air called "Hooversvill":

Ramblin', gamblin', rickety shacks, That's Hooversvill;

Rusty tin an' raggedy sacks

Makes Hooversvill;

On the skeeter bit end of the th garbage dump,

30 million people slump

Down where the big rats run an' jump

In Hooversville (Kaufman 7)

Through the medium of radio, Guthrie had the ear of thousands, if not eventually millions. The freedom granted him by his employer allowed him to deliver his form of public pedagogy to numbers of people previously unavailable to folk singers before his time. Thus, he not only provided a source of news, entertainment, information, and identification to his listeners, but he also implicitly educated the public as to the type of work in which folk singers participate.

The 1930s also saw great advancements in recording technologies, which quickly led to the capitalist boom of the recording industry. Father and son folklorists John and Alan Lomax undertook multiple trips in the early 1930s throughout the South to collect audio recordings of ostensibly authentic folk songs for the sake of archiving and preserving music as a part of American folklore and history. From these recordings, initially, the Lomaxes transcribed and printed sheet music. Certainly, these publications helped distribute folk songs to wider audiences, but the circulation of printed folk music pales in comparison to the subsequent commercial boom of recorded and broadcast music. Newly formed record labels began to create catalogs or even specialize in vernacular music, and for the first time, one could peruse a section of "ballad," "hillbilly," or "race" music. The early recordings by the Lomaxes, followed by similar 
posterity recordings by the likes of Moses Asch and Guy Carawan, were soon dwarfed by the volume of commercial recordings performed by established musicians. While this again helped spread folk music around the country, the commercial aspects of the recording industry suddenly presented a new complication in that folk music — a highly democratic, evolutionary style of musical performance—became a fixed, capitalist enterprise. As the music business sought to define their niche markets, the range of vernacular music styles that might have comprised folk music ten years prior was quickly becoming codified and calcified, circumventing and in some ways superseding the oral/aural transmission of songs that had been the primary way folk music developed since human beings began creating it. Moreover, due to the increased musicianship and the distance both recordings and radio broadcasts created between performers and audiences, commercialized folk music, unlike its participatory roots, increasingly became a spectator sport. Guthrie's songs were singable and memorable, and he worked hard to present himself as a relatable character, but his prowess as an entertaining performer contributed to his rising status, and songs that had previously belonged to anyone and everyone became known as "Guthrie's songs."

Through the crackle of a crystal set or the scratch of a phonograph needle, Guthrie's voice traveled the country, capturing the attention of countless audiences who would come to depend on him for a mix of nostalgic folk wisdom combined with sharp humor and keen insight into the matters of the day. But it was not only new technologies that delivered Guthrie's work to the masses - newspapers played a prominent role as well, particularly with regard to his essays and political cartoons. From May 1939 to January 1940, Guthrie penned a column called "Woody Sez" in the communist 
newspaper People's World. In those nine months, Guthrie wrote 174 articles, many of them several hundred words and typically featuring at least one comic sketched by Guthrie. The articles were yet another opportunity to showcase his Okie persona, and Guthrie wrote playfully in an affected dialect, rife with purposeful misspellings and clever wordplay, and often delivered under the guise of not fully understanding the situation. While not explicitly political, Guthrie's opinions were nevertheless strongly and politically charged.

These media worked together to show the public a multi-layered, threedimensional image of who Guthrie was, which was an enormous part of his success and fame. In this way, these technologies functioned as the agencies that enabled his work. At the same time, Guthrie was able to deliver a much more "functional" type of art activism to his listeners, one that truly pushed public pedagogy toward rhetorical education. To use a different sense of "agency," Guthrie offered a message that reminded marginalized audiences that they were not alone, that they were oppressed by the greedy and powerhungry, and that they could do something about their situations if they relied on their numbers and worked together. Even when not presenting specific strategies for increasing civic engagement, Guthrie fostered agency among his listeners and readers by articulating social issues in ways that denounced power and revealed social relationship (again, following Roberts and Steiner's definition of a critical public pedagogue). His style of writing used satire and wit to ridicule the financial and political leaders of the country while praising and encouraging the working class.

This is perhaps most evident in "Woody Sez," in which he tackles the same range of topics addressed in so many of his songs. For example, he discusses migration in an 
article called, "My People, the Dustbowl Refugees." In it, he observes that not only are the bankers enemies of the farmers for taking their lands when they needed help the most, but even challenging them can result in trouble:

When the drouths drove all the folks out of Oklahoma, an' Arkansaw, into the cow country, wheat fields, an' oil towns of West Texas, I was in the runoff. We had a hard go of it. I've picked it by asking questions that the bad weather drove 1, an' the banker drove 9 out of every ten families thet deserted there farms by the oodles an' gobs in eastern Okla., Arkl, Missouri, Kansas, Alabama, Georgia, Texas, an' Tennessee. (Naturally my stetistics is jest a guess, but a mighty good guess, I think.) (Woody Sez 4)

Again, Guthrie employs empathy in service of identification, building his relationship with the audience in contrast to their relationship with the banks that took so many of their farms and livelihoods during the Dustbowl era. One way this participates in rhetorical education and builds agency is by helping them see that their lot is not one of simple misfortune (bad weather) but greedy bankers. By more fully understanding their circumstances and who and what caused them, listeners are better able to understand their relationship to the dominant structures in society.

On politics and politicians, Guthrie was merciless. After joking about the national debt, he writes: "If the nation is the government, and the government is the people, then I guess the people owes the people, that means I owe me, and you owe you, and I forget the regular fee, but if I owe myself something, I would be a willing just to call it off rather than have the senaters argue about it, and I know you would do the same and then we wouldn't have no national debit" (Woody Sez 22). Emulating his hero, Will Rogers, Guthrie affects a similar type of cornpone wisdom to remind his readers that public servants are meant to serve the public, and that citizens in a democracy are really the ones in charge if only they could recognize it. While not being overtly political, Guthrie nevertheless subtly encourages civic engagement through educating oneself on 
politicians' platforms and participating in voting. In another example, Guthrie pulls no punches, directly calling out voting citizens for contributing to the evils of war: "You holler, Oh, I didn't have anything to do with all this waste of time, money, and lives. You did, you voted for the very man that had the power to spend your money for you." (Woody Sez 64).

Despite his harsh and frequent criticism of politicians and policies, Guthrie was intensely patriotic, continually highlighting the ideals promoted in the founding of the nation. His version of patriotism took "liberty and justice for all" quite literally, and thus he refused to remain silent when he saw anyone — politician, citizen, police, boss, etc.break this bond he held so sacred. While he could certainly employ sarcasm and anger effectively, Guthrie is more remembered and celebrated for being a champion of hard work, human achievement, and the beauty of his country. Interestingly, technology and agencies come to bear in one of his career highlights and possibly the most prolific month of his life.

In May 1941, Guthrie was tapped by the U.S. Department of the Interior to narrate and score a documentary about the Bonneville Power Adminstration and their construction of the Grand Coulee Dam in the Pacific Northwest. He was so inspired by the confluence of majestic nature, human ingenuity, and the pride in hard work that he composed 26 songs in the single month he spent in Oregon and Washington observing the process. Out of those 26 songs came "Roll On, Columbia, Roll On," which eventually became the official song of the State of Washington, and "Pastures of Plenty," which remains one of his most enduring songs. The lyrics narrate the work of migrant laborers from a first-person perspective and again praise human dignity in the face of hardship: 
It's a mighty hard row that my poor hands have hoed

My poor feet have traveled a hot dusty road

Out of your Dust Bowl and Westward we rolled

And your deserts were hot and your mountains were cold

I worked in your orchards of peaches and prunes

I slept on the ground in the light of the moon

On the edge of the city you'll see us and then

We come with the dust and we go with the wind

California, Arizona, I harvest your crops

Well, its North up to Oregon to gather your hops

Dig the beets from your ground, cut the grapes from your vine

To set on your table your light sparkling wine

Green pastures of plenty from dry desert ground

From the Grand Coulee Dam where the waters run down

Every state in the Union us migrants have been

We'll work in this fight and we'll fight till we win

It's always we rambled, that river and I

All along your green valley, I will work till I die

My land I'll defend with my life if it be

'Cause my pastures of plenty must always be free

The first verse establishes the speaker as a migrant worker, acknowledging the

"mighty hard row" that represents the difficult life of the working class. Verse two

describes the strong work ethic Guthrie believed was an essential component for

cultivating pride in one's work, as the speaker describes the hard work of manual labor

while not earning enough to secure a bed for the night. Verse three reveals that the

speaker is addressing the United States, and the juxtaposition of the harsh, violent verbs

"dig" and "cut" with the image of "light sparkling wine" suggests that from this hard

work comes pleasure and, in this case, the enjoying the literal fruits of one's labors. Verse

four begins to more explicitly connect the speaker's labor with larger themes of (a)

humans harnessing the power of nature, shown in the conversion of "dry desert ground"

to "green pastures of plenty" and the power produced through the Grand Coulee Dam; (b) 
the power of the collective through using the word "union" to stand in for the United States and expanding the first-person perspective to the plural in "us migrants"; and (c) validating the struggle for unity through collective effort by linking work and war in the final line, "We'll work in this fight and we'll fight till we win." Finally, verse five unites the speaker to the land itself and, echoing similar sentiments in "This Land Is Your Land," stakes a claim in the country because the speaker has worked tirelessly and will continue to "work till I die" - no longer for the sake of hard work as in verse one, no longer for the sake of producing sustenance as in verses two and three, and no longer for the sake progress as in verse four, but for the sake of the future, and for the sake of freedom.

This close reading of the lyrics lays out a simple but powerful prescription for the type of freedom Guthrie repeatedly imagined, which should "include 3 square meals a day and a good job at 'honest' pay" (Garman 106). Yet despite the song's simplicity, Guthrie manages to comment on the value, dignity, and reward of labor, the power of the collective, the nature of ownership, and an attitude of freedom that considered a future, more utopian society in which everyone who worked could eat, and all who participated shared equally. In terms of rhetorical education, then, "Pastures of Plenty" models Guthrie's ideal work ethic for achieving this egalitarian community.

As these examples demonstrate, the circulation of Guthrie's music and messages heavily depended on the emerging technologies of his day. At the same time, Guthrie was able to use the mediation of both his music and image to cement in the public consciousness the role or function a folk singer performs in society. In this way, Guthrie enacted the "now-ness" of folk music (as described earlier by De Mille) by embracing 
technology as he did, effectively stretching his stance to keep one foot in the past while firmly placing the other in the present. Rather than outdating folk music, technology and mass media propelled it forward, and in the same way radio literally amplified Guthrie's voice, the technologies he used amplified his frames, allowing him to reach everwidening audiences simultaneously.

If a song's uptake is any indication of its rhetorical effectiveness and, by extension, the sense of agency a public feels in adopting and performing it, then "This Land Is Your Land" is unequivocally Guthrie's most successful song. It also provides one of the clearest examples of public pedagogy through framing, and therefore offers a nice summation of the theories and examples detailed above. The song has been so greatly circulated over the past 75 years that it is impossible to count the times it has been covered and translated by other artists around the world. As with many songs that become a part of popular culture and American consciousness, many revere the song for its patriotic themes, its praise of the beauty of American landscapes, and its egalitarian ideal — all of which may be gleaned from the first verse of the song. And, also as with many folk songs, the verses that are most frequently overlooked complicate the narrative. Verses five and six tackle property ownership and poverty issues respectively:

As I went walking I saw a sign there And on the sign it said "No Trespassing." But on the other side it didn't say nothing, That side was made for you and me

In the shadow of the steeple I saw my people, By the relief office I seen my people; As they stood there hungry, I stood there asking Is this land made for you and me? 
In that fifth verse, Guthrie shows his communist leanings with regard to the haves and the have nots in modern society, using the blank backside of a sign to humorously expose the capitalist philosophy of owning land. In the harsher sixth verse, he condemns both the religious mainstream and a broken welfare system for allowing "my people" (and by extension, him) to go hungry, thereby depriving them of basic human rights. And once again, Guthrie relies on empathetic identification with the constant refrain of "you and me," and as the phrase repeats, it gains force each time, finally culminating into a juggernaut of human will in the final verse:

Nobody living can ever stop me, As I go walking that freedom highway; Nobody living can ever make me turn back This land was made for you and me.

As the song closes and the final refrain repeats for the last time, it becomes clear that the "me" and "I" that refer to the speaker in the first three lines of this verse are not his leaving behind the audience but rather pioneering the trail in front of them and offering an invitation to follow. This is Guthrie's Kingdom Come, that all may one day be free, and Guthrie's speaker models the path to freedom by walking it first.

Ultimately, Guthrie would blame capitalism and the allure of its "simple jingle of a palmful of coins" for doing in folk music itself as the House Un-American Activities Committee began to sweep through the remaining folk singers who had not already softened their message for a more commercial appeal. By the late 1940s, Guthrie's symptoms of Huntington's chorea began to manifest such that it was painfully clear he had inherited the disease from his mother, who had wasted away in her final years in an asylum as he would eventually do, too. Increasingly removed from the public until his permanent hospitalization, Guthrie could only watch as colleague after colleague either 
fled to the safety of gentler lyrics or suffered under the weight of congressional scrutiny. Even his own music was being revised to remove some of the sharper language, and he was at this point, of course, powerless to stop it. In a last effort to preserve his legacy, he took his son Arlo aside during a weekend visit to his hospital room and taught him the oft-omitted, controversial verses to "This Land Is Your Land," barely able to strum a guitar at this point, but concerned that the words will be forgotten. As Arlo explains, “Kids are singing 'This Land Is Your Land' in school and people are talking about making it the national anthem. Bob Dylan and all the others are copying him. And he can't react to it ... The disease doesn't affect his mind. He's sitting there in a mental hospital, and he knows what's going on, and he can't say anything or tell anyone how he feels" (Klein 479).

Woody Guthrie died in 1967 after a 20-year struggle with Huntington's disease that caused him to slowly and steadily lose control of his body and mind. By the time he died, his music and example had inspired a new generation of folk singers who would continue the fight for the side "that every child knows is the right side" (Rodnitzky 15), but as he feared, the music industry defanged and hobbled folk music, turning the genre into a very narrow, specific style that would be breathing its last in the form as he knew it by the time Woodstock arrived in 1969. Nevertheless, Guthrie's music and persona have been indelibly stamped into the American imagination, and whenever someone says, "folk singer," the image of a lone man in a work shirt carrying a guitar, singing songs about hardship, injustice, and freedom typically springs to mind. A cultural representation of the Everyman and the ultimate American proletariat, Guthrie taught his audiences to respect each other, wonder at the beauty of the country, and to never stop fighting for 
freedom. But most of all, Guthrie lent his voice to the voiceless, articulated in this Whitmanesque quote:

You may have been taught to call me by the name of a poet, but I am no more of a poet than you are. I am no more of a writer of songs than you are, no better singer. The only story that I have tried to write has been you. ... You are the poet and your everyday talk is our best poem by our best poet. .. . I am nothing more nor less than a photographer without a camera. So let me call you the poet and you the singer, because you will read this with more song in your voice than I will. (Rodnitzky 15)

In this final quote, Guthrie again demonstrates rhetorical framing - this time of his own life's work — and emphasizes his sincere persona as a public pedagogue. Interestingly, he frames his career in the terminology of media and mediation, as a photographer who takes snapshots of people in his songs rather than in photographs. And, like a photographer chooses what to include or exclude in the image frame, so too does Guthrie spend his career deciding what to highlight, what to crop, and what to blow up for closer, clearer scrutiny. The mediation of Guthrie's music and public career effectively set up collective action frames that called for political action, but they also allowed him to methodically establish his own persona as a public pedagogue. As much as he drew on the invoked authenticity and sincerity of earlier folk music, Guthrie refashioned the persona of a folk singer to take advantage of contemporary technological advances, a pattern that can be observed repeating in the case studies to follow. If the folk singers who came after Guthrie learned what it meant to be a folk singer from his example, as so many of them have claimed, it seems evident that they would have likewise learned how to stay relevant in changing social, political, and technological landscapes from him as well. 


\section{BOB DYLAN}

In what seemed an odd pairing to many, the 2015 Super Bowl commercials included a Jeep advertisement featuring Woody Guthrie's "This Land Is Your Land," prompting many to flood social media platforms with comments about the unlikely juxtaposition, arguing that Guthrie would never have wanted his song used to promote Jeep's SUV. Coincidently (or perhaps not), one year prior, Chrysler aired an advertisement during Super Bowl XLVIII featuring Guthrie's erstwhile mentee and onetime heir apparent to the American folk throne, Bob Dylan. Throughout the commercial, Dylan talks about the values of American industry and pride embodied in the American car generally and Chrysler specifically, stating with poetic gravitas into the camera, "Detroit made cars, and cars made America." As the two-minute advertisement comes to a close, Dylan stands in a pool hall surrounded by men in working-class clothing and, leaning forward for emphasis, says, "We will build your car." Although the commercial alludes to auto workers "on the line" as the reason for Chrysler's success, the ad ends by announcing the 2015 Chrysler 200, which Chrysler calls “America's Import.” The highprofile commercial instantly drew criticism toward Dylan for selling out, exemplified by such articles as The Huffington Post's op-ed, "Bob Dylan, Corporate Shill," in which the author confidently claims, "As I watched the commercial ... I thought, would Woody Guthrie, voice of the working man, have done a commercial for a major multinational corporation? No, of course not" (Fine). (The author's blog, incidentally, where he 
archives his articles, is curiously absent of any commentary on Guthrie's music in the Jeep commercial that aired the following year.)

However, this was not the first time Dylan licensed his music or even appeared in a commercial for a large corporation, having previously appeared in ads for Victoria Secret, Apple, and Pepsi. Nevertheless, the online discussion surrounding this Chrysler commercial suggests the advertisement left many Dylan fans feeling betrayed, as if the iconoclast the public remembered and loved had been replaced by a card-carrying capitalist, leaving the rebellious poet of his youth a shrinking figure in the rearview mirror. To be fair to Dylan's fans, Dylan did intentionally model himself in the first stage of his career after Woody Guthrie, who had overtly aligned the identity of a folk singersongwriter with the role of political activist and public pedagogue. The effects of that alignment proved to be so lasting that even more than 50 years later, Dylan apparently cannot be regarded without some comparison to Guthrie or his pedagogical and rhetorical work. The criticism from The Huffington Post underscores this in its reference to Guthrie, as if surmising "What would Guthrie do?" provides sufficient evidence of Dylan's errant decision to participate in Chrysler's ad.

When Dylan began achieving his initial acclaim in the early 1960s, he found a hungry audience for his particular product. Insightful and incisive lyrics, passionate performances, disarming humor, and a unique style of singing put him squarely at the front of the folk music scene, drawing the attention of not only his fellow youth but also the old guard of folk, leading many to declare him the next torchbearer of American folk music. Placing him in a lineage following Woody Guthrie and Pete Seeger, the public seized upon Dylan with a fierceness that simultaneously thrilled and repulsed him. He 
played the role of their messiah for only a few years until, to the complete surprise of many, he appeared to turn his back on everything his adoring audience thought they held in common.

In 1965, five full decades before appearing in that Chrysler commercial, Dylan released two significant albums, Bringing It All Back Home and Highway 61 Revisited. Between the releases, he stunned the folk world by performing an electric set at the Newport Folk Festival, alienating fans and friends alike for appearing to both disregard and disrespect the folk music idiom so many held so dear. Despite his billing as the headliner that year, Dylan's performance lasted a mere fifteen minutes, kicking off the set with a raucous rendition of "Maggie's Farm," a song that appeared on Bringing It All Back Home. While the lyrics appear to fall in step with Guthrie's type of protest song about the exploitation of workers, the song might equally be construed as a declaration of independence from the folk scene, or a protest song protesting protest songs. The first stanza suggests that Dylan is ready to move on: "Well, I wake in the morning / Fold my hands and pray for rain / I got a head full of ideas / That are drivin' me insane / It's a shame the way she makes me scrub the floor / I ain't gonna work on Maggie's farm no more." In verses two through four, the speaker refers to Maggie's brother, pa, and ma as equal participants of exploitation. Maggie's brother "hands you a nickel / He hands you a dime ... Then he fines you every time you slam the door." Maggie's pa's bedroom window “is made out of bricks," and Maggie's ma is “sixty-eight, but she says she's twenty-four." These three characters may point to music industry executives who are only interested in protecting their profits, to those lacking vision, imagination, or creativity, and the self-righteous, pretentious attitudes held by folk purists who expected 
old forms to continue to be relevant in a changing culture. But the final stanza of the song is the most telling:

I ain't gonna work on Maggie's farm no more No, I ain't gonna work on Maggie's farm no more Well, I try my best to be just like I am

But everybody wants you to be just like them They say sing while you slave and I just get bored I ain't gonna work on Maggie's farm no more

If Dylan occupies the role of narrator, he is bored of being a "slave" to the expectations thrust upon him as the new savior of folk music. Years later, Dylan recounted his irritation at his introduction at the previous year's festival, "And here he is...take him, you know him, he's yours," recalling, "I had failed to sense the ominous forebodings in the introduction. . . . As far as I knew, I didn't belong to anybody then or now" (Chronicles 115). This sentiment, so sharply reflected in the lyrical choice "slave," dramatically highlights the gulf between Dylan and the public in terms of their respective commitments to Dylan's music and position. The irony, of course, is that Dylan very consciously and successfully tried "to be just like them," enough to convince them that he indeed was. Lyrics aside (at least in part because many claimed the lyrics were unintelligible, given the inadequacies of the sound system to handle a rock band), the force of the volume and spectacle largely dismayed the audience. Todd Haynes, director of the creative Dylan biopic I'm Not There, portrayed the emotion of this event with a scene showing Dylan and his bandmates firing machine guns into the festival crowd.

Dylan's departure from the folk scene left many to wonder why he seemed to have lost interest in folk music, raising widespread doubts, questions, and concerns about his own methods and motives. More than abandoning a particular style of music, however, Dylan appeared to be shirking his responsibilities as a public pedagogue. This 
student of Woody Guthrie and the "voice of his generation" suddenly seemed to stop caring about the people Guthrie had spent his life trying to empower, prompting one interviewer to ask, "Do you care about what you're saying?" to which Dylan retorts, "How can I answer that if you have the nerve to ask me?" (Pennebaker). Changing course so dramatically while positioned at the top of his field, Dylan not only disappointed a great many fans and friends, but he cast doubt on Guthrie's legacy and destabilized what had become a fairly secure understanding about folk singers and their activist ends. And yet, given Dylan's ostensible rejection of the political aims so frequently ascribed to him, the public nevertheless have continued considering him a leading voice of protest, even going on more than 50 years now.

Despite his many musical turns, ambiguous statements, antagonistic actions, and flat-out denials of activist intentions, Dylan still appears to occupy a certain kind of role in the minds of many; his music underpins the folk revival of the 1960s, and in retrospect, his move toward rock and roll is now often framed as a kind of prophetic extension, rather than rejection, of activist music, out in front of the socially conscious rock music to follow. Because Dylan is widely regarded as one of the most important and influential figures in popular music and a significant icon in popular culture, his work and persona, like Guthrie's, may be examined as a form of public pedagogy. However, the apparent disconnect between Dylan and the public's impression of him raises significant questions and complications of the more straightforward analysis of public pedagogy as applies to a figure like Guthrie. Specifically, who decides what counts as public pedagogy or who is or is not a public pedagogue? Whereas Guthrie chose for himself to assume the role of a public pedagogue, it seems that the public vetoed Dylan's desires to remain ambivalent 
and elected him to the position against his wishes. In this way, in addition to being one of American music's greatest treasures, Bob Dylan might simultaneously be one of its greatest disappointments.

Additionally, if it is the public and not the person who casts the role a public figure should play, then it indeed appears to be an illegitimate—or at least unproductive - proposition to try definitively determining Dylan's motivations in light of his mercurial and multiple personalities in a career now spanning over half a century. Instead, Dylan and his work provide an opportunity to track the circulation of public texts as a process of public pedagogy, revealing the participants and practices at work in the recursive mechanism of meaning-making in the public sphere. In this regard, the public of Bob Dylan effectively excludes Dylan himself (or, perhaps more accurately, Bob Zimmerman-Dylan's given name) from determining his own public fate, suggesting that perhaps too much focus has been given to the word "voice" and not enough to "of the people."

The previous chapter considers ways in which folk music is intrinsically rhetorical and political, particularly in modern society, owing to its populist heritage, history of applications, and the out-of-time-ness that critiques modern culture by simply showing up in it. By the time Dylan arrived, however, the popularity of folk music recordings and performances had been cemented by Dylan's forebears and capitalized upon by the recording and broadcast industries, allowing Dylan to reap the benefits of a more established genre. As much as American folk music was already its own antecedent genre when Guthrie and company spread the form like traveling preachers, Dylan was able to cash in on their foundational work with the flair and fame of a televangelist. But 
Dylan didn't simply repeat what had been done before; by the time he began his career, several cultural and technological developments facilitated achievements that his elders could only have dreamed of even twenty years earlier.

This chapter describes Bob Dylan's trajectory from first embracing to then critiquing Guthrie's model of a folk singer as public pedagogue. In particular, Dylan tries on the Guthrie persona almost as disguise, ultimately shedding the costume toward a more authentic expression of himself. However, the relationship between Dylan and the public, increasingly complicated by the growing ubiquity of media and accelerating rate of public circulation, reveals that Dylan seemed to have less control over his own persona than he desired. Through a review of the agencies that both enable and constrain his work - specifically televisual technologies, the press, and a booming music industrythis chapter demonstrates the multiple ways Dylan nevertheless enacts rhetorical education through public pedagogy despite his ostensible rejection of such motivations. Ultimately, these revisions to Guthrie's model of musical activism, along with the public's tenacity in keeping Dylan locked in the role they wish to see him perform, help refine theories of public pedagogy and suggest a mid-century cultural shift in the relationship between publics and texts.

Image, Identity, and Authenticity as Public Pedagogy

As the Second Red Scare began to fade in the late 1950s, and along with it the conservative notion that folk music was a subversive tool of communist propaganda, the beatniks, Bohemians, hippies, and any other societal outcasts began to find in each other inspiration and possibility. Artistic experimentation flourished, and as new forms of 
creative expression emerged, it became clear that folk music activism might again have a role to play in the critique of culture and politics. Although commercial folk music had continued to sell well enough, the HUAC and McCarthy investigations had largely scrubbed it of its political content. Even if the musicians themselves had radical leftist opinions, the music itself less often conveyed such perspectives. However, the "folk consciousness" that offered a form of resistance by simply showing up was a proven method of social commentary that fit neatly with the hippies and beats, and traditional folk music found a new, young generation who were ready to explore artistic and activist expressions outside of the mainstream in new and exciting ways.

As this new folk revival began to take hold, audiences heard their own frustrations, concerns, and struggles reflected in folk songs of the past. Simultaneously, folk singers composed new songs in that older style, using the genre of folk music to signal the message and purpose - the cultural, pedagogical, and rhetorical work - of their new songs. As important to the sound of the music was the persona of the performer; as so clearly observed when Guthrie joined The Almanacs, the perceived authenticity of the folk singer directly corresponds to the perceived veracity of the music. ${ }^{3}$ Thus, without discounting "folk consciousness" as a form of resistance, it should be noted that the need for authenticity in folk music effectively links identity with uptake. In other words, presenting the correct image increases the musician's chances of financial success. Most significant in this construction is the word "perceived," since it is the audience who decides whether or not to attend a performance, buy a record, or become a fan.

\footnotetext{
${ }^{3}$ This is not unique to folk music, nor is it a shared feature of all music. It appears to show up most significantly in genres of vernacular music whose heritage and subject matter are more firmly situated in the working classes, such as folk, blues, country, and hip-hop.
} 
Bob Dylan began his career as a folk singer and proved so adept at presenting himself after the fashion of Woody Guthrie that the public perceived him to be cut from the same cloth. Time (and the eventual public knowledge of Dylan's background) would prove otherwise to a certain extent, but after Dylan made his left turn away from folk music, many seemed to reject his choice of new direction. In fact, the popular perception of Dylan's role was so complete that the more he insisted he was something else, the angrier many of his fans became, insisting he was still the person and performer they wanted him to be.

One way of accounting for this conflict of identities is to examine the relationship between publics and public texts. As discussed in the introduction, publics emerge around public texts, and the circulation of a public text provides a reflexive shaping of interpretation, understanding, and identity for both the text and the public(s) in which the text travels (Warner 66). As publics align with or against texts based on the ideologies inherent in the texts, publics adopt texts in certain ways that constrain textual meaning to resonate with a public's investments, creating frame resonance (Snow and Benford). The increased circulation of image-based media, coupled with a ubiquitous discourse of consumption, has led to a significant shift in the way publics regard public figures, suggesting that the public comes to understand public figures as icons rather than individuals. Therefore, we might usefully understand Bob Dylan in this regard as himself a public text, for which the public—not Dylan—shapes, constrains, interprets, and in many ways controls who and what Dylan publicly is. ${ }^{4}$ Thus, what Dylan came to realize

\footnotetext{
${ }^{4}$ This is, in fact, Larry David Smith's opening-if implicit-thesis in Writing Dylan, in which he chooses to refer to Dylan throughout the book as Bob Zimmerman, highlighting the fact that "Bob Dylan" is a carefully constructed persona composed by Zimmerman.
} 
too late to prevent it was that the circulating public texts-his songs, his performances, the hype within the folk community, the press coverage, the events he attended, his associations, his explicit alignment with Guthrie, and, ultimately, the persona of Bob Dylan - collectively birthed a public. Those texts called that public into existence, and it was their discourse, not his, that crowned him king, that dubbed him their spokesperson, and that still will not let him escape the role of public pedagogue.

Dylan appears to have been attentive to the way others perceived him even in childhood. Born Robert Allen Zimmerman in 1941 in Duluth, Minnesota, the boy who would become Bob Dylan revealed early a hunger for attention and eagerness to perform. Biographer Larry David Smith details a story of Mother's Day in the Zimmerman house, in which several family members had been taking turns singing songs to Bob's grandmother. When the family invited the five-year-old Bob to sing, he demanded the room be absolutely quiet before he began. He sang two songs with gusto, receiving such praise that he was asked for an encore performance at his aunt's wedding reception two weeks later. Again he instructed the audience to be silent before he started, and again he enjoyed the hearty approval from family and friends (5). Music critic Robert Shelton recounts Dylan's early talent at composition, which often involved revising lyrics to extant songs (along with claims of authorship of the entire piece) and exploring different instruments until he settled on the guitar, refusing various musical instruction from adults because he wanted to play his songs "his way" (12).

Additionally, the young Dylan seemed equally intent on letting his outward appearance communicate his attitudes about society. Remote as his childhood town of Hibbing, Minnesota, was, Dylan learned about the world outside Hibbing the world of 
entertainment, which delivered to him a range of characters who seemed important and noteworthy by their very presence on radio, television, and film. He particularly admired the contradictions inherent in James Dean and Marlon Brando, their film characters conveying both passion and detachment, making their own ways in a society that did not fit them, and doing so with unique style and mannerisms that Dylan reflected in his leather jacket and fascination of motorcycles, like Brando's Johnny Strabler character in The Wild One. Dylan even recruited friends to form a club that wore black leather and affected their speech and mannerisms after their imaginations of how bikers and rebels would speak and act — perhaps the first of many times Dylan would don the habit of his heroes.

Studying and emulating figures like Dean and Brando, along with observing the differences between Hollywood and Hibbing, Dylan quickly determined that much of popular culture was fake, a false, sanitized, and scripted representation of reality that bore little resemblance to the world around him. Hibbing, once a bustling and wealthy mining town, had been dying since 1950, and popular songs of his youth like "How Much Is That Doggie In the Window" or "Accentuate the Positive" were little more than temporary diversions from reality (Scorsese). After high school, in which he had floated from band to band, he enrolled at the University of Minnesota. Although he quickly decided college was not for him, it was the university environment in Minneapolis, a region called Dinkytown, that introduced Dylan to a new world of thought, argument, and creative expression.

A combination of influences including various roommates, fellow musicians, and a local record store led Dylan to conclude that a new-or, rather, old - style of music 
would suit him much better. In the liner notes for his box set compilation, Biograph, Dylan explains,

The thing about rock'n'roll is that for me anyway is wasn't enough... There were great catch-phrases and driving pulse rhythms... but the songs weren't serious or didn't reflect life in a realistic way. I knew that when I got into folk music, it was a more of a serious type of thing. The songs are filled with more despair, more sadness, more triumph, more faith in the supernatural, much deeper feelings. (Crowe)

Dylan found he resonated with the "poets and painters, drifters, scholarly types, experts at one thing or another who had dropped out of the regular nine-to-five life" (Crowe). He drew inspiration from the beat scene, absorbing the nomadic spirit of Jack Kerouac's On the Road while immersing himself in borrowed (or, by some accounts, stolen) record collections from friends and acquaintances. Old songs and wanderlust commingled and prepared him to receive his greatest inspiration thus far when a friend loaned him a copy of Woody Guthrie's memoir, Bound for Glory. Dylan was immediately taken with Guthrie, and he hunted down as many recordings of the folk legend as he could. In numerous places, he has described the discovery of Woody Guthrie as a revelation, an epiphany. As he recalls in the documentary No Direction Home, Guthrie had "that particular sound. And besides that, he had something to go along with that sound. ... He was a radical; his songs had a radical slant. Ooh, that's what I want to sing-I want to sing that." Indeed, he was so enamored with Guthrie that he asked his friends in Dinkytown to call him "Woody," making it clear that he longed not only to emulate the man but to actually be him. Paul Nelson, a folk music scholar from whom Dylan had helped himself to several records, agrees: “Obviously, he was channeling Woody Guthrie, everything about it. It was a way of finding who he was, in the end, by assimilating and channeling Woody Guthrie" (Scorsese). 
Perhaps even more than the music, it was Guthrie's persona that attracted Dylan:

In Guthrie, Bob found more than a genre of music, a body of work, or a performance style: he found an image - the hard-travelin' loner with a guitar and a way with words, the outsider the insiders envied, easy with women, and surely doomed. An amalgam of Bob's previous heroes, the Guthrie he found in Bound for Glory was Hank Williams, James Dean, and Buddy Holly — a literate folk singer with a rock and roll attitude. (Hajdu 70)

Thus, in terms of framing, when Dylan began experimenting with his image as a teenager, he adopted a countercultural frame by patterning himself after the rebel characters of Brando and Dean. In Dinkytown, Dylan embraced an intellectual (but still countercultural) frame in the style of Guthrie, effectively coalescing these frames to begin circulating himself as Bob Dylan the Folk Singer.

Ultimately, Dylan was impressed enough with Guthrie that he made the choice to leave Dinkytown to make his pilgrimage to meet his hero in person, who was by that time living full-time at Greystone Park Psychiatric Hospital in New Jersey, steadily wasting away from Huntington's disease. Dylan took up residence in Greenwich Village amid the burgeoning folk scene there, frequently traveling to the hospital to visit Guthrie. At Guthrie's bedside, Dylan would sing for him, solicit stories about Guthrie's travels, and learn anything Guthrie was willing to teach him.

Although Dylan performed Guthrie (both his music and his persona) with ostensible sincerity, his emulation was received as something of a gimmick in New York that both amused and impressed his fellow musicians. Not only had Dylan managed to learn scores of Guthrie songs, he could deliver them in Guthrie's voice and posture. Eventually, friend and harmonica player Tony Glover showed him a recording of another of Guthrie's disciples, Ramblin' Jack Elliot, and Dylan was dismayed to find that Elliot could imitate Guthrie even more accurately than he. Perhaps even more frustrating was 
the discovery that Elliot was only interested in sounding like Guthrie, seeming not to have been at all interested in Guthrie's worldview or activist agenda.

Dylan's visits to Guthrie became less frequent, and he once again widened his gaze to embrace more styles, seeking out inspiration and instruction from the musicians with whom he shared the tiny stages of the coffeehouses and bars each night, augmenting his catalog of songs as much as possible. But the spirit of Guthrie remained woven into the fabric of Dylan's craft, even as he began to seek a career on his own merits. Around this time, he legally changed his name to Bob Dylan and inked his first deal with Columbia to record his first album, featuring only two original songs, one of which marked the indelible influence the ailing musician had on Dylan.

I'm out here a thousand miles from my home Walkin' a road other men have gone down I'm seein' your world of people and things Your paupers and peasants and princes and kings

Hey, hey, Woody Guthrie, I wrote you a song 'Bout a funny ol' world that's a-comin' along Seems sick an' it's hungry, it's tired an' it's torn It looks like it's a-dyin' an' it's hardly been born

Hey, Woody Guthrie, but I know that you know All the things that I'm a-sayin' an' a-many times more I'm a-singin' you the song, but I can't sing enough 'Cause there's not many men that done the things that you've done

I'm a-leavin' tomorrow, but I could leave today Somewhere down the road someday The very last thing that I'd want to do Is to say I've been hittin' some hard travelin' too ("Song To Woody")

In "Song to Woody," Dylan manages to fully capture Guthrie's sound and language as he offers fitting tribute while simultaneously distancing himself from his hero, effectively starting a new chapter of his identity, changing his name as he launches his first record. While the song indeed sounds very much like something Guthrie would 
have sung, Dylan acknowledges in the first verse that he and Guthrie inhabit different spaces and times, noting the "road other men have gone down," and using the pronoun "your" to note that Dylan is looking through Guthrie's eyes rather than his own: "I'm seein' your world of people and things / Your paupers and peasants and princes and kings." The third verse defers to Guthrie's authority- "I know that you know / All the things that I'm a-sayin' an' a-many times more"—-before admitting Dylan's own inexperience: 'I'm a-singin' you the song, but I can't sing enough / 'Cause there's not many men that done the things that you've done."

Finally, in the last verse, Dylan is curiously ambiguous, noting some intention to depart, but from or to where or what and why is unclear. But the last couplet is most interesting: "The very last thing that I'd want to do / Is to say I've been hittin' some hard travelin' too." Dylan's voice is close on the microphone, gentle and almost reverent in his admiration of Guthrie's own "hard travelin'," and at first listen, it seems that Dylan might be telling Guthrie that he's off to pay his dues in the boxcars, on the highways, and in the fields. However, the third line says "the last thing $I$ 'd want to do," not "the last thing $I$ want to do," suggesting that this is not Dylan's final word before he leaves for some hard travelin', but Dylan is instead making a strong statement about his decision to stop pretending to be Guthrie, essentially saying, "I'm not going to give lip service to an ethic you embodied, Woody." Perhaps Dylan has come to know and respect the man too much to continue channeling him, or perhaps Dylan has been convicted of the hollowness of pretending to be someone else, observing the "cult of authenticity" (Filene). For whichever reason, "Song To Woody" represents the closing of a chapter, and, coincidentally or not, the beginning of Dylan's own prolific songwriting career. 


\section{Becoming Bob Dylan and Building New Frames}

Dylan seemed to make an effort to distinguish himself from Guthrie with his second album, The Freewheelin' Bob Dylan. The album title suggests that Dylan has gained some independence and is perhaps no longer tethered to past commitments. Several of his songs on this album, however, continue to follow Guthrie's model of a critical public pedagogue. Dylan acknowledges this aspect of Guthrie's songs in No Direction Home, noting the "radical slant" he wanted to adopt in his own songs while admiring Guthrie's pedagogical efforts toward rhetorical education: "You could listen to his songs and actually learn how to live." Dylan's phrasing suggests that this was a revelation to him, something that profoundly affected his perspective toward songwriting, and thus it is no surprise that Dylan's first release featuring his own original songs provides several offerings that perform the type of social critique Guthrie exemplified, even if the sound and structure of those songs were beginning to reveal more sophisticated craftsmanship than most of Guthrie's oeuvre. Perhaps tapping into the postmodern impulse, however, Dylan offered much less explicit instruction than Guthrie did, even as he spoke about injustice with similar conviction.

The lead track, "Blowing In The Wind," instantly became a (if not the) folk anthem. Covered by countless artists, the song sits firmly in the folk genre, utilizing "simple noise" (Brand) and a repetitive structure that would invite and prepare listeners to join in the refrain by the second verse. And yet the refrain - the part of the song that is meant to be the most memorable and from which the title is derived—offers no instruction, no guidance, and in fact no hope. The verses ask poignant questions that decry war, racism, and above all, apathy, but the only response to these questions is an 
ambiguous one. If the answer is "blowin' in the wind," does this mean that the solution is on its way, the way one observes a weathervane indicating a new airstream? Or does it mean that no one knows or understands when or how to solve these social problems? Dylan does not pretend to offer or even know the answer, but he nevertheless reveals his opinion of the solution, and it is an individual one rather than a political or societal one, implied through his questions: ban cannonballs, allow people to be free, don't pretend you don't see injustice, look around, hear people cry, acknowledge that too many people suffer and die. Rather than blaming specific people, Dylan tells his listeners that they are the individuals who comprise society, and change comes through them, one person at a time adjusting their own perspective. Thus, when the repeated refrain prompts the audience to sing along, Dylan is in a way repeating the effect Guthrie created in "Reuben James," in which "what were their names?" and "did you have a friend on the good Reuben James?" create the rhetorical effect of implication, leaving it to the listener to fill in the blank. Dylan, similarly, leaves his questions, leaving it to the listener to decide if he or she will remain complacent or demand justice.

Other songs on this record reveal a righteous anger that Dylan certainly could have drawn from Guthrie; songs like "Masters Of War" and "Oxford Town" match the sobriety of Guthrie's "Union Maid" and "Tom Joad." Others rely on the type of satirical humor Guthrie deemed useful in mitigating the heavy-handedness of topical songs, such as “Talkin' World War III Blues" and "Bob Dylan's Blues.” But perhaps second only to "Blowin' In The Wind" in terms of a song that captured the folk community's attention was “A Hard Rain’s A-Gonna Fall,” in which Dylan sings again about suffering, injustice, and apathy, though in much more poetic terms than the lead track. Through the 
voice of a father querying his son about his travels and experiences, Dylan deploys the type of rhetorical education Guthrie handled so frequently, first by defining the situations that cause oppression, offering those who suffer language to articulate their problems, and then by suggesting a way to combat those problems. The lyrics to the fifth and final verse read,

Oh, what'll you do now, my blue-eyed son?

Oh, what'll you do now, my darling young one?

I'm a-goin' back out 'fore the rain starts a-fallin'

I'll walk to the depths of the deepest black forest

Where the people are many and their hands are all empty

Where the pellets of poison are flooding their waters

Where the home in the valley meets the damp dirty prison

Where the executioner's face is always well hidden

Where hunger is ugly, where souls are forgotten

Where black is the color, where none is the number

And I'll tell it and think it and speak it and breathe it

And reflect it from the mountain so all souls can see it

Then I'll stand on the ocean until I start sinkin'

But I'll know my song well before I start singin'

And it's a hard, it's a hard, it's a hard, it's a hard

It's a hard rain's a-gonna fall

When the final verse asks, "what'll you do now?", the child replies, offering

listeners a set of destinations (which implies they should go where the suffering is) and a set of instructions: "tell it and think it and speak it and breathe it ... reflect it from the mountain so all souls can see it." Far from exhibiting a passing interest in injustice, oppression, and suffering, Dylan appears to be advocating a fairly complete immersion in understanding and speaking out against the issues identified in the song. Even more committed than these instructions are the next two lines, "Then I'll stand on the ocean until I start sinkin"” suggests that the singer will continue this project until his own death, and "But I'll know my song well before I start singin"' implies that he will prepare to keep himself informed and equipped so that he can accomplish some good, rather than 
simply hope his lone voice makes any kind of change. The implicit instruction in these last lines is, "learn about the issues, speak truth to power, and never give up the fight." The song then closes with the refrain in which the audience would certainly be expected to sing along, invoking an eschatological element common in spirituals and gospel music, and in keeping with the epic, biblical proportions present throughout the rest of the song. Dylan has described this "hard rain" as a type of cleansing rain (Scorsese), though whether it cleanses through forgiveness, healing, or judgment remains unclear.

Structurally, the song offers a map to follow the narrative: the first two lines of each verse pose a sequence of questions in the parental voice: "where have you been?", "what did you see?", "what did you hear?", "who did you meet?”, and "what'll you do now?" These questions allow Dylan, through the voice of the son, to bear witness to and provide testimony of the people and their troubles. Each verse is a different length than the previous, challenging the simplicity axiom by reducing the song's predictability, but still working in a familiar idiom of the call and response song, as the first two and last two lines of each verse provide repetitive brackets for the listener to recognize and join. The song draws on and thus produces a type of religious invocation, lending a spiritual and moral dimension of righteousness to not just the lyrics but also the performance of it, thus creating a space for building consensus and solidarity in a familiar idiom. In the liner notes of the album, Dylan revealed that each line in the middle sections of every verse is meant to be the first line of some other, unwritten song. Larry David Smith dubbed this technique as "narrative impressionism," observing that what Dylan tries to do with storytelling here becomes a framework that he will explore throughout the rest of his career (30). Additionally, it leaves room for the audience to spin out the rest of these 
untold stories in accordance with their own experiences and imaginations, thus eliciting their participation on multiple levels.

The Freewheelin' Bob Dylan serves as a supremely important entry in the Bob Dylan canon in that the record communicated to the public who Dylan was and what he was about every bit as much as it offered a collection of songs. The title of the album says as much: these are not songs by the freewheelin' Bob Dylan-this is the freewheelin' Bob Dylan. Put another way, the people who bought the album by and large were also buying into the image of Dylan. Through this album, Dylan was able embody the ethos of his past heroes while identifying himself as another in the same tradition. In short, Dylan signaled to the folk world that he was an authentic, legitimate folk singer who should be taken seriously as a critical public pedagogue.

Although his first album, Bob Dylan, had been favorably reviewed, it failed to sell very many copies when it first debuted — only about 5,000 copies. The Freewheelin' Bob Dylan, however, was an instant hit when it landed in May 1963, selling 10,000 copies per month and eventually going platinum (one million copies sold). The album attracted the interest of international musicians, including The Beatles, and two months later, Dylan appeared at the Newport Folk Festival as the hype surrounding him reached a fever pitch. Also during this period, Dylan began to perform regularly with Joan Baez, who was already well-established at the time, and the two began an understandably high-profile romantic relationship that only fueled Dylan's fame and added to his credibility. Dylan was officially a superstar, and the future of folk music under his leadership seemed secure. 
Dylan's popularity among the youth offered the promise of a new generation's engagement in politics and social justice, and the Civil Rights movement, rumors of war, atomic fears, and continued economic inequity provided an urgent milieu for such an iconoclast. In addition to offering songs that resonated with his generation, Dylan participated in the kinds of events that demonstrated his commitment to the topics in his songs. With Baez, Dylan sang at the March on Washington. With Pete Seeger, he traveled with the Student Nonviolent coordinating Committee (SNCC) to Greenwood, Mississippi, participating in a voter registration drive. Perhaps more because of Seeger's name, the New York Times ran a brief story about the event, referring to a "Bobby Dillon." The Times reported that

One of the more popular songs presented by a local singer was one dedicated to Medgar W. Evers, the Mississippi field secretary of the National Association for the Advancement of Colored People, who was slain last month in Jackson, Mississippi.... The refrain of that song was that the man who shot Mr Evers didn't know what he was doing and should be forgiven: "He's only a pawn in their game." ("Northern Folk Singers")

That the times would (a) bury this tiny story on their page 43, (b) botch Dylan's name, (c) mistakenly identify him as a local singer (after noting "Bobby Dillon" had come with Seeger from New York), and (d) appear to misunderstand the point of his song would surely have solidified Dylan's status among the folk community as their hero, that despite his endearment to their scene, he was still flying somewhat under the radar of the mainstream. However, Dylan's profile would raise dramatically, dizzyingly, over the next months, and his status as a public figure would soon make it nearly impossible to appear in public without being mobbed.

Dylan released The Times They Are A-Changin' in 1964, doubling down on the topical songs, satire, and irony present in his previous release. Another opportunity to 
revise his image, the album's artwork differs greatly from the previous; whereas Freewheelin' features a colorful, carefree Dylan on this streets of New York with thengirlfriend Suze Rotolo laughing and clinging to his arm, Times displays a sepia-toned bust of Dylan in a denim work shirt, looking down with a pensive frown, appearing decades older than the adolescent face smirking on Bob Dylan's cover only two years before. The combined effect of the artwork and songs on this third album offered yet another portrait of a populist prophet, a leader capable of speaking truth to power while rallying the masses to affect change, and a singer-songwriter whose talent seemed to grow exponentially with each album.

The imagery on the front cover was only the beginning of this frame transformation. The title track, which leads the album, is a rousing anthem of progress and solidarity, urging people to wake up and pay attention. Specifically calling out parents, politicians, and pundits, the song uses the familiar devices—simple structures, repetitive refrains, biblical imagery, and a prophesy of reckoning - while drawing a line between those who understand what is happening and those who do not. As the Civil Rights movement continued to gain momentum, songs like "Only A Pawn In Their Game" and "The Lonesome Death Of Hattie Carroll" spoke directly to racial killings. Other songs spoke to poverty, labor, violence, suicide, and war ("Ballad of Hollis Brown," "With God On Our Side," "North Country Blues"), and the final lines of the final song, "Restless Farewell," seem to indicate, at least to a casual listen, that Dylan will continue the good fight: "If the arrow is straight and the point is slick / It can pierce through the dust no matter how thick / So I'll make my stand / And remain as I am / And bid farewell and not give a damn." 
Those who recall their initial impressions of Dylan when he arrived in Greenwich Village remember him physically as much as musically, describing him as young, boyish and diminutive. Understandably, the wisdom espoused in Guthrie's music and writings may have fueled Dylan's desires to be taken seriously, both as a musician and as a man, and he managed to therefore borrow Guthrie's ethos as he cultivated his own image of authenticity. He describes seeing the more seasoned performers in the Village as possessing a similar quality to Guthrie that he desired: "There was something in their eyes, like they said, 'I know something you don't know.' I wanted to be that kind of a performer" (Scorsese). And if Guthrie was a hero to those performers, what better way to join them than to continue practicing the act he had already been perfecting? Dylan saw an opportunity—-some might even call it a shortcut — to achieve some recognition quickly, and it paid off, if a little too well. A line from "It's All Over, Baby Blue" confesses that Dylan was indeed calculating in this move, as he sings, "Leave your stepping stones behind.” Guthrie, his idol, and Pete Seeger, Dave Van Ronk, Liam Clancy, and other friends in the scene - these are his stepping stones, he says, adding insult to injury, acknowledging that they helped him get where he is going, but he had to walk on them to get there. Worse, calling them stepping stones implies that was their purpose, and he thus sidesteps any responsibility for actually walking on people.

However, it was those people who latched onto him and, through their endorsement of him, helped him gain the massive following that made him a superstar. In Dylan they found a willing participant, a marvelously talented artist who appeared only too eager to occupy the role of Guthrie, who was by that time only a shadow of his former self. Perhaps they saw Dylan as not merely a successor, but as a kind of 
reincarnation; it would not be difficult to picture someone like Pete Seeger resurrecting his pre-blacklist optimism at the potential work Dylan might accomplish, particularly in a society that appeared to need a new Woody Guthrie more than ever. Joan Baez, similarly, no doubt played a similarly, important role in catapulting Dylan to the top. A Life magazine article from 1964 features pictures of Dylan and Baez side by side, as well as a shot of Dylan working at a typewriter in Baez's home, thus allowing Dylan to borrow Baez's impeccable ethos, despite the "sloppy, disheveled, unshaven" appearance of "The Angry Young Folk Singer," whose portrayal in the piece is nonetheless endearing. In one photo, Dylan wears his trademark black sunglasses and a barely-there smile while Baez beams at him, clearly smitten. The caption reads:

Joan Baez, the queen of the folk singers, and Dylan are good friends. He visits her in California and wrote a poem about her for the jacket of her last album. They often make surprise appearances at each other's concerts. Joan has included many of his songs in her repertoire. "These days I feel they are the only things making any sense," she says. ("Angry Young Folk Singer" 110)

While Dylan was noticed by his fellow musicians for his own talent, such associations and national press launched his profile and career into the stratosphere, and that ringing endorsement from someone as connected to the heart of the folk scene as Baez would certainly have convinced anyone that the future of folk music had arrived.

By the time Dylan felt the unease caused by Peter Yarrow's introduction of him at Newport in 1964 ("take him, you know him, he's yours"), the public had fully embraced him-music, image, and all. The surprise that lie in wait for his adoring audiences in the months and years to come would not simply make for an uncomfortable transition from folk singer to rock star, but it would in many ways haunt the rest of career. Simply put, 
the public so fully bought into the image he sold them that he would never fully be able to convince many people that he could be anything other than who they thought he was.

“Spokesman Denies He’s a Spokesman”

At some point approaching 1964, Dylan seems to have recognized two things:

first, that he was increasingly trapped by the public's constraining definitions of him, and second, that he was ready to move on to new pastures, both musically and philosophically. During this time as well, cracks in the veneer of Dylan's image were already beginning to show. For example, in the weeks after John F. Kennedy's assassination, Dylan found himself at a dinner hosted by the National Emergency Civil Liberties Committee (NECLC), who presented him with their annual Tom Paine aware "in recognition of distinguished service in the fight for civil liberty" ("Bob Dylan and the NECLC”). In his rambling, extemporaneous (and by some accounts, drunk) acceptance speech, Dylan refers to people in the room as old and bald, mentions that he tries not to think about trivial things such as politics, before finally blundering into dangerous territory when he admits that he "saw some of myself" in Lee Harvey Oswald, insofar as he, too, was disillusioned with the direction of the country, though Dylan quickly noted that he would not have taken things so far, "not to go that far and shoot." The transcript of Dylan's speech indicates booing and hissing at this statement, and after a stumbling mention of "just being honest" and invoking "free speech" at the Bill of Rights dinner, Dylan accepts the award and is ushered off stage to a mixture of booing and applause. Although he wrote a follow-up letter to the NCELC to explain his emotional turmoil 
during the dinner and his discomfort at speaking in public, the event haunted him and would surely have been in his mind as he prepared his next steps.

Although the public appears to have been blindsided by Dylan's transformation, looking back at the songs he produced leading up to and through his transition suggest that Dylan was attempting to subtly prepare his audience—or perhaps even himself—-to accept and understand his apparent change. Indeed, both his lyrics and public commentary suggest strongly that Dylan was being a direct and honest as he knew how, in the period between emulating Guthrie and the chaotic, recalcitrant character that emerged in late 1965. It is during this period in which some of Dylan's most compelling demonstrations of public pedagogy occur, even if his "curriculum" bears little similarity to Guthrie's agenda. Nevertheless, many of his songs include not only opinions and advice about existential concerns, but they frequently include instructions on how to interpret Dylan himself. Unfortunately, the unsuspecting public largely missed these cues because they were so strongly committed to the intersubjective reality they created in defining Dylan as a public text. To compound the public's difficulty in understanding Dylan and his motivations, Dylan himself seemed to be purposefully attempting to confound the public by rejecting previous and known frames in favor of a kind of "antiframe" that would resist easy interpretation. Such an anti-frame would flip the script, so to speak, suggesting that his audiences needed to rely not on him but on themselves for framing activities.

For example, the lyrics to the final track on The Times They Are A-Changing, "Restless Farewell," seem painfully obvious in light of future events. Verse one refers to a night spent with friends coming to an end, as Dylan sings, "But the bottles are done / 
We've killed each one / And the table's full and overflowed / And the corner sign / Says it's closing time / So I'll bid farewell and be down the road." Verse two describes wisdom gained from severed romantic relationships, perhaps advice for those he knew he would disappoint: "But to remain as friends / And make amends / You need the time and stay behind / And since my feet are now fast / And point away from the past / I'll bid farewell and be down the line." Particularly telling is the demarcation of time and direction between the speaker and listener, as Dylan says "you ... stay behind" he now moves "away from the past," referring to the roots and traditions of folk.

Perhaps anticipating a critical backlash, verse three begins with Dylan assuring his listeners that his words and deeds were sincere:

Oh ev'ry foe that ever I faced The cause was there before we came And ev'ry cause that ever I fought I fought it full without regret or shame But the dark does die as the curtain is drawn And somebody's eyes must meet the dawn And if I see the day I'd only have to stay So I'll bid farewell in the night and be gone That "the dark does die" uses death to metaphorically indicate finality, and that he has only a small window in which to make his exit. Noting that "he'd only have to stay" if he remained suggests that it would not be of his own volition, which would violate his agency as a performer and certainly be incongruent with the authentic nature of a respected folk singer. In a sense, without coming out and saying it, Dylan is implying that they would not want him to stay under such conditions - that would actually be the real betrayal.

The final verse now assumes a new weight under this particular reading: 
Oh a false clock tries to tick out my time

To disgrace, distract, and bother me

And the dirt of gossip blows into my face

And the dust of rumors covers me

But if the arrow is straight and the point is slick

It can pierce through dust no matter how thick

So I'll make my stand

And remain as I am

And bid farewell and not give a damn

Given the release date of the song, it might be that Dylan is writing from his imagination of the future, realizing that his image will be obscured by the speculations and accusations of others. This is particularly significant in light of struggle for dominance in terms of who determines the role Dylan plays. Is he a pedagogue or not? Is he a spokesman or not? Is he a sellout or not? Dylan appears to be asking and answering these questions himself, and even as he seems ready to step down from a pedestal he will soon claim to never have occupied, he nevertheless offers another nugget of pedagogy: Dylan is offering a new frame for how to grapple with the abandonment he anticipates the public will accuse him of, and, perhaps, how to grieve the loss of their leader when the time comes. He is providing instructions for how to read him. Knowing that this move is in the near future, one understands the "restless" aspect of "Restless Farewell," and it becomes impossible to interpret Dylan's follow-up album, Another Side of Bob Dylan, as anything but a continuation of this exit strategy.

A month before Another Side would be released in August of 1964, Dylan premiered a number of his songs at Newport. Critics noticed an introspective turn in Dylan's lyrics, and none of the "finger-pointing songs" that peppered his previous releases (Hentoff, “Crackin'”). The lead song, “All I Really Want To Do,” includes the lyrics, “I don't want to fake you out / Take or shake or forsake you out / I ain't lookin' for you to feel like me / See like me or be like me / All I really want to do / Is, baby, be 
friends with you." From the opening song, Dylan swings wide of the previous, passionate anthems with this declaration of amiable intention, much in the same way a teenage lover might breakup with a partner while saying, "But I hope we can still be friends." However, even Dylan seems to know that such hopeful suggestions are rarely possible, as the closing track, "It Ain't Me, Babe," seems to indicate. Verse one opens with the command, "Go "way from my window," and although the speaker does not define his auditor, his subsequent lyrics make it painfully obvious that he is speaking to an admirer (or thousands of them) who is misplacing enormous amounts of responsibility on him that he is not willing to assume: "You say you're lookin' for someone / Never weak but always strong / To protect you an' defend you / Whether you are right or wrong / Someone to open each and every door / But it ain’t me, babe." In Dylan's interpretation of the role the public wants him to play, he notes unrealistic expectations ("never weak," "always strong"), an unwillingness to be self-critical ("whether you are right or wrong"), and a desire for the speaker to serve the listener ("to open each and every door").

Verse two adds to the speaker's self-awareness, again offering a pedagogical turn in how to understand Dylan with the line, "I will only let you down," before returning to criticism: "You say you're lookin' for someone / Who will promise never to part / Someone to close his eyes for you / Someone to close his heart / Someone who will die for you an' more / But it ain't me, babe." An artist willing to close his eyes and heart for loyalty closes himself to art and truth, which Dylan appeared to be seeking more and more fervently at this point in his career, and, as the final verse indicates, his heart was already elsewhere: "Go melt back into the night, babe / Everything inside is made of stone / There's nothing in here moving / An' anyway I'm not alone." That the speaker is 
"not alone" smacks of a lover's ultimate betrayal, and Dylan confesses here that his imminent departure from folk will be regarded as such. The song then closes thusly:

You say you're lookin' for someone

Who'll pick you up each time you fall

To gather flowers constantly

An' to come each time you call

A lover for your life an' nothing more

But it ain't me, babe

No, no, no, it ain't me, babe

It ain't me you're lookin' for, babe

How cruelly ironic these lyrics must have come to be regarded by the folk community once their full import was finally realized the following year. Although the title of Dylan's next album, Bringing It All Back Home, would no doubt have excited those fans who were becoming dubious of Dylan's new direction, the opening song, "Subterranean Homesick Blues," featuring an electrified rock band, would certainly have only deepened their concern. Critics who worried that Another Side revealed Dylan succumbing to the trappings of fame and commercial interests declared their predictions correct, and Dylan's "betrayal" would come full circle and complete itself at Newport in the summer of 1965.

Possibly the most defining, and certainly the most notorious moment in Dylan's public identity, the 1965 Newport Folk Festival is considered by many to be the dividing line between the old and new Bob Dylan. After a one-sentence introduction by Peter Yarrow, Dylan's band dove into "Maggie's Farm" to a mixture of boos and cheers that continued into "Like a Rolling Stone." They performed one more song and exited the stage. Unsatisfied on many levels, the crowd and Yarrow goaded Dylan to return, but Dylan had only rehearsed the three songs with his band. He took the stage and performed "Mr. Tambourine Man" to the relief of many, but then only one more, "It's All Over 
Now, Baby Blue." For those realizing Dylan was making his farewell, the lyrics and Dylan's performance — video footage shows a very agitated Dylan delivering each line crisply, pointedly—surely sunk in sickening weight. The song's narrator describes an "orphan with a gun ... crying like a fire in the sun" and an "empty-handed painter ... drawing crazy patterns on your sheets" before making it clear that nothing the listener can say or do will change what is happening to them: "The lover who just walked out your door / Has taken all his blankets from the floor / The carpet, too, is moving under you / And it's all over now, Baby Blue." Dylan ends the song and leaves the festival with sharp criticism, advice, and instruction in the final verse:

Leave your stepping stones behind, something calls for you Forget the dead you've left, they will not follow you The vagabond who's rapping at your door Is standing in the clothes that you once wore Strike another match, go start anew And it's all over now, Baby Blue

Although the song might easily be interpreted as Dylan blasting the folk community, an equally available reading suggests that Dylan's song is actually much more personal. Having noted in both lyrics and interviews that he had begun to write for himself, rather than for others, perhaps the entire song is Dylan giving himself some advice. The stepping stones are the folk songs and musicians who led him to where he is now, the dead singers (and the living ones who sing "dead" songs) will stay dead, the people emulating Dylan as he once did Guthrie are perpetuating a dying legacy, and the only way to begin again is to burn the whole enterprise to the ground. In a way, Dylan is explaining that he cannot slip out the back door quietly, as he hoped to do in "Restless Farewell," for the folk world would simply not allow it. Instead, the only way they'll allow him to depart is if he plays the role of a young boy trying to cast off the stray dog 
who followed him home, offending them so thoroughly that just maybe they'll leave him alone. And yet, while this song may be intensely personal, it nevertheless offers a new frame for his public, in which he perhaps rejects not so much the genre of folk music itself but in fact the current framing of folk music that existed at the time.

A highly publicized press conference in 1965 featuring a reticent, playfully combative, and even mischievous Dylan made it clear he had no intention of returning to folk music, or even ready to acknowledge his participation in the scene. Dylan shakes off every attempt to pin him down, turning the conference into something resembling a comedy routine, with Dylan playing the simultaneous roles of crowned prince and court jester:

Press: Are you going to participate in the Vietnam Day Committee demonstration in front of the Fairmont hotel tonight?

Dylan: No, I'll be busy tonight.

Press: You planning any demonstrations?

Dylan: Well, we thought—one. I don't know if it could be organized in time.

Press: Would you describe it?

Dylan: Uh - well, it was a demonstration where I make up the cards, you know, they have - uh - they have a group of protestors here - uhperhaps carrying cards with pictures of the Jack of Diamonds on them and the Ace of Spades on them. Pictures of mules, maybe words and - oh, maybe about 25-30,000 of these things printed up and just picket, carry signs and picket in front of the post office.

Press: What words?

Dylan: Oh, words: "camera," "microphone"—-loose"—just wordsnames of famous people. (Zagone)

Dylan appears more patient and open in longer form interviews, perhaps for no

other reason that he has time to think and acclimate to the situation— he has often referred to insecurity and awkwardness when called upon to speak off the cuff (as with the Tom Paine award dinner debacle). However, when an interviewer presses a topic when Dylan feels he has already given a satisfactory answer, he returns to form. From a 
Playboy interview in 1966, Nat Hentoff repeatedly asks if Dylan regrets leaving folk, rephrasing the question various ways in an attempt to either glean more information or to push Dylan into some sort of apology or defense. Eventually, when Hentoff asks, "Mistake or not, what made you decide to go the rock-'n'-roll route?” Dylan rushes through an impromptu tall tale:

Carelessness. I lost my one true love. I started drinking. The first thing I know, I'm in a card game. Then I'm in a crap game. I wake up in a pool hall. Then this big Mexican lady drags me off the table, takes me to Philadelphia. She leaves me alone in her house, and it burns down. I wind up in Phoenix. I get a job as a Chinaman. I start working in a dime store, and move in with a 13-year-old girl. Then this big Mexican lady from Philadelphia comes in and burns the house down. I go down to Dallas. I get a job as a "before" in a Charles Atlas "before and after" ad. I move in with a delivery boy who can cook fantastic chili and hot dogs. Then this 13-year-old girl from Phoenix comes and burns the house down. The delivery boy - he ain't so mild: He gives her the knife, and the next thing I know I'm in Omaha. It's so cold there, by this time I'm robbing my own bicycles and frying my own fish. I stumble onto some luck and get a job as a carburetor out at the hot-rod races every Thursday night. I move in with a high school teacher who also does a little plumbing on the side, who ain't much to look at, but who's built a special kind of refrigerator that can turn newspaper into lettuce. Everything's going good until that delivery boy shows up and tries to knife me. Needless to say, he burned the house down, and I hit the road. The first guy that picked me up asked me if I wanted to be a star. What could I say?

Hentoff: And that's how you became a rock-'n'-roll singer? Dylan: No, that's how I got tuberculosis. ("Interview")

A world tour in 1966 revealed that Dylan was perhaps shifting gears too quickly for many of his fans to keep up. D. A. Pennebaker's film, Dont Look Back, documents how night after night, Dylan's audience contained a mix of delighted fans and horrified folkies, eliciting wild applause and broad smiles punctuated by boos and accusations of “Judas!” As radio host John Gilliand reflected, Dylan “electrified one half of his audience, and electrocuted the other." Whatever side the folk audience came down on, there was no question that their beloved Dylan was gone for good. Shortly after the end 
of the tour, Dylan had a near-fatal motorcycle accident that provided a decent excuse (and, by some reports, a timely blessing) for a break, and Dylan withdrew from the public for an extended hiatus. Although Dylan's career has extended fifty years past the bulk of analysis thus far, the portrait revealed in these first five years is sufficient to demonstrate the way public pedagogy works in the case of a reluctant pedagogue. A combination of internal and external forces animated the public texts surrounding Bob Dylan, leading to the emergence of a public increasingly more committed to his leadership than he was, to such an extent that his departure from that role has never been fully realized. The deliberative nature of publics as texts recirculate is precisely what has allowed Dylan to participate in the publicity — or perhaps counterpublicity — for which he was (and indeed continues to be) both celebrated and scorned. Dylan's constant additions and revisions to the corpus of public texts, particularly the text of Bob Dylan, thus expose significant new dimensions to the pedagogical and rhetorical implications of public texts, complicating the role of a folk musician as a public pedagogue in a culture that only grew more complicated since Guthrie's time.

\section{Mass Media, Market Forces, and Counterpublicity}

Critics regularly categorize Dylan's reticence, disregard for facts, and silliness in the face of serious topics as the artist's idiosyncratic way of needling people and evading the truth. While Dylan did often try to make good faith efforts to explain his reasons for some of his larger decisions, few things seem to have agitated him more than an interlocutor who appears more interested in sound bites and magazine sales than any type of truth. In actuality, Dylan has told reporters time and again about his philosophy of 
truth and their collective failure of reporting it. Typically, Dylan managed to maintain a

"who cares?" attitude during many of his interviews, even when the interviewer's

frustration was palpable - indeed, that seemed to encourage Dylan that he was doing

something right—-but one particular interview featured in Dont Look Back shows an

exhausted Dylan lose his cool and decide to make an example of a reporter from Time

magazine. After the journalist responds that he will be at the show, Dylan launches into a

rapid-fire diatribe on mass media's inability and/or unwillingness to report truth:

Okay you'll hear it, see it, and it's gonna happen fast and you're not gonna get it all, and you might even hear the wrong words. ... I've never been in Time Magazine, and yet this hall is filled twice, you know. I've never been in Time magazine, I don't need Time magazine and I don't think I'm a folk singer. You'll probably call me a folk singer but the other people know better, 'cause, you know, the people that buy my records and listen to me don't necessarily read Time Magazine. . . . If I want to find out anything, I'm not gonna read Time magazine, I'm not gonna read Newsweek, I'm not gonna read any of these magazines, I mean cause they just got too much to lose by printing the truth. You know that. (Pennebaker)

Not only does Dylan make a case against Time and similar magazines for not being interested in truth, he indicts the journalist - who is at this point it the interview quite flummoxed - for being aware that this is the case. In the ellipses, Dylan explains that those who do read Time magazine are a specific class of people who also do not care about truth, eventually leading the journalist to ask, "What is really the truth?" Dylan replies,

Really the truth is just a plain picture. A plain picture of, of, let's say a tramp vomiting, man, into the sewer, you know? And then, and uh, next door to the picture you know, is Mr. Rockefeller or you know, Mr. C.W. Jones on a subway going to work, uh, you know, any kind of picture. Just make some collage of pictures which they don't do, there's no ideas in Time magazine, there's just these facts, which too are serious. Even the article which you're doing, the way its gonna come out, but you see it can't be a good article because the guy that's writing the article is sitting at a desk in New York, and he's not even going out of his office, he's just 
gonna get these 15 reporters and they're gonna send him a quote. (Pennebaker)

Part of what is so intriguing about this segment (beside the fact that Dylan seems to be preceding Jean Baudrillard and Neil Postman on this topic by two decades) is that Dylan appears to still have similar convictions that led him to write songs like "A Hard Rain's A-Gonna Fall," "The Times They Are A-Changin'," and "With God On Our Side," in which truth belongs to the people, and the powerful are not only disinterested in truth, but they in fact benefit and prosper from keeping it concealed. Over the next several years, Dylan refers to mass communication as inherently flawed and largely responsible for not only misguiding the public but mistreating him. What he seems to understand is the role mass communication plays in circulating the public texts that recursively and reflexively alter his original intentions. His attempt to set the record straight, sometimes via these very sources of mass disinformation, is an attempt to remain an active participant in the public discourse that shapes interpretations of who he is and what the figure of Bob Dylan is all about. As described in the previous section, Dylan's vexed relationship with the press and the publics that consume mass media makes sense in light of rhetorical theories of the public sphere. However, Dylan's attitude and language in the above illustration reveal an attempt at counterpublicity; that is, Dylan engages in oppositional communication to co-author and revise Dylan the Public Text and, more broadly, to reject known frames.

Nancy Fraser offers a handful of helpful correctives toward recognizing the exclusion inherent in imagining a bourgeois public sphere as described by Jürgen Habermas, in which educated and literate private citizens met in public to discuss matters of the day and, engaging in rational critical debate, worked toward consensus on topics of 
common concern. Specifically, she points out that such a sphere as Habermas recounts could not have truly been egalitarian, that despite the purported bracketing of self-interest and the acceptance of all participants in Habermas' model, it overlooks and suppresses the reality that marginalized groups nevertheless could not participate in rational critical debate of common concern. Furthermore, Fraser posits that the only feasible, realistic model of a public sphere is one of multiplicity; rather than a single public, many publics coexist concurrently (57). Fraser's model of multiple publics naturally allows that some publics will align with dominant forces while others will engage in opposition to the first. These subaltern counterpublics thus discount the Habermasian ideal of bracketing selfinterest, instead foregrounding interest as a cause for multiplicity and opposition. Moreover, Fraser argues that counterpublics function as "spaces of withdrawal and regroupment" and as "bases and training grounds for agitational activities directed toward wide publics (68). This concept of counterpublics is remarkably similar to Jessica Enoch's definition of rhetorical education, and it suggests that counterpublic activitynot necessarily explicit instruction — can serve educational ends that support people who are otherwise excluded from participating in publics.

Also, similar to Denisoff's "folk consciousness," the mere existence of a counterpublic signals an argument against hegemonic policies and institutions. As Robert Asen insists, the mere fact of exclusion is not what puts the "counter" in counterpublic, but it is the essential recognition of exclusion that "situates counter as a constructed relationship" (427). As Michael Warner further describes, "A counterpublic, against the background of the public sphere, enables a horizon of opinion and exchange; its exchanges remain distinct from authority and can have a critical relation to 
power...participation in such a public is one of the ways by which its members' identities are formed and transformed" (56-57). Like Hauser's focus on publics as processes rather than entities, Frank Farmer posits that heeding their call allows one to get past the endless reification of "counterpublic" as a fixed entity - that is, whether a group is or is not a counterpublic — toward a richer exploration of people, texts, conversations, and actions that might be read as counterpublicity, or contributing to counterpublic work (126). Or, as Eric Doxtader suggests, we should regard "counterpublic" as a verb, which places emphasis not on location but action. Rather than a participant or a text being inside or outside, we may more usefully analyze "how oppositional communication works" (65). Through this lens, Bob Dylan can be viewed as a counterpublic pedagogue; not that he is necessarily, essentially, or even functionally a member of an excluded population, but that many of his songs and actions can be construed as counterpublicity. Put another way, Dylan participates in the "poetic world making" (Warner 114) that occurs via public discourse, and because his songs and actions frequently critique, confuse, and subvert dominant institutions and ideologies, the counterpublicity in which he engages opens new spaces for discussion, action, and understanding. It certainly could be argued that Guthrie might likewise be regarded as a counterpublic pedagogue, and one may conversely point out that anyone who sells millions of records like Dylan did cannot be considered non-dominant, or counterpublic. However, while the content of Guthrie's output may have been subversive or counterpublic in nature, his activity much less so. Guthrie — or at least the way the public chose to perceive him in his public rolenavigated the mainstream fairly comfortably. He even managed to stay largely out of the fray during HUAC investigations, possibly owing to his declining health and gradual 
shift toward more personal songwriting nearer the end of his life. By contrast, Bob Dylan's creative content, even when it was squarely positioned as succeeding Guthrie's, was readily accepted by the public; again, consider the paradox of an album of protest songs selling a million copies. However, it is Dylan's actions - his methods and motives - that operate as counterpublicity, as oppositional communication.

Therefore, two related conclusions can be drawn about Dylan's counterpublicity: first, he fully understands that the media is both incapable of and unwilling to convey the truth about him, and second, he thus spends a great deal of time exploring and exploiting the media as a means of creatively manipulating his own image as an attempt to simultaneously coauthor himself and comment on the false reality media fosters. One of the curious forms his counterpublicity takes is the way Dylan seems to turn mainstream media back on itself, allowing him to critique media while yet benefiting from them. Indeed, as much as media circulation allowed Guthrie to become a celebrity, the changes in technology and mass media by Dylan's time allowed him to become exceeding more famous in a significantly shorter time period. (It may be no surprise or coincidence that Moore's Law, which predicts the rate of technological development, was proposed in 1965.)

One important and obvious example of technological advancement between Guthrie and Dylan is recording quality. The rough recordings of Woody Guthrie by Alan Lomax and Moses Asch are distinctively dated when heard alongside Dylan's first recordings, which, even though they sound primitive compared to today's recordings, feature significantly increased fidelity. Whereas Guthrie's jangly guitar and projected voice created the effect of "a big truck going down the highway with the riders bouncing 
around in the front seat" ("Oral Histories"), Dylan's recordings—even those in Guthrie's style - were warmer, deeper, and significantly more intimate. Better microphones, more advanced recording equipment, and higher quality tape allowed the listener to hear more of Dylan's body — his fingers and his mouth. Maybe even more than the recordings, the fact that Dylan was popular primarily among the youth meant that his records would frequently be heard through headphones, away from their disapproving parents. That subtle influence of rebellion, along with the closeness of the headphones, heightened the sensation of connection between listener and performer. Obviously, plenty of music had been purchased and consumed in this manner by the 1960s, and much of it fit these descriptions, but when Dylan's lyrics and artless style resonated with the emotions and unvoiced sentiments of the American youth, it forged a relationship, albeit a constructed façade, between Dylan and his fans that would unquestionably contribute to his rapid rise to fame.

For Guthrie, radio played a crucial role in spreading his music and message around the country and, eventually, overseas. Compared to radio in Dylan's era, however, Guthrie's audience was much smaller. In describing his hunt for Guthrie's music, Dylan noted that he couldn't just turn on the radio to hear it—he had to seek out records. As folk music again became a marketable commodity, however, Dylan's music was heard much more widely and rapidly throughout the nation, which directly contributed to the enormous sales of Freewheelin'. Television, too, was usurping radio as a mechanism for introducing new music to the public, a technology that was mostly unavailable to Guthrie. But it would be film, perhaps more than any other medium, that would carry Dylan's image far and wide, animating the static images in print. 
Footage of Dylan singing "Only A Pawn In Their Game" on a farm in Greenwood, Mississippi, or of Dylan's first set at the Newport Folk Festival, could circulate and bring a living version of Dylan to the masses who had yet to see him perform. D.A. Pennebaker's film of Dylan's tour through England, however, placed Dylan on the silver screen, a location reserved for American royalty, from the heroes that inspired Dylan, such as James Dean and Marlon Brando, to the musical legends in the making, like Elvis and The Beatles. Even the mere fact of Pennebaker's choice of subject proved that Dylan was worthy of a similar type of reverence, and the character portrayed in the film was certainly larger than life, thus raising Dylan's mystique and status to even more mythological proportions. Reflecting on the film in 1978, Dylan says, "When I saw it in a movie house, I was shocked at what had been done. I didn't find out until later that the camera had been on me all the time... The movie was dishonest, it was a propaganda movie.... it's one-sided. Let's not lean on it too hard" (Rosenbaum). Pennebaker shares a different memory, however:

We showed him the first rough cut. What he saw must have made him look like he was bare bones, and I think that was a big shock to him. But then he saw, I think the second night, he saw that it was total theater. It didn't matter. He was like an actor, and he suddenly had reinvented himself as the actor within this movie, and then it was OK. (Scorsese)

Thus, per Pennebaker's impression, the film made sense to Dylan along the lines of his constant image-crafting and reinvention, and, despite his grumblings about propaganda, led to a keen interest in film for Dylan that would result in multiple attempts at filmmaking himself, though never to commercial or public acclaim. Of filmmaking, Dylan explains his revelation: "The more I looked at the film, the more I realized that you could get more onto film than just one train of thought. My mind works that way, anyway. ... In another age, moviemakers would most likely be painters" (Rosenbaum). 
Film provided Dylan a new, larger canvas, with an enormous amount of new colors previously unavailable to him, and it facilitated new artistic expression that would then participate in his textual circulation.

One possible lens for Dylan's philosophy on film is Andy Warhol's art project, Screen Tests, a series of 472 short films of celebrities. In the project, Andy would load a fresh roll of film into a $16 \mathrm{~mm}$ camera, point it at his subject, and then let the film run out. As Warhol biographers Tony Scherman and David Dalton explain the project,

When movies were invented, their critics claimed there was one thing they couldn't do: capture the soul, the distillation of personality. Ironically, this turned out to be one of film's greatest capacities. Operated close up, the movie camera lets us read, perhaps more clearly than any other instrument, a subject's emotions. As his hundreds of sixties, seventies, and eighties photo-silk-screen portraits attest, Warhol was compelled to portray the human face. The Bolex [camera] let him home in on flickering expressions and shifting nods, a near-instant raising and lowering of eyebrows, a quick sidelong glance, pensive and thoughtful slow nods, or a three-minute slide from composure into self-conscious giddiness-fleeting emotions that neither paint nor a still camera could capture. Andy's ambition for the Screen Tests, as for film in general, was to register personality. (232)

Dylan participated in the project in 1965 , and the six minutes of footage indeed accomplishes Warhol's vision of registering personality, even if the personality registered is ultimately one fashioned in the mind of the viewer. Considering Dylan's anti-framing activities as a whole, Screen Tests neatly falls within Dylan's project of inverting Guthrie's model of public pedagogy.

Another significant voice that Dylan would have at least been aware of if not familiar with in the mid-1960s was media theorist Marshall McLuhan, whose revolutionary text, Understanding Media was published in 1964. Incidentally, McLuhan's very first rock concert was Bob Dylan in Toronto in 1966 (McClure). As widely read as Dylan was_-and as popular as McLuhan and his theories were becoming 
in an increasingly media-saturated society—it is easily possible that Dylan would have understood the ways in which various media would affect the translation of his messages. Whether broadcast on a radio, played on a turntable, performed in concert, or projected on a screen, Dylan's music and persona reached out to the public in multiple channels, making Dylan possibly the first multimedia singer-songwriter, and making the public text of Dylan potentially the first transmedia narrative. Media studies scholar Henry Jenkins observes that transmedia storytelling — that is, a story whose parts are told across multiple platforms - is infinitely more engaging because it demands an element of participation by the consumer to connect the story across various media (108). In light of this, Dylan's ability to achieve superstardom, facilitated by technology, becomes increasingly understandable, and we find in Dylan a blueprint for the type of media promotion and saturation, a practice that would become popular beginning with MTV and practically required in the age of YouTube and social media.

As much as Bob Dylan's adoption of multimedia was prophetically ahead of its time, so too was his insight into the capitalist consumption of the music industry. His record label, Columbia, convinced Dylan to record and release six albums in his first three years, setting a pace that would solidify his status as one of the most prolific songwriters in history. Moving forward, in between original records, various compilation, live, and bootleg albums were released, such that 64 official Bob Dylan albums have been released by Columbia since Bob Dylan in 1962. In addition to pressure from his label, Dylan signed with an aggressive and, by many accounts, exploitative manager, Albert Grossman in 1962. Grossman was responsible for the formation of Peter, Paul and Mary, and by the time he signed Dylan, he had already worked out something of a 
scheme by which he could claim a portion of profits from every angle, from managing artists to holding copyrights to licensing songs to eventually building his own recording studio. One famous plan that paid dividends including licensing Dylan's "Blowin' In The Wind" to Peter, Paul and Mary, allowing him to scoop up a portion of Dylan's songwriting royalties as well as Peter, Paul and Mary's performance royalties and record sales. According to Ellis Amburn, Grossman's drive for wealth was so complete that when he discovered one of his artists, Janis Joplin, was taking drugs intravenously—a violation of their agreements - rather than confront her, Grossman took out a life insurance policy on her for $\$ 200,000$ should she die in an accident (216). These business dealings allowed Dylan to see first-hand the capitalist exploitation of the music business, even among progressive artists like his peers, eventually leading Dylan to fire (and subsequently sue) Grossman in 1970 after discovering Grossman's contract gave the manager a full fifty-percent of Dylan's songwriting income.

More than the business dealings and commodification of artists and their material, however, Dylan was vocally critical about the way the business had corrupted the genre itself. When a publicist for Columbia Records first interviewed Dylan back in 1961 and asked for a definition of folk music, Dylan replied simply, "songs handed down." When asked the same question by a reporter in 1965, after his recent departure from folk music, Dylan gave a surprising reply: "a constitutional replay of mass production” (Zagone). Invoking Marxist terms, Dylan links folk music to capitalism with an indictment that would have made Woody Guthrie cringe. Lawrence Grossberg observes that ever since the new middle class in the post-war 1950s, America has been steadily sliding into a new conservatism that "is being put into place through cultural rather than political strategies" 
(15). Perhaps Dylan observed (or maybe simply reflected) this, too, when he told the NECLC that he tried to avoid trivial topics such as politics. For Grossberg, the depoliticization of Americans results in the denuding of expressions that were once considered subversive because of their political resistance. Thus when political art becomes mere art, the focus shifts from activism to entertainment, and forms like folk, rock, rap, punk, and metal no longer frighten the mainstream. This manifests in a variety of ways in society, including hearing songs from 1980s rock bands over the grocery store sound system or heavy metal riffs during sports highlights on the evening news, and it also introduces unique ironies into the culture, such as ignorantly chosen political campaign songs.

Jacques Attali analyzes this concept similarly:

There is no power without the control of noise and without a code for analyzing, marking, restricting, training, repressing, and channeling sound. ... When the market lays siege to and invests in music, it reduces the musician to a consumer good, an inoffensive show of submission and subversion, the first product of mass production and mass sale, with rebellion as its raw material. ... This is a pretext for reasonable people to make money through a senseless enterprise; like Lent disguised as Carnival, the music industry is an instrument of social pacification that gives each person the illusion of tasting forbidden passions. The legion of interchangeable songs and stars - although they may appear violent or rebellious, libertarian or subversive - enforces the limits of a daily life in which no one really has the power of expression, in which music is simply a method of playing at fear, a trivial topic of conversation, a means of preventing serious speech and action. (x-xi)

Although the sounds, stories, and people of folk music attracted Dylan for their outsider, rebellious ethic, Dylan learned after only a few years that commercial folk and pop music were essentially identical. Far from announcing any solution to this condition, Dylan seems to lay back into the current. He makes no pretense that rock music is any different than folk, other than to say that the sounds and rhythms of rock are more 
satisfying to him and more suitable as a musical context for his lyrical ideas. When asked about getting caught up in the system, he resignedly answers, "I'm a part of the system. I have to deal with the system. The minute you pay taxes, you're part of the system" (Rosenbaum). And yet the example he provides through counterpublicity is that mediaand, by extension, the Bob Dylan portrayed in media—never reveals the truth. In this way, though by 1966, few could argue Dylan still resembled Guthrie, they likely would have agreed about how dominant narratives obscure truth.

Consider, for example, Dylan's proposal of what truth in a magazine might have looked like: a homeless person vomiting in the gutter, juxtaposed with a rich businessman taking the train to work. The truth in his suggestion is not in either picture, but in both pictures taken simultaneously. In a sense, Dylan is attempting to reveal a counterpublic that exists in opposition to a public, suggesting that seeing both at the same time is the only way the truth about either can be understood. This is entirely similar to the impetus behind Guthrie's composition of "The Land Is Your Land," which was prompted by the endless repetition of Irving Berlin's "God Bless America" he heard through his travels. The subversive (or counterpublic) verses in Guthrie's songs perform the same juxtaposition Dylan describes: "In the shadow of the steeple, I saw my people / By the relief office, I seen my people / As they stood there hungry, I stood there asking / Is this land made for you and me?" Although Dylan's comment about truth and other, similar counterpublicity rarely become as clear as the injustice frames Guthrie crafts, his rhetorical project can arguably be read as engaging in a revised version of the same kind of work. 
When considered this way, Dylan's rhetorical education via public pedagogy demonstrates something like a flipped classroom: while Guthrie offered lectures, Dylan used the public's anger, frustration, and confusion as his course material. Particularly between 1964 and 1966, it is almost as if Dylan says, "I've already told you that you won't see the truth; now I'll show you." His so-called antics during this period could likewise be considered as employing the Socratic method, in which he is less interested in telling the truth than in goading his audiences into finding it out for themselves. It seems reasonable to think that this type of public pedagogy in the 1960s was only possible through the manipulation of mass media and the leveraging of celebrity, precisely because of the increased speed and truncated narratives inherent in an increasingly complex public sphere. In terms of uptake, however, Dylan's work reveals a somewhat disconcerting reality in that, despite the efforts of a public pedagogue, audiences may miss the lesson entirely, or worse, learn the wrong lesson. Dylan seems to have found a place of resigned comfort with this reality, but it remains a troubling notion for the artist functioning as critical public pedagogue, and these problems will be explored more fully in the following chapter. Critics and fans can debate whether Dylan is sincere or a sellout, a god or a gadfly, but he is simply uninterested in engaging with that type of discussion. And as a single voice among millions discussing who Bob Dylan really is, Dylan's own voice is barely audible and, according to the public, hardly credible. As he reminds Nat Hentoff, "After one or two of these unsuccessful attempts, one realizes that his resultant message, which is not even the same message he thought up and began with, he's now got to stick by it; because, after all, a song leaves your mouth just as soon as it leaves your hands." 
When Dylan fell into relative obscurity during the 1990s, he celebrated the break from the press, stating that he had "escaped the organized media. They let me be. They considered me irrelevant, which was the best thing that could have happened to me" (Hedin 247). In light of the more sophisticated theories of counter/public pedagogy, another way of phrasing Dylan's statement might be to say that the circulation of his public texts slowed down. His departure from folk may have been a rejection of a role he did not wish to occupy, and it may have been a recognition that folk music had lost its teeth by the time he had entered the picture, but he never stopped writing songs that attempted to make sense of his environment, to find beauty in ugliness, to search for truth among the illusion.

As with any journey, any evolution, Dylan could not have become everything he has become without taking every step he has taken; "Like A Rolling Stone" could not have been written without “Blowin' In The Wind.” More importantly for folk music, Dylan's exit may have very well been the event that would save folk music, for who better to fling the curtain aside on folk music than Bob Dylan? He had crafted for himself a sort of post-graduate level of education in folk music by the time had come to New York at the young age of 20, not only learning hundreds upon hundreds of songs, but absorbing the mannerisms and inhabiting the identities of numerous folk singers, including, and most convincingly, the godfather of American folk, Woody Guthrie. He marched, protested, and sang alongside the biggest icons in the genre, and he tapped into the consciousness of the 1960s generation as none other, penning some of this nation's most enduring anthems as quickly as a seasoned secretary would take dictation. Indeed, if 
future generations were going to rediscover any kind of political power in music, it would be through the unique public pedagogy and rhetorical education provided through the lessons Bob Dylan learned himself and then conveyed through his transformed frames.

That his songs have been taken up by so many different artists in a wide range of styles speaks not only to his songwriting prowess but to the malleable applicability of his type of musical and lyrical exploration. As to his ever-changing nature, Liam Clancy of the Clancy Brothers, friend to Dylan from the early days in the Village, described him as the Irish mythological "shapeshifter," able to change himself at will to suit the current need. Author and musician Sam Shepard regards Dylan as an invention, created from "the things he had around him and inside him":

What happens when someone invents something outside himself like an airplane or freight train? The thing is seen for what it is. It's seen as something incredible because it's never been seen before, but it's taken in by the people and changes their lives in the process. They don't stand around trying to figure out what isn't, forever. They use it as a means to adventure. (L. Smith 15)

Shepard's description of Dylan's self-invention supports the theory of Dylan as a public text while also forecasting the future generations who would learn from Dylan, using their art to reinvent folk music, returning to it activist potential while simultaneously broadening the folk ethic into new forms of vernacular music.

As much as Woody Guthrie promoted collective action frames within new media spaces created by radio, Dylan even more readily embraces new technological spaces available to him by actively resisting them. This resistance is not a rejection of technology but instead a critique, an attempt to keep visible the meaning-making processes that technology tends to make transparent. Therefore, instead of using older, existing folk frames within new technological contexts, Dylan suggests that a radically 
new kind of framing is needed to engage those spaces. He demonstrates this by holding himself aloof from them, thereby frustrating audiences and rejecting easy interpretations. However, whether viewed as frame transformation or anti-framing, Dylan's shifting image actually allows his counter/public pedagogy to come into sharp focus, and he successfully adds timely and necessary correctives to Guthrie's model of a critical public pedagogue that will be adopted and again revised by future folk singers. 


\section{ANI DIFRANCO}

In the January/February 1998 issue of Ms. magazine, the editors ran an article titled " 21 for the 21 st," a list of 21 "accomplished, promising young feminists" under 30 who were "paving the way" for the 21 st century (102). Among the notable women is Ani DiFranco, a diminutive do-it-yourself folksinger from Buffalo, NY. In a single paragraph, the magazine praised DiFranco's success and commitment to feminist politics.

Di Franco is the "chick singer" with the acoustic guitar who turned a living room recording operation into her own profitable label, Righteous Babe Records - without ever compromising her feminist message. At 26, she's turned down all offers from the major labels, maintained artistic control, and inspired many young women musicians to do the same. DiFranco's nine-album catalog sales exceed three quarters of a million; her latest CD, the live Living in Clip, debuted at \#59 in Billboard's Top 200; and she recently went on the Financial News Network to explain why she makes more money per album sold than Hootie and the Blowfish. Yet DiFranco keeps her focus on the songs, which combine personal reflections with potent politics. "It's not about money," she told a music industry convention this year. "I hope when we measure our success, our bank accounts don't figure into it." Only women's voices, on their own terms. (107)

DiFranco, who has been featured in $M s$. several times before and since that article was published, counts herself a fan and reader of the magazine. Although the brief profile is entirely positive and complimentary, DiFranco penned an open letter to the magazine, gently but clearly chastising them for their representation of her and her career. Her problem was not so much with any of their facts, but with the way they foregrounded her success in financial terms. 
What got me was that it largely detailed my financial successes and sales statistics. My achievements were represented by the fact that I "make more money per album sold than Hootie and the Blowfish," and that my catalogue sales exceed $3 / 4$ of a million. It was specified that I don't just have my own record company but my own "profitable" record company. Still, the ironic conclusion of the aforementioned blurb is a quote from me insisting "it's not about the money." Why then, I ask myself, must "the money" be the focus of so much of the media that surrounds me? Why can't I escape it, even in the hallowed pages of Ms.? ("Open Letter")

Ostensibly, DiFranco is concerned with the way the magazine - and, by extension, women - measure success in competitive, masculine terms. How much money did she make? How many units did she sell? Indeed, the list of feminists $M s$. magazine offers might be construed as "women who succeed in a man's world," which raises questions about the rules by which women must play to be successful. That the magazine creates a list of exceptional women achieving success in ways that would be considered less remarkable if they were men simultaneously highlights the very issue that underlies why feminism exists in the first place. And DiFranco notes the irony in her letter, as she continues:

$M s$. is a structure of media wherein women are able to define themselves, and articulate for themselves those definitions. We wouldn't point to 21 of the feminists moving into the 21st century and define them in terms of "Here's Becky Ballbuster from Iowa City, she's got a great ass and a cute little button nose..." No ma'am. We've gone beyond the limited perceptions of sexism and so we should move beyond the language and perspective of the corporate patriarchy. The Financial News Network may be ultimately impressed with me now that I've proven to them that there's a life beyond the auspices of papa Sony, but do I really have to prove this to you? ("Open Letter")

DiFranco effectively links capitalism, sexism, and patriarchy to the restrictive ways women are defined even in the "hallowed pages of Ms.," observing that the magazine's editors appear to measure success with a false scale, based on a patriarchal perspective that even this feminist periodical cannot seem to escape. 
Near the end of the letter, DiFranco drops the sarcasm and irony to plainly summarize her admonition: "We have the ability and the opportunity to recognize women not just for the financial successes of their work but for the work itself. We have the facility to judge each other by entirely different criteria than those imposed upon us by the superstructure of society. We have a view that reaches beyond profit margins into poetry, and a vocabulary to articulate the difference" ("Open Letter"). Ensuring none should miss her point, DiFranco reminds the magazine that they can circumvent "the superstructure of society," resisting patriarchal ideals and adopting language and perspectives that demonstrate new ways of praising work that not only opens new spaces for women but for all people who might escape the more narrow and rigid definitions and identities within patriarchy.

On another level, however, DiFranco's letter may be interpreted as brand management, or damage control to the image of "Ani DiFranco" that she has worked so hard to craft. Temporarily setting aside questions of sincerity or authenticity, one might read DiFranco's letter as an indignant response to the magazine's exposure of and focus on her financial success, a facet of the music industry that many use to question the sincerity of independent musicians. Calling a musician a "sell out" is a common critique of folk, punk, and rap artists who speak out against capitalist structures but then achieve some level of relative success and exposure, suggesting that some level of obscurity is important to the ethos of protest singers, at least in particular genres. After the first paragraph in her letter, in which she praises Ms. magazine generally, DiFranco says, "I couldn't help but be a little weirded out by the paragraph next to my head that summed up her me-ness and my relationship to the feminist continuum" (“Open Letter”). 
"Summed up her me-ness" is an unusual construction that is both third- and first-person, which interestingly signifies multiple facets of identity, particularly for public figures. Her concern invokes the reader, particularly one who does not know DiFranco's work and career and who will thus form an opinion about DiFranco based on that paragraph. This is made all the more apparent by the fact that DiFranco chose to write an open letter, published and republished widely, rather than sending her note directly to the magazine to be included in its regular "Letters" section.

Clearly, DiFranco wants to clarify her position beyond the reach of the magazine, perhaps aware of how content can be syndicated and circulated. Layered between her comments about measuring feminist success differently are several descriptions of her own identity that work together in an effort to rebuild her image more suited to her work. Even while acknowledging that everything $M s$. magazine printed was correct, DiFranco attends to her public persona: "So, here I am, publicly morphing into some kinda Fortune 500-young-entrepreneur-from-hell, and all along I thought I was just a folksinger!" ("Open Letter"). At the close of the letter, DiFranco again reminds, "I'm just a folksinger, not an entrepreneur. ... I mourn the commodification and homogenization of music by the music industry, and I fear the manufacture of consent by the corporately controlled media. Last thing I want to do is feed the machine.” More than simply clarifying or justifying her choices, DiFranco directly states which terms she feels appropriately describe her and which do not. She gives the final word in the last sentences of the letter, penning her own tombstone: "Just promise me one thing; if I drop dead tomorrow, tell me my grave stone won't read: 'ani d., CEO.' Please let it read: songwriter, musicmaker, storyteller, freak." DiFranco's attempt to set the record straight reveals more than her 
desire to see feminism offer a better option than patriarchy; it reveals the importance she places on establishing an authentic image as essential to performing her work as a public pedagogue.

DiFranco positions herself as a folksinger in the musical lineage of Woody Guthrie, and her work can be mapped on the model of critical public pedagogy Guthrie provided. In addition to explicitly naming Guthrie as a major influence and inspiration, she has also performed Guthrie's songs, organized an all-star tribute album, and performed at the opening of the Woody Guthrie Archives in New York. A regular in the folk music festival circuit for over two decades, DiFranco has cemented her status as a folksinger. And while DiFranco sings about many of the same issues that concerned Guthrie, she also borrows his model of activism to support feminism, demonstrating the flexibility of his methods. Like Guthrie, DiFranco constructs rhetorical frames to persuade her audiences to see themselves as victims of oppressive systems, but she identifies patriarchy as the underlying cause of most of society's problems. In this way, DiFranco attempts a type of frame bridging to reorient perspectives around a new paradigm, linking issues together for people with similar grievances but who exist in different publics. Thus, DiFranco offers a way not only for other women to see how patriarchy oppresses them, but also for men to understand how patriarchy harms them, too.

Guthrie's public pedagogy was animated by the new technologies of his day, including broadcast radio, audio recordings, and mass media print. Similarly, Bob Dylan embraced the televisual technologies of the 1960s as a means of distributing not only his music but also his image, participating in press conferences, making films, and sitting for 
photo shoots - all of which would circulate the globe infinitely faster than the media of Guthrie's day. Following Guthrie and Dylan, Ani DiFranco likewise participates in the circulation of her music, message, and image via technological channels that would include global broadcast cable television (via MTV and televised benefit concerts) and the early days of the Internet (via websites and fan forums). As telecommunications gained both popularity and speed in the late 20th century, DiFranco was able to position herself at the front of a revolution in do-it-yourself music production and promotion, reclaiming an important part of folk music that was largely lost in its commercialization.

This chapter examines DiFranco's performances of public pedagogy through her construction of collective action frames, which persist not only her music but throughout her interviews, poems, essays, and even her entrepreneurship. When observed as a careerlong project, DiFranco's resistance to patriarchy reveals her creative and critical output to be a calculated effort to highlight the injustices of patriarchal structures while fostering a collective identity among her listeners, and thus her business maneuvers may be reframed as creating agency for not only her own career but for the larger feminist work in which she participates.

\section{DiFranco's Public Pedagogy and Collective Action Frames}

Ani DiFranco was born in Buffalo, NY, in 1970. She has shared very few details about her family beyond the fact that her childhood situation was an unstable one, and that she found solace early on in music. Shortly after beginning to learn the guitar at age nine, DiFranco began busking with her guitar instructor, giving her an early taste of her future career. By the time she was a teenager, she regularly performed in bars and 
coffeehouses, singing her own compositions as early as fourteen. By fifteen, she had emancipated herself from her parents, found a residence and a job, and by sixteen she had graduated high school. Trying to start her musical career in earnest in New York City, she found that performing by herself with an acoustic guitar offered not only the autonomy she desired but also the mobility that allowed her to travel from coffeehouse to coffeehouse. With hardly any overhead and minimal requirements in the way of equipment, she went wherever she could, frequently relying on friends and strangers to offer couches and spare rooms as she traveled regionally, steadily building up a following that could justify the effort and expense of her first recording.

After briefly entertaining the idea of signing with a small, independent label, DiFranco ultimately rejected the idea, opting instead to form her own at age eighteen. As the head and sole employee of Righteous Babe Records, DiFranco released her first record in 1990. Over the years, several labels have approached DiFranco with deals, but she has remained firm in her independence, growing her own label into a "peoplefriendly, sub-corporate, woman-informed, queer-happy small business that puts music before rock stardom and ideology before profit” (“Open Letter”). Even today, her label only employs a dozen or so individuals, and DiFranco acknowledges that it only ever grew out of necessity, never from a desire to run a business. DiFranco's strong ethic of independence and her stance against the corporate music industry has not only granted her complete freedom in designing her own career, but it has also played a significant role in cultivating her image as grassroots folksinger. Her ability to remain independent while sustaining her career demonstrates the possibility of thriving outside "the 
superstructure of society," which communicates as much to her loyal fans as her lyrics do.

Although DiFranco is highly esteemed within the folk music community, those outside that particular sphere might have trouble recognizing DiFranco as a folk singer. Certainly, this is in large part due to the trope of the American folk singer so strongly cemented by Woody Guthrie and the countless "Woody's Children" who followed in his footsteps, patterning their music, appearance, and mannerisms after their musical forebear. Though DiFranco does primarily play the acoustic guitar, her music blends folk music with jazz, funk, punk, and hip hop through intense guitar virtuosity and dense language delivered in winding melodies and odd meters that have resulted in a form of music entirely her own. She frequently relies on non-standard tunings to create atypical chord structures, and her style of playing is often described with violent imagery — as clawing, scratching, or attacking her guitar. As much a poet as a songwriter, she inserts spoken word poems into her recordings and live sets, delivered in a fast-paced style with keen attention to rhythm, sound, and patterns, significantly more reminiscent of the artistic diatribes of Gil Scott-Heron than the talking blues of Guthrie or Dylan.

Despite these vast stylistic differences between DiFranco and traditional folk musicians, DiFranco makes her connection to folk music very explicit, branding herself from the beginning of her career as "the little folksinger," and taking every opportunity to expand upon the public's notion of what folk music actually is. In September of 1996, the NPR series E-Town aired a performance of DiFranco and Utah Phillips, a veritable folk legend who had spent decades "tramping," jumping trains, and exploring the country. Picking up songs and stories from and about those he met along the way, Phillips 
embodied the folk singer ethos modeled by Woody Guthrie. DiFranco, who was 26 at the time, provided a unique counterbalance to the old guard of folk. The audience reflected the performers' diversity, including older patrons who knew Phillips' long career, folk aficionados who respected the old and new traditions of folk represented on stage, and feminist and lesbian fans who resonated with DiFranco's political and cultural activism. According to author and academic Dick Weissman, who was in attendance as well, "The audience was respectful for Utah's part of the performance, but when Ani started to play, the young people all got up and danced as she viciously attacked her acoustic guitar" (265). Phillips and DiFranco appeared on E-Town in part to promote their collaborative album, The Past Didn't Go Anywhere, which features Phillips telling stories and discussing issues while DiFranco provides music and atmosphere. A second album, Fellow Workers, followed in 1999, this time culled from a series of live performances in front of a small audience at Kingsway Studios in New Orleans, featuring songs and stories old and new. Between the two albums, Phillips was honored with a lifetime achievement award from The Folk Alliance, and DiFranco took this opportunity to sit down for an interview with him, discussing the legacy, utility, and meaning of folk music. Phillips, taking the long view granted him by his age and wisdom, described the tradition that informed his work:

"Growing up — really growing up - means at some point in your life discovering what you authentically inherit. Culturally. What you culturally inherit. Finally acknowledging that, finally recognizing that, and that's what you try to put in the world. See? And that's what I do now. As I find that my inheritance is a wealth of song and story and poem from my elders, especially the radical elders, who never had that wide a voice in their lives... They give me those treasures, they're gone, I'm here. And that's what I put in the world. That's it. There isn't any other life for me." (righteousbaberecs) 
Phillips' description of folk music is a familiar one, hearkening back to the days of sharing songs on front porches and in moving boxcars, retelling the stories of hardship and frustration of the marginalized populations "who never had that wide a voice." His definition paraphrases many of Woody Guthrie's declarations about the nature and purpose of folk music, and it also resonates with Bob Dylan's early explanation, that folk music is simply "handed down songs" (Dylan, Chronicles 8). After Phillips shares his perspective, however, DiFranco offers her own, seeming to choose her words carefully to both respect and delicately challenge Phillips:

Yeah... I've often thought—for myself - that folk music is not an acoustic guitar, necessarily. That's not where the heart of it is. It is... it's an attitude, it's an awareness of one's heritage, like you say, and a community. It's sub-corporate community-based music which, you know, like this album that we did... You know, the people who think of folk music as a piece of wood, ignoring all the other political and economic implications, I guess are probably going to have some problems with it. (righteousbaberecs)

While DiFranco acknowledges the value of recognizing the heritage of folk music, her definition simultaneously decouples folk music from any necessary connection to the past. Her recognition of folk music's heritage is in service to the development of community. For DiFranco, folk music circulates among and serves people in community, supporting them and speaking to their present-day concerns. Likening some others' perceptions of folk music to "a piece of wood"- $\mathrm{a}$ dead object once living - she offers a subtle but harsh critique that does not necessary negate but certainly revises Phillips' definition. And in doing so, DiFranco draws a line between folk music as a cultural artifact and folk music as a cultural force. Demonstrated by the respectful older concert attendees at E-Town described by Weissman above, popular opinion of folk music in the 1990s was very much connected to history, fixed in the past. 
Songs that had once been seen as radical, even dangerous, were now things of comfort and reminiscence, or, for some, the target of jokes or ridicule. And for younger generations without personal memories of labor struggles of the 1920s and 1930s, or the Civil Rights movement or antiwar protests of the 1950s and 1960s, folk music held no personal relevance. Or, as DiFranco puts it, "People my age find folk music very uncool, you know? Just terribly, terribly, uncool" (righteousbaberecs). And yet, although DiFranco has never achieved A-list musician status, she has nevertheless managed to make a living as a folk musician, supported by the very people who ostensibly find folk music so "terribly, terribly uncool." She explains this apparent incongruity, once again, by broadening or reframing the definition of folk music:

But for me, I use the word "folk music" in reference to punk music, and to rap music, and those are all, you know, there are so many indigenous music forms that come out of, sort of, you know, my world and the country that exists around me growing up, that I think have an impetus in non-corporate... kind of, giving voice to different communities, you know, the youth of those communities, and the struggle against authority . .. coming up against some kind of societal brick wall that's been built there, you know, for us to run into at some point in our lives. (righteousbaberecs)

Again, while DiFranco's definition is not necessarily at odds with her musical forebears, she emphasizes the contemporary relevance of folk music among communities, particularly communities that struggle in the larger systems and structures of society. Including other genres of music like punk and rap make perfect sense with regard to explanations of folk music's function or role in culture, even if they fly in the face of generic descriptions or traditional perspectives. DiFranco is arguing that one can identify folk music not by what it sounds like or looks like, but by what it does.

By the same token, DiFranco widens access to folk music. Although the history of folk music in America was never solely the domain of white men, the calcification of the 
genre through the music industry and consumer culture overwhelmingly shaped it in that direction. However, if through DiFranco's definition one could consider the music of black punk band Bad Brains, the consciousness rap of Queen Latifah, or the genredefying music of queercore band Bitch and Animal "folk music," DiFranco both reclaims and reframes the influences that not only shaped folk music in the past but led to the proliferation of vernacular music genres among communities for which the idea of an aging white man with an acoustic guitar singing about disappearing flowers bore no resemblance to the lived experiences in so many cities across America in a post-Vietnam era. Much more significantly than merely redefining folk music, DiFranco's explanation actually outlines how cultural revolution takes place. Capping off her discussion of "giving voice" to the youth of various communities, she says, "Like, you either conform to a way of life that you just can't stand, or you become... you kind of give voice to various objections to it. So to me, folk music is so many different kinds of folks and their music" (righteousbaberecs). It is significant that DiFranco mentions "objections" rather than solutions, aligning with Denisoff's discussion of rhetorical songs as being persuasive without proposing concrete action or remedies. As Dylan noted during his transition away from "finger-pointing songs," the solutions are too elusive, too varied, too subjective, or too complex to be appropriately discussed in music, but DiFranco's career, music, and interviews suggest that the objections are in fact the solution, that the protest is itself the point.

Referring to "so many different kinds of folks," DiFranco implies that folk music has no one, monolithic heritage, but many. Not one community, but many. Multiple varied experiences and expressions all find a home in "folk music," and this is the real 
reason she offers objections rather than solutions: her activism via folk music performs a type of cultural archeology in which she attempts to uncover and mark out patriarchal, heteronormative, and binary-based structures and their implications. The work of protest - the objection - is indeed the solution, because she is not attempting to create a new structure, but rather dismantle the current ones. This work is reflected in the lyrics, poems, essays, and plays she writes, the causes she supports, the labels and stereotypes she rejects, the way she manages her music business, and her own appearance and image. Additionally, DiFranco's work suggests the belief that "so many different kinds of folks" applies as equally to the individual as it does to the community, that each person contains a multiplicity of perspectives, roles, identities, and ideas, again offering a strongly feminist challenge to patriarchal perspectives. It is a position that is based not on securing identities but destabilizing them, not on continuing narratives but disrupting and changing them. She acknowledges folk music's heritage not merely to venerate it, but to challenge it. Phillips closes the interview segment with an apt metaphor: "When I was tramping on the trains, I learned to live in the cracks. I learned to find out where the cracks were, and then how to live in them. And no matter how monolithic the wall gets, you'll find a crack" (righteousbaberecs). It is precisely these cracks that DiFranco has dedicated her career to finding and inhabiting, even when the cracks appear in the communities of which she appears to be a part.

Focusing on community-based, sub-corporate, non-conformist aspects of a range of musical genres not only allows DiFranco to widen her musical palette while still branding herself as a folk artist, but it also invites numerous potential examinations of artistic endeavors and cultural activities through the lenses of folklore, folk art, and folk 
activism. Additionally, just as her music diverges from tradition yet still remains loyal to a redefined folk ethic, so too does her radical feminist message break from traditional, cultural impressions of folk songs. Despite these differences, however, the rhetorical and pedagogical models outlined thus far reveal that DiFranco's creative and critical work still clearly follow the trajectory laid out by Guthrie and Dylan.

Like Guthrie, DiFranco fills the role of a "critical public pedagogue" in that she acts as a servant-leader who offers social, cultural, and political critiques of the economic and political systems that structure identity in limited and oppressive ways (Roberts and Steiner 26). To do this, DiFranco constructs her own collective action frames, which function along the same lines of Gamson's three-part structure (identity, injustice, agency), but represent a new way of joining seemingly unconnected issues. In the case of Guthrie, he focused primarily on the "hard hit masses" whose identities fell outside of the mainstream largely because of their poverty, decrying the banks who preyed on the downtrodden, the bosses who exploited them, and politicians who failed to protect them. Guthrie's pedagogical performances not only indicted the structures that oppressed the masses, but they also participated in the restructuring of identity as described by Steiner and Roberts, recasting the players, so to speak, in terms of who were the villains and heroes, the haves and the have nots. Through reassigning value to hard work, simple pleasures, charity, and human dignity, Guthrie's work praised those who were excluded, marginalized, and trapped by the oppressive structures that fueled the American economy and political engines. For them, his messages provided something of a curriculum that outlined the roles people played in society, how those roles came about, why they persist, and how to proceed. 
Although DiFranco's song topics frequently address situations of poverty and politics in this country, her primary focus of critique and aimed at patriarchy, and her identity concerns address issues of radical third-wave feminism, aimed at empowering both women and men to see themselves in different terms than the limited binaries expressed and reinforced through mass media, consumer culture, and bureaucracy. David Snow et al. explain how this framing of injustice provides "a mode of interpretation that defines the actions of an authority system as unjust and simultaneously legitimates noncompliance" (466). Once patriarchy is successfully framed and interpreted as unjust, participants can justify and defend their identification and alignment with the feminism. This is precisely the method of rhetorical framing DiFranco employs again and again in her music, poems, essays, and interviews. Specifically, DiFranco's pedagogy follows a process whereby people must first become aware of the power plays behind their oppression, unite with likeminded others, and then pressure those in power to make society more equitable and free. This pattern closely follows Snow et al.'s frame alignment process, using the organization and presentation of ideas as a rhetorical construct to highlight what she feels is at stake. Jim Kuypers observes that "Frames operate in four key ways: they define problems, diagnose causes, make moral judgments, and suggest remedies." He then emphasizes the rhetorical aspect of framing, noting, "Frames are so powerful because they are able to make some information more salient than other information" (8, emphasis his). Therefore, the artistry involved with such public pedagogy is in constructing rhetorical frames (or tapping into existing ones) that allow complex and/or controversial issues to be understood in the desired way and achieve the intended effects in the space of a three-minute song. 
Like Guthrie, DiFranco's songs offer a metanarrative to construct collective action frames in which listeners are invited to identify with those who suffer at the hands of patriarchy. While one might argue that DiFranco is largely "preaching to the converted," the persuasive and educational elements of her texts are undeniable, and she has clarified in interviews time and again that her message is not merely for women. Part of her challenge, then, is to show men - those who ostensibly benefit from patriarchyhow patriarchy actually harms them as well. DiFranco's injustice frame may not initially resonate with all women or with many men, but through frame bridging, she reaches past common perspectives of patriarchy to argue that seemingly unconnected problems in society indeed relate to patriarchy—issues that affect everyone, not just women. Therefore, such framing is required to provide the cognitive cues to her audience that patriarchy is indeed the problem.

For example, in her song “Origami,” DiFranco describes a relationship in which the speaker tells the invoked listener (the "you" in the song) why she is unhappy in the relationship. As simple and common as a song topic as this is, DiFranco uses the narrative to construct a collective action frame that reframes frustration as injustice, offers a nuanced (or perhaps complicated) identity alignment, and provides agency (in the form of language and action) for those who opt-in the collective identity offered by the speaker. She opens with the following lines: "I am an all-powerful amazon warrior / Not just some sniveling girl / So no matter what I think I need / You know I can't possibly / Have a need in this world." Beginning with a declaration of power, contrasted immediately against society's view—and, in this case more specifically, a man's view— of who and what she (and, by proxy, every woman) is, DiFranco resets the natures and 
roles of women and men. Lines three through five use irony to acknowledge a common patriarchal perspective, that women's needs are secondary to men's and are thus still inconsequential in the eyes of modern society, underscored by the second stanza: "Come and come for that sweet sweetness / I'll be your never ending vending machine / I could never need to be alone / Never need to be my own / As much as you need your queen." Again, voicing a male perspective, DiFranco likens herself to a vending machine, an inanimate object without needs or opinions that only exists to give what the user wants when the user wants it.

However, she then calls herself a queen, which allows two simultaneous interpretations. One is that of the speaker as the object of desire, and the protected property of the king, in keeping with patriarchal language sometimes adopted as men describe their attitudes toward "their" women. At the same time, enough ambiguity in the phrase exists that DiFranco might be referring to a queen and her subject- "your queen" does not indicate the role of the listener in this dyad. Therefore, "queen" may also be a term that connotes power over the man, an explication supported by her statement about the listener's "need." Lines three through five in this stanza also appear to continue the irony in stanza one, but if taken sincerely, these phrases argue that this type of man truly does need her more than she needs him. Rather than stating the opposite of the truth as in stanza one, her switch to literal meaning pivots the lyrics toward the punchline of the chorus.

As in the opening verse, in which DiFranco redefines herself as an "all-powerful" contradiction to society's construction of her gender, she similarly redefines men in the chorus: "I know men are delicate / Origami creatures / Who need women to unfold them / 
Hold them when they cry / But I am tired of being your savior / And I am tired of telling you why" (DiFranco "Origami"). She does not say "you are delicate" but "men are delicate," underscoring her intention to reconstruct gender, that her message is about more than a single person, more than one problem male. The chorus also suggests that experience informs her opinion, as DiFranco sings "I know..." and "I am tired..." to indicate a repetition that builds sufficient evidence to support her claim. Then, in the last couplet, she delivers the culminating point, which is an assessment of the futility of imbalanced relationships. She makes clear that it is not her existential purpose to fix, restore, complete, or redeem her partner, and that men who approach relationships in that paradigm only perpetuate inequality between genders. Singing, "I am tired of telling you why," which garners loud cheers during recordings of live performances, reveals a shared experience among women that not only are men guilty of repeatedly placing unreasonable, unfair, and inappropriate expectations on women but that they are either unable or unwilling to understand why that would cause problems.

Two larger ideas in particular seem significant in the explication of this song. First, DiFranco seems clearly interested in parity between partners - men and women in this case, but her fluid sexual orientation suggests she would argue this applies to any partnership regardless of gender. In keeping with third-wave feminism, DiFranco does not think a patriarchy should be replaced with a matriarchy, confirming this in numerous interviews and instead offering the word "balance" as the way to rectify the manifestations of patriarchy in society (FaceCulture).

Second, although DiFranco's lyrics appear to be complimentary of women and disparaging toward men, they actually contain a similar project for both genders in the 
way she counters cultural narratives and complicates identity for both. For women, she describes their strength, power, and independence, and she reinforces the need for balance in support of equality and equity in relationships. More subtly, she also shows different sides of her personality, different impressions others possess of her, to push back against monolithic descriptions of what women are and how they behave. At different times in the song, the speaker is compared to an "all-powerful amazon warrior," a "sniveling girl," a "queen," and a "savior." Although the second line of the song is contesting the portrayal of the "sniveling girl," it does not fully dismiss that characterization: "not just a sniveling girl." This might be read as DiFranco attempting to allow women some duality, to be both secure and insecure simultaneously, or, in essence, to be complicated.

DiFranco also offers some pushback against cultural depictions of men, presenting them as needy, subservient, delicate, and infantile, needing to be held and comforted when they cry, which she suggests is often enough to be a common trait among men. But as much as she portrays men as obtuse, unable to understand why women cannot solve their problems, DiFranco's comparison of them to “delicate, origami creatures" equally allows them to be complicated as well. Her description leaves room for men to be intricately constructed contradictions, themselves victims of their own culture of patriarchy. This, too, is a conviction she has repeated in interviews, observing that patriarchy ultimately causes harm to men and women alike. She emphasizes, "It doesn't help men. It doesn't serve men. That's the lie. The idea that, you know, maybe you can feel like you have a little power for a moment because you're controlling a situation ... But the end result of patriarchy resonating off of itself again and again is equally as 
damaging and awful for men" (FaceCulture). And indeed, in the context of the song "Origami," men suffer the consequences of participating in patriarchal constructions of identity and gender roles.

DiFranco constructs an injustice frame that condemns patriarchal values, but she also bridges the frame to show men how patriarchy negatively affects them as well. Understood as public pedagogy, "Origami" does not simply examine a situation between two people; DiFranco does use personal pronouns in the song, but they are clearly placeholders for their respective genders. The narrative of the song features a woman recognizing specific reasons why imbalance is causing her relationship to fail, and she realizes through the course of describing her problems that part of the issues is that her male partner is perpetuating damaging cultural expectations. When she finally gets to the crowd-pleasing last lines of the chorus, she offers women everywhere a succinct response to their own male partners who hold similarly problematic expectations, an articulation that can be recited verbatim: "I am tired of being your savior, and I am tired of telling you why."

In this way, DiFranco's public pedagogy enacts rhetorical education insofar as it offers listeners a method for developing identity through awareness and language (Enoch 7-8). Moreover, DiFranco demonstrates a kind of activist work within her community, not simply for her community, which supports reading her work as a kind of rhetorical education. While such rhetorical education may not directly lead to a greater engagement in community and civic affairs in any political sense, it nevertheless fosters selfactualization and, by seeking to create frame resonance, does suggest at least latent possibilities exist for community and civic transformation. 
Criticism, Contradictions, and a Pedagogy of Discomfort

Viewed as a collective action frame, the overarching message of DiFranco's music has been remarkably consistent over the past 25 years, broadly pointing out myriad ways patriarchy poisons society and damages its citizens. Within this frame, several salient points emerge that provide a set of recurring arguments defending her perspective. At the same time, DiFranco's attitudes, expressions, questions, and even her identity have all evolved — as humans are wont to do—in such a way that she has drawn criticism from her own followers at various points for "betraying" them. As discussed in the previous chapter regarding Bob Dylan's apparent inability to shake the "spokesman" label, public figures such as DiFranco become, in effect, public texts that circulate recursively through various publics. Such circulation provides publics with opportunities to read and interpret her through their own perspectives and ideologies, until the public text of Ani DiFranco may or may not resemble the actual person of Ani DiFranco. This section first considers the set of arguments DiFranco uses to build her collective action frame and then examines the contradictions and ambiguities that have drawn criticism from her community. Ultimately, however, I argue that allowing those contradictions and ambiguities to exist becomes a part of her feminist project, facilitated through her music and engaging in rhetorical education through a pedagogy of discomfort, which retains rather than resolves unanswered questions and complications (Boler).

DiFranco's rhetorical framing should be understood through Steiner and Roberts' definition of a critical public pedagogue, specifically in the way their pedagogue helps broaden the possibilities of identity construction (26). Again and again in her lyrics and interviews, DiFranco describes various ways of seeing the world, understanding 
situations, and regarding ourselves and each other that run counter to cultural narratives.

In the circumstances described in these songs, she attributes injustice to patriarchal values, and she uses narratives of emancipated thought, speech, and action as the antidote, addressing both individual and community concerns. For the individual, DiFranco focuses on reversing or disrupting binaries to reveal power imbalances, as demonstrated above in the song "Origami." For communal or social concerns, DiFranco engages in frame bridging by linking patriarchy to more visible elements of society, like capitalism, war, education, religion, and the environment. In an interview with Sekou Sundiata, DiFranco elaborates,

When I look at things like peace and justice in this world, naturally, it is my womanhood that looks. And I see patriarchy at the root of social injustice and war. Patriarchy, an undisputed fact of human society, is inherently imbalanced, and nature favors balance. I believe the shift in consciousness that is a prerequisite to peace is the very one that will occur through the total empowerment and participation of women in society. When we will finally incorporate ideas like personal freedom and autonomy, with the understanding that no one exists except in relationship to others. This interplay between masculine and feminine wisdom, in the world around me and within myself, is at the core of my writer's voice, my life experience, and my political ideals. (DiFranco, Verses 93)

Part of DiFranco's public pedagogy, then, which is intensely feminist, is keeping the personal and public connected. As they enact rhetorical education, her pedagogical performances demonstrate a wider view of private life, inviting listeners to consider both the broader repercussions of personal actions as well as the implications of culture for individuals, and how the two are inextricably linked.

In "Fixing Her Hair," DiFranco connects patriarchy with beauty standards, revealing a link between normative femininity and the disempowerment of women. Verse one describes a familiar story: "She's looking in the mirror, she's fixing her hair / And I touch my head to feel what isn't there / She's humming a melody we learned in grade 
school / She's so happy, and I think, 'this is not cool' / 'Cause I know the guy she's been talking about / I have met him before and I think, "what is this beautiful beautiful woman settling for?'" The narration describes one female friend looking out for another, while the action of the scene shows a woman attending to her appearance in anticipation of pleasing a man. The speaker intimates that this man is more concerned with this woman's external appearance than with his own internal values, and, as with "Origami," the speaker observes the disparity between the two individuals in the relationship as the root of the problem.

Verse two builds on the common tale, adding commentary to the narrative, and providing the articulation of DiFranco's injustice frame: "She bends her breath when she talks to him / I can see her features begin to blur / As she pours herself / Into the mold he made for her." In these four lines, the speaker observes that her friend's identity is in crisis because the expectation of this man, which is again a stand in for patriarchal expectations of beauty and female identity, is reconstructing her in an image of its own design. DiFranco ties together these strands of patriarchy, beauty, and cultural norms as impediments to female self-actualization in the final verse, singing, "And she still doesn't have what she deserves / But she wakes up smiling every day / She never really expected more / That's just not the way we are raised / And I say to her / You know / There's plenty of really great men out there / But she doesn't hear me / She's looking in the mirror / She's fixing her hair." DiFranco reinforces the injustice frame by using the word "deserves," suggesting that mutual fulfilment is more of a right than a privilege in the politics of relationships. This communicates to her listeners that they, too, deserve to be 
treated appropriately and loved on their own terms, not the "mold" set before them by culture.

Furthermore, DiFranco highlights the consequences of women buying into the patriarchal definition of femininity, showing this character who "wakes up smiling every day" because "she never really expected more." Referring to the indoctrination of patriarchy with the line "That's just not the way we are raised" is particularly powerful because of her use of the present tense "are" instead of the past tense "were." Again, DiFranco demonstrates how this problem is systemic, that it is not a misfortune but an injustice. The most damaging aspect of the situation described in this song is not the way this particular man treats this particular woman, but it is the internalization of cultural expectations and the enforcement of beauty standards to such an extent that women fail to see how patriarchy robs them of both their individual and collectively shared identities. In this way, too, DiFranco answers one of Gamson's biggest critiques of ineffective collective action frames, which is to focus so intently on the responsible parties of injustice that one fails to connect the actions of individuals as complicit in larger, structural problems (93). While it is true that the main character in "Fixing Her Hair" acts as she does because one man objectifies her with his expectations, DiFranco importantly connects his actions with the culture that produced him.

DiFranco observes how consumer culture contributes to these issues more broadly in "Fuel," in which she laments the loss of artistic identity, sacrificed on the altar of marketing. She sings, "People used to make records / As in a record of an event / The event of people playing music in a room / Now everything is cross-marketing / It's about sunglasses and shoes / Or guns and drugs / You choose . . 'Cause we know the 
difference between / The font of $20 \%$ more / And the font of teriyaki." The irony in this song comes out in the short line, "You choose," noting the way consumer culture has promoted the concept of the individual and customization, as if having a unique background or case for one's iPhone makes a difference when the masses still scramble every nine months for the latest model of the device. The fact that "we know the difference" between fonts used for different marketing campaigns suggests that consumers in America have internalized the marketing structure to such an extent that we do not even see it. DiFranco points to the collusion of mass media as part of this process elsewhere in the song: "All the radios agree with all the TVs / And all the magazines agree with all the radios / And I keep hearing that same damn song everywhere I go.” Curiously, DiFranco assigns agency to the media, rather those who control it - she does not say, "the people on the radio agree with the people on the TV," and so on. Given the topic, it seems likely that this adds further commentary to the way consumer culture values and even fetishizes objects and devices, that they were designed to capture our attention and buy our allegiance as they do. Ultimately, DiFranco simplifies this message in "To The Teeth" with an explicit explanation of who is to blame: "Look at where the profits are / That's how you'll find the source / Of the big lie that you and I both know so well / By the time it takes this cultural / Death wish to run its course."

DiFranco repeatedly wrestles through moments where individuals surrender their own freedom and autonomy to cultural norms and oppressive systems, such as the speaker's friend in "Fixing Her Hair." However, her injustice frame consistently points more to structures than individual people as the true culprits of oppression. According to her lyrics and commentary, the larger the structure, the more significant the influence of 
patriarchy. For example, DiFranco expands on her criticism of mainline Christianity as an organization exceedingly more interested in power than in spirituality, using Christian mythology as the ultimate, supernatural expression of patriarchy. Referencing her own experience giving childbirth as an event that greatly intensified her own concepts about feminism, she refers to the idea of a masculine God creating man, from whom came woman, as “the craziest bullshit I've ever heard." DiFranco continues, “These stories we're told are about a reversal and about ejecting women from their seat of power," noting that even childbirth has been taken away from women—-first in the creation story, and even now culturally, citing the difficulty she had in finding a midwife and conducting a home birth. (FaceCulture). In the poem, "Literal," DiFranco links fundamentalist expressions of religion with abuses of power and missing the point of community: "literal people scare me / out there trying to rid the world / of its poetry / while getting it wrong fundamentally / down at the church of 'look, / it sez right here, see!"” DiFranco's condemnation of Christianity at large is therefore not at all a dismissal of the spiritual, but instead calls out the ways the religion itself undermines its own spiritual potential by using its stories and myths as justification for systematically oppressing women.

More specific to the United States, DiFranco links the patriarchal influence of religion to education, indoctrination, government, and citizenship. In one of her more ferocious critiques, she sings,

We start out sugared up on Kool-Aid and manifest destiny / And we memorize all the presidents' names / Like little trained monkeys / And then we're spit into the world / So many spinny-eyed TV junkies / Incapable of unravelling the military industrial mystery / Preemptively pacified with history book history / And I've been around the world now / And I can see this about America / The mind control is steep here, man / The myopia is deep here ("Serpentine") 
The "mind control" begins, according to DiFranco, in childhood, as public education in particular combines a selective historical account with jingoistic activities. The Kool-Aid most certainly invokes the poisoning of the men, women, and children of the Jamestown cult, but it becomes an even more chilling image in this context of public school, where the sugary drink is indeed a part of children's daily lives. Pairing it lyrically with manifest destiny indicates her belief that education is purposefully designed to brainwash children into thinking America's greatness comes through some kind of God-ordained military might. The myopia in the closing line of this excerpt points to the lack of empathy fostered by such perspectives, that children growing up reciting the names of presidents and lauding the slaughter of indigenous peoples as God's plan would surely support the spread of American ideals throughout the ends of the earth at any cost.

In "Not So Soft," DiFranco pushes harder on the disconnection between America's ideals and America's actions, again implicating education as a form of indoctrination:

Those who call the shots are never in the line of fire, why / Where there's life for hire / Out there if a flag of truth were raised we could watch every liar / Rise to wave it here / We learn America like a script / Playwright, birthright, same thing / We bring ourselves to the role / We're all rehearsing for the presidency

This passage begins with DiFranco criticizing the country's leaders for their lack of accountability and their avoidance of personal involvement in decisions that directly affect and are indeed carried out by significantly more vulnerable populations. Nevertheless, these leaders_-"every liar"—hold up America's oft-voiced values as guiding their actions, declaring themselves on the correct side of truth. The remaining four lines consider the concept of America as a piece of fiction, written by those fortunate enough to be born into its elite, and performed nationwide on a daily basis in schools, in 
the media, in the courts, and in government. Because of the American exceptionalism paired with individualism, "we bring ourselves to the role" in the way children are told they can be anything they want to be when they grow up, even the president.

These examples offer a sampling of the many ways DiFranco employs collective action frames to reveal injustice, build collective identity, and offer some agency as a way forward. This is a similar project to Guthrie's and the work of Dylan early in his career, but DiFranco revises their model, in true feminist fashion, to allow more complicated sets of identities into the narratives. The irony in building a career around a message that seeks to expand and complicate the construction of identity is that, upon becoming a public figure (and, as explained previously, a public text), DiFranco's audience continually constructs her identity in ways that co-opt and limit her own expression. One criticism DiFranco routinely receives - which is a similarly frequent criticism of many punk musicians - is simply her success. As one music blogger rants, “Laugh at the millionaire poser. Ani doesn't like it to be pointed out that she's a millionaire several times over. And certainly that fact doesn't jibe with her 'protests' songs" (Kat). She won a Grammy award (in 2004 for best album packaging), and has performed at hallowed music industry venues like the Rock and Roll Hall of Fame (who houses one of her guitars in their collection), and frequently appears in industry magazines like Rolling Stone and Musician. The question of success in folk music naturally occurs because it relates to authenticity, or the ethos of the musician. As with both Guthrie and Dylan in previous chapters, the impression of authenticity played an enormous role in the widespread acceptance of these musicians as icons within their field. Even though the personas of Guthrie and Dylan were both very intentionally crafted to 
convey such authenticity, their respective successful careers highlight the fact that the public's perception of authenticity is infinitely more significant in terms of uptake than the actual sincerity of the musician. Audiences respond to these musicians through a screen of cultural narrative: that is, Guthrie affects an Okie accent and manner, thus his voice is trusted by migrant workers from Oklahoma hearing him on the radio in California. Dylan wears the uniform and affects the hard gaze of a hard-travelin' folksinger, and "The Times They Are A-Changing” carries more gravitas, to which audiences favorably respond. DiFranco rejects offers by corporate record labels, and her fans celebrate her independence, assuming she would rather eschew fame and thus struggle through a career than "sell her soul" to a corporation.

The flipside of this process, of course, is what happens when a musician, having entered into this sort of unspoken contract with her public, defies her audience's expectations. Much of the previous chapter examines Dylan's infamous departure from the folk music scene in 1965 and the sheer horror of his fans at this perceived betrayal. Because Dylan's status circulated among the public who loved their particular reading of him, he provides a clear example of how celebrity status can cause one to become a public text themselves. Audiences who participate in the circulation of the celebrity-astext also participate in co-authoring that text, as the reading and meaning of texts are recursively reinscribed as they circulate. In the case of DiFranco, then, it becomes obvious that there would certainly be those in her audience who would question her authenticity if she were to become identified as a successful entrepreneur (observed in the earlier account of Ms. magazine's characterization of DiFranco and DiFranco's subsequent response). Whether DiFranco was truly appalled by the assessment of her 
business or not is really beside the point; the presentation spoke to a culture that DiFranco had spent 15 years working against by that point, and DiFranco's criticism of the column provided the response that her audience needed to see from her if she were to retain some of her credibility as an anti-capitalist.

Her position has been additionally compromised by two other significant events. The first was her decision to perform a cover of the Burt Bacharach and Hal David song “Wishin' and Hopin"” for the 1997 romantic comedy, My Best Friend's Wedding. Played during the opening sequence of the film, the song appeared on the soundtrack and raised not only DiFranco's visibility but also her bank balance. A short article in the LA Times noted the incongruity, observing,

Ani DiFranco--the new Celine Dion? DiFranco, the folk-pop maverick who has steadfastly held to both her feminist stance and indie-label approach to the music business, has indeed side-stepped into Dion territory. The critical darling has recorded a pop song touting "traditional" romantic values for a major film ... the very kind of thing that swept Dion to the top of the charts last year. (Hochman)

When the journalist asked DiFranco about her participation in the film, she sort of simultaneously acknowledged and sidestepped both the commercial aspect of Hollywood and the traditional values in the song's lyrics, reflecting, "I guess the irony appealed to my sick sense of humor. It's important for all of us to be able to poke fun at ourselves. People have always tried to rob me of my sense of humor. There's a perception for some that I'm kind of a dire, dogmatic person" (n. pag.) Whether perceived as ironic, humorous, contradictory, ambiguous, or some combination of all of the above, DiFranco's participation in the film's soundtrack was viewed by the media and public alike as noteworthy, leading one reviewer to report the song is "inexplicably performed 
by Ani DiFranco" (Angyal, emphasis hers) and another to mention "the unprecedented vocals of Ani DiFranco. Yeah, Ani DiFranco" (Smetana).

A similar apparent contradiction that drew additional criticism occurred when DiFranco's manager, in an effort to mitigate flagging record sales, licensed her song " 32 Flavors" to the NFL. DiFranco defended his action and the licensing, but her fans were divided, leaving many scratching their heads. DiFranco refuses to license her music to commercials, and although this particular license was for a series of documentaries, a clip of the song appeared in a promotional advertisement for the series, leaving many to assume DiFranco went back on her word. Some supported her, arguing that "it doesn't mean Ani is selling out. What it means is that people are enjoying her music" (Jeremy). Others took a much dimmer view of the deal: "I wonder if Ms. DiFranco thinks that supporting the stereotype-perpetuating cheerleaders of the NFL can be justified by the fat royalty check in her mailbox" (Burlingham 101). Initially, DiFranco reasoned that she supported the choice because, although she was not personally a fan of football, she believes professional sports bring races together, allow some minorities an avenue out of poverty, and might also be a great way for men with too much testosterone to take out their aggressions in a more constructive manner (Keast). Over a fairly brief period, however, her tone changed, eventually dismissing not only the issue but the people who made a big deal over it. "I think that the people who have reacted adversely to that are probably white people," she laughs to one journalist. "They're fucking white people with too much time on their hands" (Pancratz). As a white person herself, the implication of race is an unusual one, but it seems likely that she is making a subtle criticism of privilege that permits endless fascination with other people's issues. 
More recently, however, race became an enormous factor in a debacle that saw DiFranco issuing public apologies. In December 2013, DiFranco scheduled an artists' retreat for women at the Nottoway Plantation and Resort in Louisiana, a hotel that was once a thriving slave-worked plantation. The location had not been announced before several had signed up to attend, including co-facilitator Toshi Reagon (daughter of Civil Rights leaders and musicians Cordell Hull Reagon and Bernice Johnson-Reagon). DiFranco was oestensibly unaware of the location's history, which infamously romanticized its past (but who has scrubbed all such language from their website since the debacle). When news of the location reached the public, the outcry was swift, leading many to accuse DiFranco of being a range of things from tone-deaf to blatantly racist. DiFranco issued a statement through her website, saying, "When I found out it was to be held at a resort on a former plantation, I thought to myself, 'whoa"' (Rao). She did not, however, cancel or relocate the event. Toshi Reagon was significantly more decided in her response, posting on Facebook, “'II don't like big white buildings—you can call it a mansion all you want-I just say it's the big house... Even though I never had to pick cotton - whenever I see places like that-I feel like I can see people picking cotton. So I never would want to be at Nottoway... I would never want to sing there" (Rao).

The event was subsequently canceled entirely, with DiFranco issuing an apology that many read as defensive. Acknowledging the troubling history of the location, DiFranco suggested that there could have been productive dialogue that arose organically over the course of the retreat about the site's history, but this too was criticized harshly from several outlets. Eventually, DiFranco released a second, more contrite statement that 
acknowledged she still had some work to do and things to learn. A single paragraph on her Facebook page, DiFranco posts,

It has taken me a few days but I have been thinking and feeling very intensely and I would like to say I am sincerely sorry. It is obvious to me now that you were right; all those who said we can't in good conscience go to that place and support it or look past for one moment what it deeply represents. I needed a wake-up call and you gave it to me. It was a great oversight on my part to not request a change of venue immediately from the promoter. You tried to tell me about that oversight and I wasn't available to you. I'm sorry for that too. Know that I am digging deeper. (Coker)

This second apology was strikingly more effective, with many news outlets calling it "the real apology" or "the apology for the non-apology." But once again, what is important rhetorically is DiFranco's need to restore her impression of authenticity among her fans and to the general public. As an intersectional feminist, DiFranco claims to be interested in bringing together all women, regardless of color or orientation — an issue that has vexed feminism at large for most of its history. To respond slowly to women of color within her ranks indeed comes across as tone-deaf at the very least, and her apology was a necessary correction if she were to restore her public image. Again, whether or not DiFranco was truly contrite is less the issue than whether or not her audience believed her to be.

Perhaps the largest area of contradiction and ambiguity, however, and one for which DiFranco has been overtly unapologetic, is with regard to her own personal identity. When her self-titled debut was released in 1990, the album's images and promotional materials featured DiFranco with a shaved head and wearing jackboots. Never seen in a dress, DiFranco bore the stereotypical look of a 1990s lesbian, and songs like "Both Hands," "She Says," and "If It Isn't Her" seemed to make clear her homosexual identity, which quickly became a significant part of her musical identity and 
her following. When she began dating a man, however, many fans voiced a sense of betrayal, sometimes in the middle of concerts. The first time she wore a dress on stage, DiFranco recalls several women screaming "Sellout!" (Rothschild 38).

In 1992, DiFranco released a song called "In Or Out" that deals with way she felt others wanted to pin down her identity. She sings, "Guess there's something wrong with me / Guess I don't fit in / No one wants to touch it / No one knows where to begin / I've got more than one membership / To more than one club / And I owe my life / To the people that I love.” The song then continues by relaying the attention she has received and entertained by a hypothetical man and woman, when she delivers the following, "Somedays the line I walk / Turns out to be straight / Other days the line tends to deviate / I've got no criteria for sex or race." This seems to assert that the speaker (and thus, the listener presumes, DiFranco) is bisexual, but DiFranco tries to push that label off the table as well: "Their eyes are all asking / Are you in, or are you out / And I think, oh man, / What is this about? / Tonight you can't put me / Up on any shelf / 'Cause I came here alone / I'm gonna leave by myself." The last two lines suggest that DiFranco is going to keep her identity private, not allowing onlookers to form conclusions based on whether she departs with the narrative's male or female suitor. However, given the openness and vulnerability DiFranco reveals in so many of her songs, a more appropriate interpretation is that DiFranco is refusing an answer rather than hiding one. The last two lines, then, speak more to her independence and self-reliance than any sort of unwillingness to be forthcoming.

Though DiFranco acknowledges "bisexual" is an accurate term to describe how she views her own orientation, she prefers the term "queer" as "an open-ended word. It 
means, like, the kind of love I experience is not the kind of love that's on TV" (Obejas 26). Linking identity with television as she does here continues her work as a critical public pedagogue, and it again demonstrates how her activism engages in rhetorical education within — not merely on behalf of - her community. Certainly, the best outcome for dismantling patriarchy would be for those who perpetuate patriarchy to be convicted by DiFranco's work, but DiFranco knows that they are not her primary audience. So, if her primary audience is women — especially women sympathetic to feminism—it makes sense that her role as a public pedagogue would be to equip those women with the tools to improve their situation through ideas, language, and action. Supporting Jessica Enoch's definition of rhetorical education, DiFranco's lyrics, essays, and activism do indeed enact this, and not only when she appears to be "preaching to the converted." Indeed, when DiFranco's audiences are frustrated with her "betrayal" for widening or queering her sexual orientation, or for expressing various forms of identity, she may in fact be performing some of the more difficult but more important pedagogical lessons. In a recent interview, when asked if she felt her music was mostly "preaching to the choir," DiFranco responds that she's in fact trying to "inspire the choir to sing louder, to sing their all of themselves" ("Kyle Meredith"). If her intention is to increase autonomy and personal freedom, but her audience seeks to limit hers, it seems DiFranco is perhaps even obligated to reinforce a message of acceptance and unity among the masses who are fighting against different manifestations of a similar kind of oppression on other fronts.

Taking a queer approach to her life and work thus welcomes contradictions and ambiguity. It in no way excuses oppression, microaggression, or offensive comments and choices, and as someone who accepts the servant-leader role as DiFranco has done by 
choosing to be a mouthpiece for several significant issues, she cannot escape the standards and expectations placed upon her from audiences who think "she should have known better" regarding whatever issue might bother them. And DiFranco seems aware that this is the contract between her and her audience, having sung about such concerns repeatedly. In one of her best-known songs, "32 Flavors," she announces, "I am a poster girl with no poster / I am 32 flavors and then some / And I'm beyond your peripheral vision / So you might want to turn your head." The paradox of a poster girl with no poster is a striking image, evoking Utah Phillips' comment above about "living in the cracks." DiFranco realizes that she represents various ideas, goals, people, and causes to her listeners to different degrees, and that she is quite literally on posters that hang on many of their walls. However, by declaring that she has "no poster," she insists that the person on the poster is in fact not really her. Just as Bob Dylan continually reminded his audience, "I'm not there," so too does DiFranco recognize the difference between Ani DiFranco the celebrity and Ani DiFranco the person. Adding "1" to Baskin-Robbins' 31 flavors of ice cream, DiFranco continues pushing on the notion of various, coexisting identities within one individual. Suggesting that her listeners "turn their heads" becomes an invitation to widen their gaze, to embrace more identities that those which they "see on TV."

Finally, lest her audience think she has entirely figured out how life works and is simply teaching it to them one song at a time, DiFranco has also written her own questions and uncertainties into her music. In "The True Story Of What Was," DiFranco tackles her own doubt head on: "To search for the downbeat / In a tabla symphony / To search in the darkness / For someone who looks like me / (Though I'm not really who I 
said I was / Or who I thought I'd be)." In the context of song, in which the speaker considers trying to capture the truth in a language inadequate to the task, these lines affirm the great difficulty in a person figuring out who she is for herself, let alone anyone else. The power in the parenthetical phrase is two-fold: the first line is external, referring to times the speaker has tried to convey her identity to others, but the second line is internal, confirming that the speaker's life trajectory has led her somewhere she did not expect to be. While this seems an accurate portrayal of the complicated nature of human existence, it unquestionably frustrates fans who want their celebrities to remain fixed texts.

DiFranco's life and work certainly offer other apparent contradictions, ambiguities, and transformations, and the issue of celebrity and success complicate most of them. However, understanding the work of feminism and the process of frame bridging resolves many of them, and allowing DiFranco to continue to work through her own questions and stumble forward resolves many of the remaining ones. But it seems a feminist approach to analyzing feminist activity grants a certain level of unresolvedness. Megan Boler suggests a "pedagogy of discomfort," which "begins by inviting educators and students to engage in critical inquiry regarding values and cherished beliefs and to examine constructed self-images in relation to how one has learned to perceive others" (176). Viewing DiFranco's rhetorical education as a feminist revision to Guthrie and Dylan to incorporate a pedagogy of discomfort contextualizes the range of responses she receives from her audiences, both the intense love and passionate frustration, suggesting that the two - and every emotional reaction in between - is epistemological and in fact a vital part of feminist activism. 
DIY Music Business and Media Discourse

As described previously, part of DiFranco's image of authenticity comes from her do-it-yourself approach that she maintains is less about control and more about denouncing capitalism. At the same time, DiFranco's popularity owes a great deal to existing and emerging technologies during her career that facilitated her entrepreneurship, supported her performances, and circulated her music. Not only did her identification as a folksinger grant her great exposure to large audiences at festivals, but the social aspects of festivals and large-scale events supported her political project in key ways that have no doubt assisted in developing her popularity and effectiveness. Music festivals and similar events create specific and unique social conditions that can greatly enhance political work and foster both intangible and tangible participation in audiences. DiFranco's initial rise in acclaim occurred during a time in which such events, both live and broadcast, proved greatly effective in mobilizing audiences and creating the type of frame resonance required to build a successful collective action frame. More than viewing her entrepreneurship as a means of control or a middle finger to capitalism, however, this section demonstrates how DiFranco includes technology and her business model in her collective action frame as a form of agency.

In 1990, major record labels were unwittingly racing toward their own destruction, creating an increasingly unsustainable business model based on oppressive contracts, unfair compensation, and rising retail prices. Even so, major labels overwhelmingly dominated the field, and it was not viewed as a smart time to buck the system and begin a small, independent label of one. But DiFranco recalls coming close to signing a deal—even a deal with a smaller label_-but reading through the contract 
sickened her, realizing that she would be participating in the process of corporatizing her art and participating in the music machine that was responsible for what amounts to indentured servitude for many musicians. Rather than examine the business maneuvering that has led to financial stability for DiFranco, however, this section focuses on the cultural, economic, and especially technological situations that enabled, constrained, and mediated DiFranco's music, image, and message.

DiFranco's control over her own product has always been complete, and she notes that one of the early design choices she made was to include an address on her first tape. She remembers, "My first cassette tape had an address on it and that's how I started touring. Basically, young women at colleges would get a tape and write to that address and say, 'Can she come play?"' (Maistros). She would soon come to rely on those "young women at colleges" to spread her music through the very method feared by the major labels: illegal duplication. In 1990, still several years before wider Internet bandwidth made file sharing common, DiFranco's first albums were copied and shared between friends throughout North America, quickly catching on in certain communities. Soon she began receiving invitations to play coffeehouses, bars, colleges, rallies, and festivals across the United States and Canada. Traveling from gig to gig in a Volkswagen Beetle, DiFranco toured relentlessly, averaging 200 shows per year.

Of all the venues, it was the folk festivals where DiFranco felt most herself. Elsewhere, she says her image was quickly becoming cemented as the stereotypical angry girl, but it was meeting and sharing the stage with the likes of Pete Seeger, Utah Phillips, and Tom Paxton that helped contextualize a longer view of her work. "When I showed up at the folk festival, those men were not threatened. They did not describe me as angry. 
They recognized me as, "She's one of us. And thanks for bringing the teenagers! Maybe this folk festival will continue" (Amos).

The folk festival, a tradition that grew out of the hootenannies of the GuthrieSeeger era, played a significant role in boosting the early stages of DiFranco's career. Guthrie, Seeger, Dylan, and many others in those days would travel to specific sites to sing and raise awareness for specific issues, sometimes setting up a stage in the middle of a field or on the back of a truck — another affordance of highly portable music. Even earlier, at the start of the 20th century, labor organizers and union musicians like Joe Hill and Ella Mae Wiggins traveled the south to support labor efforts. These, of course, represent the early incarnations of the benefit concert. By the 1980s, benefit concerts and folk festivals were close cousins, and DiFranco's music and message fit in easily with both.

When considering concerts and technology, the more obvious aspects are elements like sound reinforcement, which includes amplification, loudspeakers, and mixing consoles, and lighting, including spotlights and ambient light. More basic but less obvious technology might include stage construction, seating, and acoustic design. However, thinking holistically and somewhat more abstractly, one might argue that the concert itself can be regarded as a technology — that is, a machine or mechanism containing many constituent parts that allows a musician to perform for a group of people in a live setting. Holistically, this would also include promotion, ticket sales, parking, restrooms, refreshments, security, and certainly all the items mentioned initially that are required for audiences to see and hear the performance. And, like any piece of technology, the concert exists to fulfill a need. Although monetary gain is a justifiable 
enough need for a commercial industry, activists have greatly supported their causes by harnessing the technology of the concert.

In America, the first benefit concert took place in 1971 at Madison Square Garden in New York. Organized by George Harrison, the Concert for Bangladesh featured several prominent musicians including Harrison, Ringo Starr, Bob Dylan, Eric Clapton, and Ravi Shankar. Raising nearly a quarter million dollars for Bangladesh war refugees, the concert was lauded as an outstanding success, providing a blueprint for future events. In the 1980s, even more successful benefit concerts followed, including the Nuclear Disarmament Rally in 1982, followed by Farm Aid and Live Aid in 1985. A contemporary technology during this time was the rise of global telecommunications-in particular, cable television — which allowed millions of viewers to participate in these events, both by watching and calling toll-free telephone numbers to donate funds. Originally organized by musicians, benefits concerts soon proved so effective in raising funds and awareness that charity groups like UNICEF and Amnesty International began organizing series of benefit concerts throughout the world. Such high profile concerts have been employed toward tangible goals, like raising money or promoting legislative change, and others have been used for intangible purposes, like the 2001 Concert for New York City, designed to pay tribute to the victims and survivors of the September 11 attacks on New York. Such an event, though it did raise money in the style of a telethon that aired on all U.S. television networks, played a significant role in uniting and consoling participants and viewers around the country.

The folk festival and the benefit concert offer audiences another set of rhetorical frames through which they can understand the type of work that such events aim to 
perform. As George Lakoff argues, frames exist everywhere, providing clues and information about how one should behave, what one should expect, and what possibilities exists within specific spaces (FORA.tv). For example, if students at a university announced plans to organize a "sit-in" in their school's administration building, others would understand some fundamental elements about the nature of what the students were trying to do because the concept of the sit-in exists within an established frame. For DiFranco, then, participating in a festival or benefit concert meant that those in attendance could at least in part anticipate some of the work she would try to accomplish, which would aid in their reception of her message and support her attempts to build frame resonance. Moreover, this allows a reconsideration of the concert not just as technology but as agency - a necessary component of an effective collective action frame (Gamson), but also, in a Burkean sense, the instrument/device/mechanism that permits the act.

Because they are designed to attract large audiences, festivals and benefit concerts naturally depend on popular musicians and celebrities who can successfully draw an appropriately-sized crowd to ensure the event's success. Thus the sheer number of attendees is one of the largest and easiest measures of success, making the spectacle of the event of utmost importance. Media coverage has always been a significant part of activism, from the labor reports on broadcast radio to the newspaper images and television broadcasts of the March on Washington. Martin Luther King, Jr. consistently paid attention to how the Civil Rights movement played out in the press, knowing that hardly a more powerful tool existed in their efforts than the images and updates that circulated the country. Media theorists Daniel Dayan and Elihu Katz use the generic term 
"media events" to describe such "high holidays of mass communication" (1) that are occasions outside of the normal broadcasting routine that can attract significantly more participants than usual. Media events such as benefit concerts are so highly effective because they foster a type of unity among a wide range of individuals and groups, leading to something akin to Durkheim's concept of effervescence, which adds an emotional layer of harmony and even euphoria to the event. Dayan and Katz explain:

During the liminal moments [of media events], totality and simultaneity are unbound, organizers and broadcasters resonate together; competing channels merge into one; viewers present themselves at the same time and in every place. All eyes are fixed on the ceremonial center, through which each nuclear cell is connected to all the rest. Social integration of the highest order is thus achieved via mass communication. (15)

Special broadcasts like the Olympics, presidential inaugurations, the moon landing, and the funeral of Princess Diana all qualify as media events under Dayan and Katz's definition. When paired with the unique rhetorical effects of music, which itself already possesses the ability to motivate groups of people, the media event of the benefit concert or music festival becomes a truly powerful superweapon in the activist's arsenal.

Similarly, Gamson demonstrates the necessary and significant role of media attention in collective action, even quipping, "Movement activists are media junkies" (85). According to Gamson, an event without media attention might as well not have occurred, because "media discourse" - the conversation surrounding, concerning, and indeed depending on the images and stories that circulate in public media — is essential to contextualize individuals' experiences and beliefs with a larger movement. "Experiential knowledge helps to connect the abstract cognition of unfairness with the emotion of moral indignation," Gamson explains. "Media discourse places the experienced injustice in context, making it a special case of a broader injustice; the media resource generalizes 
it and makes it shared and collective" (104). This suggests that concerts as an agency are not simply beneficial to activist musicians but are indeed essential if the collective action frame is to be robust enough to organize and mobilize participants.

DiFranco has participated in a large number of benefit concerts and festivals throughout the world. As a frame, the benefit concert has become a familiar one, and the linkage between festivals and activism is strong enough that most major festivals have some activist component, even if only a set of tables or booths with information. DiFranco has extended this concept even to her own smaller concerts, at which she provides tables for registering to vote, pamphlets regarding reproductive health, abortion, gay rights, and sexual and physical abuse, and sometimes local charities or organizations whom she prescreens, such as environmental groups, local politics, or even small businesses. Community building is high on DiFranco's list of priorities, whether that be through music or issues. On her concert DVD, Trust, interspersed between some of the songs are segments of DiFranco talking about activism and her approach to concerts as a site for like-minded people to get more information about causes and issues important to them. For DiFranco, the concert provides not one but several resources for activism, again supporting the argument for reading the whole of a concert (the complete technology, not simply the live performance) as agency.

Also on the DVD are scenes of DiFranco with then-presidential candidate Dennis Kucinich, whom DiFranco endorsed and invited to as many shows as he could attend. Kucinich would sometimes introduce DiFranco, saying a few words about his campaign to enthusiastic crowds, and then DiFranco would take the stage, mentioning her support of Kucinich. Such an approach is a microversion of the benefit concert, and the mutual 
endorsement of Kucinich-DiFranco raises the spectacle of the event, creating more media discourse. Although DiFranco's support of Kucinich did not deliver him a win, reprising Guthrie's disappointment at Henry Wallace's defeat, it again represents a powerful leveraging of the concert as agency to unite and mobilize people for multiple purposes, borrowing the affective and rhetorical aspects of the music for use toward political or activist ends.

In addition to live performances, the influence of such events has extended beyond the concert to include benefit recordings, such as Righteous Babe Records' 'Til We Outnumber 'Em: Live From Cleveland, a recorded concert featuring the music of Woody Guthrie from musicians including DiFranco, Billy Bragg, Bruce Springsteen, the Indigo Girls, and Guthrie's son, Arlo, among others. The album's profits are split between the Woody Guthrie Foundation and the educational department of the Rock and Roll Hall of Fame. Based on her long list of collaborations on such projects, DiFranco obviously sees value in contributing her celebrity and ethos to supporting causes she deems worthy. DiFranco also started the Righteous Babe Foundation, which directly supports similar efforts.

However, with such an intense focus on activism and her staunch opposition to capitalism, DiFranco was much slower to entertain the idea of merchandise. By 1995, she had hired a business manager named Scot Fisher, a complicated best friend/boyfriend/soon-to-be-ex lover who managed to somehow remain her business partner afterwards. Fisher suggested that they begin investing more in their design and packaging near the end of the 1990s, directly in response to major labels who were scaling back production and packaging in an effort to cut costs wherever possible, the 
crunch of digital music and file sharing beginning to occur. The plan was to offer a product that felt satisfying, that demonstrated DiFranco cared about what her fans purchased. Meanwhile, CDs from major labels had reached their peak cost of $\$ 18$, despite significant cuts in materials. Many labels had begun packaging CDs in simple cardboard sleeves with little to no companion materials, whereas DiFranco's albums became elaborate packages, jewel cases inserted in artistic sleeves, containing multi-page booklets with liner notes, lyrics, art, and poetry. She was nominated for four Grammy awards for packaging, finally winning in 2004 for Evolve.

The attention to craft, style, and detail paid off, and DiFranco agreed to begin offering other merchandise, including T-shirts, posters, coffee mugs, refrigerator magnets, and songbooks. Through a traditional mailing list and then through her website, the supplemental income from DiFranco's merchandise buoyed Righteous Babe Records through declining sales that eventually reached her operation. Most statistics show the year 2000 as the peak of music CD sales, and the illegal exchange of music - the process that had initially spread the word about DiFranco—was now affecting her adversely. By this point, the label had signed a small handful of eclectic artists who shared DiFranco's vision, and DiFranco and Fisher worried about how to support not only themselves but their roster of artists as well. Through online forums and fan sites, numerous DiFranco fans took it upon themselves to police file sharing websites and platforms, reporting those who illegally traded her music, but in the end, such dedicated efforts proved futile in the face of what was to come.

Exploring other avenues of income that would fit within the larger mission of the Righteous Babe vision, DiFranco and Fisher discovered an abandoned church in Buffalo, 
NY, slated for demolition. Over the next five years, the two negotiated with city officials, banks, and historical agencies to purchase and renovate the building into Babeville, a multipurpose space that would not only house the record label and provide office space for their small staff but would also contain a high quality, intimate concert hall and a basement bar that is also a performance and event space. Babeville is designed as much for the community as it is for DiFranco's music, and it has become a highly popular location for concerts, weddings, art shows, charity and community events, memorial services, dance performances, plays, and so on. The enterprise also served the financial purpose for which it was intended, becoming a profitable extension of DiFranco's business. But in the same way she wanted $M s$. magazine to focus on her music and not her entrepreneurial skills, DiFranco insists the real success of Babeville is its role in the community and the "artistic epicenter" it has become (Comingore).

Having successfully come through what she frequently calls the "white-knuckle years," DiFranco has built something of a small empire. In addition to selling her and her label-mates music through the Righteous Babe Records website, she maintains a list of recommended reading that she updates regularly and provides a host of resources for those interested in taking action on issues important to them, all categorized and linked through the navigation menu on the website. She and her staff also maintain a Facebook page and Twitter account to promote her shows, but for DiFranco, the real work happens in person. When asked recently about her feelings on the best way to connect with her audience, DiFranco is clear: "Playing live. Music is a social act, I will say it until I'm dead. It is something that we do together. I think that's the essential state of music: a moment that is shared... My art is alive in time and space, and I share it with people 
live. That's always going to be most important for me, and that's always going to be what I do best" (Donnelly).

While there are many who have now been able to leverage social media and advanced recording and distribution technologies into sustainable independent careers, DiFranco has managed to build something fairly remarkable and unique, beginning at a time when few would have encouraged a teenager with no background in business to try. She insists that every step was born out of necessity, and that there was never a master plan, but that all was in service of helping her music reach her audience. However, were it not for the ability to sell homegrown cassette tapes out of the trunk of her Volkswagen; participate in rallies, festivals, and benefits across North America; start, run, and evolve her business model to fit her needs; and collaborate with a wide range of artists on numerous high-profile projects, DiFranco would likely still be toting her acoustic guitar around New York from coffeehouse to coffeehouse. These elements of technology comprise a sort of collective agency that has allowed DiFranco to build something of a small empire that in turn lends weight to her message and participates in the promulgation of her rhetorical frames, reaching past her own music and career to become a part of the larger feminist movement.

After 26 years, 24 solo albums, an assortment of DVDs, EPs, compilations, official bootlegs, and countless collaborations, DiFranco might be the most successful feminist folk artist that many people still have never heard. Although she has slowed her pace only slightly since having two children, she continues to tour and splits her off-tour time between homes in Buffalo and New Orleans with her husband (who is also her 
producer). What DiFranco offers this study is a rich subject in grass roots activism by way of a dynamic redefinition of folk music that returns to the core of folk music's purpose. Sub-corporate, community-based, indigenous music exists in many forms across the country, and what DiFranco's example provides is an awareness that folk music evolves, both stylistically and topically. Her relationships with folk icons Utah Phillips and Pete Seeger not only demonstrate her folk music heritage but also affirm her activist work as being squarely in the folk tradition.

DiFranco's strong feminist public pedagogy builds on significant women's voices who came before, but DiFranco brought a new edge in her folk-punk sound and image that suddenly made folk music acceptable for children born too late to remember anything about the 1960s or before. If Bob Dylan left folk music on life support when he fled the scene, DiFranco helped resuscitate and rehabilitate it. Much in the same way that she describes the balance of nature when describing what she thinks should replace patriarchy, perhaps her intense feminism, designed for all gender expressions, is a part of why folk music has steadily made a resurgence since the 1990s, although current manifestations of folk music might prove too commercial, too corporate for DiFranco's sort of work.

Just as DiFranco helped folk music evolve, so too is her work designed to help humanity evolve. Through the collective action frames in her music, DiFranco rhetorically constructs a view of the world that distills complex landscapes into smaller pictures, filtered through her personal experiences that manage to resonate with her audiences. Using frame bridging, she builds a case for seeing how patriarchy provides a template for many of today's structures, and she likewise participates in reframing 
feminism as a valid (indeed, necessary) ideal for all of humankind as a means of finally achieving a natural balance that will foster peace. The narratives she constructs offer several entry points for all sorts of listeners, complicating and widening possibilities for identity alignment, inviting participants to identity as feminists regardless of their gender. Finally, DiFranco advances Guthrie's model toward the 21st century to include new technologies (and reframe old ones) as a vital part of her collective action frame, demonstrating how activist musicians can leverage performance, production, distribution, and media discourse as a kind of multi-pronged mega-agency through which they can conduct and expand their work. 


\section{TOM MORELLO}

During the presidential campaign of 2012, Republican vice-president nominee

Paul Ryan made headlines for something that likely no other candidate in history could claim: the musical acts listed on his Facebook page. While political candidates have something of a history of choosing campaign songs that might surprise the artists who produce them, Ryan's list of favorite bands included the radically progressive rap metal band Rage Against the Machine, and the media erupted over the irony. While many wondered if Rage might simply be Ryan's favorite workout music, it was only a matter of days before Rage's guitarist, Tom Morello, wrote a short piece for Rolling Stone in response to the attention. In a politely scathing rebuff, Morello takes the candidate to task for "being the embodiment of the machine our music rages against":

I wonder what Ryan's favorite Rage song is? Is it the one where we condemn the genocide of Native Americans? The one lambasting American imperialism? Our cover of "Fuck the Police"? Or is it the one where we call on the people to seize the means of production? So many excellent choices to jam out to at Young Republican meetings!

Don't mistake me, I clearly see that Ryan has a whole lotta "rage" in him: A rage against women, a rage against immigrants, a rage against workers, a rage against gays, a rage against the poor, a rage against the environment. Basically the only thing he's not raging against is the privileged elite he's groveling in front of for campaign contributions. ("Paul Ryan")

During the collective laugh the media were enjoying over Ryan's musical taste, Ryan clarified that he liked Rage for their sound, but he did not care for the lyrics, which presented his critics with an opportunity to question his ability to listen to the people if 
promoted to a higher office of public service. Morello acknowledged that Ryan was not unique in this regard, observing that

Rage's music affects people in different ways. Some tune out what the band stands for and concentrate on the moshing and throwing elbows in the pit. For others, Rage has changed their minds and their lives. Many activists around the world, including organizers of the global Occupy movement, were radicalized by Rage Against the Machine and work tirelessly for a more humane and just planet. Perhaps Paul Ryan was moshing when he should have been listening. ("Paul Ryan")

In seven paragraphs on the Rolling Stone website, Morello comfortably continues the tradition of the musician as public pedagogue, an artist activist who not only creates compelling and commercially successful art but who also uses his music as a platform from which to publicly articulate the motivations behind his art. In the first of the above paragraphs, Morello rattles off a few topics in Rage songs that seem incongruent with Ryan's political perspectives. In the second, he doubles down by showing that Ryan's own actions as a congressman are not only incongruent with but are in fact diametrically opposed to the band's mission, citing various groups of people who have suffered under Ryan's work.

When Morello suggests that Ryan "rages against" women, immigrants, workers, gays, the poor, and the environment, he rhetorically recategorizes Ryan's political work in a way that implies Ryan carries out his agenda with the same fervor as the band, that his motivations as a politician feature a similar kind of anger. Then, Morello pointedly casts Ryan as a villain, explaining his perspective of Ryan in ideological rather than political terms:

You see, the super-rich must rationalize having more than they could ever spend while millions of children in the U.S. go to bed hungry every night. So, when they look themselves in the mirror, they convince themselves that "Those people are undeserving. They're...lesser." Some of these guys on the extreme right are more cynical than Paul Ryan, but he seems to 
really believe in this stuff. This unbridled rage against those who have the least is a cornerstone of the Romney-Ryan ticket. ("Paul Ryan")

In short, as much as Morello and his bandmates have described politicians of Ryan's ilk as criminals, Morello's claim that Ryan also "rages against" offers a thumbnail sketch of his belief that rich politicians working for their fellow elites through their work in the U.S. government are not working in the interest of the people. Morello then closes the brief article with a bit of humor, wondering if perhaps Ryan is a "mole" who will secretly work to fill Guantanamo Bay with "the corporate criminals who are funding his campaign — and then torture them with Rage music 24/7” ("Paul Ryan").

Morello’s publicly voiced opinions on Ryan's musical taste blends information and satire to respond to a kairotic moment. His status as a celebrity musician grants him this platform, which he has consistently exploited in service of calling out various forms of oppression in music, interviews, essays, and actions, positioning himself as a critical public pedagogue. More than merely criticizing a tone-deaf politician, however, Morello offers a pedagogical rationale or argument for how one should listen to his music. Morello notes that the music of Rage Against the Machine has successfully politicized and radicalized other listeners, and thus he wonders if Ryan was "moshing when he should have been listening." His use of "should have" suggests something of a moral imperative, an indication that he believes Rage's music tells the truth and is capable of convicting listeners of the right way to view the world and the actions of those in power. Like Woody Guthrie, who insisted that folk music was capable of politicizing and mobilizing people, Morello believes that his music is likewise capable of pricking the conscience of those he holds culpable for oppression. 
However, a major difference between Guthrie and Morello in this regard is that when Guthrie lamented the music's inability to convert voters, he blamed Alan Lomax and the implementation of the music in the campaign. Morello, on the other hand, clearly places the responsibility on the listener. Rather than simply opposite opinions, however, this difference may be seen as a trajectory of understanding how music and audiences operate. Guthrie insisted that the folk community failed Wallace by poorly assessing their audience. Bob Dylan came to the conclusion that "finger-pointing songs" simply do not work, that a musician cannot force change on society through heavy-handed allegories and diatribes in song form. Ani DiFranco discovered that folk songs can indeed radicalize people, but reaching anyone outside her "tribe" would require a great deal of pedagogical intervention, such as continually explaining how patriarchy is responsible for seemingly unconnected issues in society. Morello, then, appears to recognize all of these perspectives of folk music: (1) folk songs indeed have the power to radicalize, politicize, and mobilize listeners; (2) some listeners will not pay attention, agree, or be persuaded; and (3) it is appropriate and perhaps even necessary for the folk musician to provide pedagogical commentary on her work and message in public spaces.

Combining his musical mission with critical commentary on current events, Morello adds an obvious educational dimension to his work and thus positions himself as a critical public pedagogue. Cornel West discusses the moral implications for public pedagogues, asserting that those in such positions have a responsibility to provide "fearless speech—parrhesia — that unsettles, unnerves, and unhouses people from their uncritical sleepwalking" (16). For West, parrhesia is a necessary precondition for paideia, "the critical cultivation of an active citizenry" (39), and thus a commitment to parrhesia is 
a commitment to democracy, which West argues is the only way to progress toward an equitable, free society. As such, he argues that public pedagogues — the purveyors of public texts - ought to cultivate a habit of questioning ourselves and institutions, of striving for justice, and of drawing on a tragicomic sense of hope (16). Parrhesia, then, is one way that critical public pedagogues can produce collective action frames, and in this regard, Morello exemplifies how folk musicians might attempt to engage and transform the public through fearless speech.

In most of his music, Morello inhabits a fairly ostentatious role, and his message is hard to misinterpret. His electric guitar style is unmistakably outrageous, and his polemical lyrics pull no punches. Thus it is unsurprising that he feels Ryan "should have been listening," if for no other reason than people like Ryan (and the effects of his actions) are discussed extensively throughout Morello's oeuvre. But more significantly, Morello seems to believe that everyone — not just Ryan — should be paying attention to the music they consume, reading and considering the lyrics, questioning the arguments, and examining their own perspectives and assumptions. This suggests that Morello agrees with critical theorists who argue that popular culture enacts public pedagogy, and his frequent participation in public conversations through interviews and essays reveals his awareness of the role he plays as a facilitator, as a critical public pedagogue.

In the Rolling Stone essay as well as throughout his music, Morello follows the folk music model of framing that has been explored throughout this project, first building an injustice frame through sketching a list of those Ryan "rages against." Through this frame, he offers a rough schema for aligning collective identity, pitting the "super-rich" against everyone else, inviting readers to identify with the "lesser." Finally, Morello 
demonstrates that his music offers agency for would-be participants, pointing to the Occupy Wall Street movement as one example of direct action taken by those who were mobilized by Rage's music.

Through his work with various bands and organizations, including his own nonprofit organization, the Axis of Justice, and his record label, Firebrand Records, Morello uses his position to enact a form of rhetorical education designed to invigorate and amplify issues and causes in service of fostering solidarity and empowering marginalized populations. In doing so, Morello engages a collective action frame that describes injustice, constructs identity, and increases agency by leveraging technology to organize and mobilize his audience. This chapter examines how Morello constructs this frame in light of his folk music forebears' work and considers how Web 2.0 technologies both resonate with older technologies and enable new modes of communication and activity.

Public Pedagogy through Injustice Frames

As Morello discusses his work, he reveals himself to be much more than someone who is merely angry at the establishment or a rebellious teenager in arrested development; rather, he demonstrates that his motivation is social in focus, and that the supreme artistry that he worked so diligently to acquire is in fact animated by his message. In describing his own perspective of his work, he offers a rhetorical theory for how his music functions:

I see myself and my music standing shoulder to shoulder, in solidarity, with people, with the voiceless, the poor, the wretched, the people who don't have a chance to even reach that bottom rung of the ladder. And if my music can give them some voice, and if my songs can give some hope to their struggle ... that's been a good day at work. (Moyers) 
No stranger to picket lines and strikes, Morello employs the language of direct action - "shoulder to shoulder" and "standing ... in solidarity" — to metaphorically place himself in the midst of the struggle. Additionally, the above statement reframes his previous work by recasting the principle players; rather than focusing on "the machine," he highlights the lowest tiers of society, specifically naming those who have been excluded from participation, who cannot "even reach that bottom rung of the ladder." Morello indicates a need for these people to have a voice, and he suggests that the musical platform he constructs is large enough to include them, specifically through the amplification of their voices he provides in the songs he sings about their situations, often voiced from their perspectives.

Morello's approach to public pedagogy points to definitions of rhetorical education from Enoch and others who agree that programs designed to empower citizens first help people to understand their condition, often by sharing the stories of an oppressive events or situations, sometimes with the composer's commentary to provide an articulation of the situation that a listener can understand and repeat. Several of Morello's songs are inspired by true events that happened to individuals but that are unexceptional among that individual's demographic, whether minorities, workers, homeless people, or soldiers, and so on. Frequently, Morello sings from the first person, adopting the perspective of the oppressed to construct injustice frames. For example, in "Branding Iron," Morello sings as a father who lost a loved one in a suspicious factory fire: “At the textile plant, sixteen dead / There's a hornet's nest inside my head / My daughter's gone, she won't be back / Behind chained doors, they burned to black." In "Stray Bullets", he sings as a patriotic soldier who realizes he doesn't support the war 
he's been commissioned to fight: " 15 months lost in Iraq / We got Stop-Loss'd, they sent us back / Why the fuck we we're even here, I'll never know." In "Alone Without You," inspired by Michael Moore's film Sicko, Morello sings from the perspective of someone with inadequate healthcare:

Sick of the waiting and praying and hoping Sick of the cold whispered dreams and not knowing Sick of the strength that it takes to keep going

Sick as I'm losing this fight and it's showing

Sick of the fear and sick of the cold

Sick 'cause it's worse for the weak and the old

With two broken legs I'm climbing this hill

Sick of deciding who gets what in my will

Sick 'cause I'm stuck on the wrong side of town

And sick 'cause I'm pulling but still sinking down

And sick 'cause I can't turn this whole thing around

And sick 'cause I'm too weak to hunt somebody down

Morello recalls that after watching an early screening of the film, he felt heavy

under the weight of their stories and wrote and recorded this song the same evening. Moore subsequently recut the end of the film to add it to the end credits. These words amplify the voices of the characters, creating a composite character that could be one person but is actually drawn from several individuals. Verse one identifies the frustration of waiting for answers and the downward spiral of untreated health conditions, and verse two names the "weak and the old," the two demographics of people hardest hit by medical issues, not only because of their frailty but also because of the system's failure to provide for people on fixed incomes like disability and social security. Combining the physical and spiritual - "with two broken legs I'm climbing this hill"- the narrator looks ahead toward death, disheartened about putting his affairs in order before he should have to do so. This verse in particular strikes back at the failure of government to ensure the 
safety and longevity of its citizens, if only through inference. Verse three mentions "the wrong side of town," observing the limited options of the poor, and the inability for one to merely help themselves through sheer will and determination as a popular narrative in American culture suggests. Finally, Morello overtly argues that despite the bad luck of poor health, the narrator does, in fact, have someone to blame, and if the narrator were stronger (physically, emotionally, or financially), "somebody" would have to answer for their actions.

The topics of Morello's songs remain squarely on the issues he feels deserve more attention and more accurate reporting than provided by mainstream media, so that individuals within oppressed populations can recognize themselves—and thus find a voice - in his music. Specifically, he accomplishes this through a kind of empathetic storytelling, frequently singing from the perspective of others. Charles Seeger, father of folk legend Pete Seeger, asserts that "music should be of the proletariat, not for them" (Roy 117, emphasis his). This type of identification through representation is a traditional application of folk songs, and the simple music and plain language (parrhesia) common in vernacular music are key features that allow such identification to occur.

Morello's essay in Rolling Stone about Paul Ryan, then, may be understood both pedagogically and rhetorically as frame extension, in which Morello brings forward past frames to foster a sense of injustice toward current politicians acting against the interests of a large segment of the population. Listing topics of songs and specific demographics in opposition to Ryan and his associates effectively sorts the involved parties into victims and villains, encouraging readers to identify with the people Ryan "rages against." Importing older, existing frames in a new era and with new issues (critiquing the failure 
of healthcare or endless war), thereby "extends the boundaries of its primary framework so as to encompass interests or points of view that are incidental to its primary objectives but of considerable salience to potential adherents" (Snow et al. 472).

As a member of Rage Against the Machine, Morello and his bandmates modeled a form of activism that was at once musical and lyrical, emotional and intellectual, creative and critical. One of the earliest rap metal bands, Rage defined their sound as delivering a hip-hop aesthetic through the context of a punk rock band, two forms of vernacular music that emerged as venues for cultural and political critique. While vocalist Zach de la Rocha delivered his aggressive rap style over the band's hard rock riffs, Morello invented new ways of playing electric guitar to recreate sounds normally provided by a DJ, mimicking record scratches, siren wails, and myriad noises that defied traditional musical categories. However, after more than two decades of establishing his position as one of the most distinctive and accomplished electric guitarists in popular music, Morello turned to folk music under the moniker "The Nightwatchman," joining the ranks of people who have discovered the unique affordances of the folk tradition in social action. Adapting his activist work to a new genre of music suggests that Morello sought a new kind of agency through which to deliver his message. At the same time, and in much the same way Bruce Springsteen's The Seeger Sessions connected Springsteen's other music to the sincere commitments of folk music, Morello's commitments to same issues across multiple genres effectively links contributes to the framing of his persona as an authentic public pedagogue.

A union member himself and a staunch socialist, Morello knows exactly the traditions he draws on in his own work, informing the Socialist Review in 2007, "My goal 
is to be the black Woody Guthrie" (M. Smith). Indeed, even while still in Rage, one of Morello's most notable features was the scrawled message "ARM THE HOMELESS" on his guitar, directly invoking Guthrie's famous "THIS MACHINE KILLS FASCISTS" message on his. Repeatedly citing The Clash and Public Enemy as bands that worked the same way Guthrie did, Morello explicitly connects folk music proper with other forms of vernacular music, all the while speaking loudly and plainly about injustice to provide an alternative source of information and education to the masses. Josh Kun describes the nature of vernacular music - particularly genres that exist on the borders of two cultures, whether geographic, musical, or otherwise - to create what he calls an audiotopia. Like Foucault's heterotopia, an audiotopia is an othered space that exists outside hegemonic influence, but one that is uniquely created by music that allows and rewards thought, speech, and action that resists dominant ideologies (2-3). Considered in these terms, Morello's music opens an audiotopian space that allows him to build a musical platform for political conversation and action.

Morello began his path to activism, however, long before he was aware of Guthrie or his music. Claiming to be the first black resident of Libertyville, IL, Morello recounts being raised by his mother in the small, northwest Chicago suburb. Mary Morello was a white school teacher and activist, whose travels and work led to a whirlwind romance with Kenyan freedom fighter (and later, the first Kenyan ambassador to the United Nations) Ngethe Njoroge. Morello's introduction to political music came not in the form of folk music per se, but instead through punk. A friend gave him a bootleg cassette of The Clash's London Calling, and Morello discovered a resonance between the band's perspectives and his own, stating, "Their lyrics spoke the truth about global politics in a 
way that the nightly news anchors didn't," and "less than 24 hours later, I was in a band" (Moyers). Although he was a fan of hard rock bands like KISS, Led Zeppelin, and Black Sabbath, he found their messages less compelling than those coming out of the punk movement. Additionally, despite earlier failed attempts to emulate the virtuosity of guitarists like Zeppelin's Jimmy Page and Sabbath's Tommy Iommi, the simplicity and rough style of punk showed him that he - that anyone — could be a musician. When he acquired the Sex Pistols' infamous Never Mind the Bollocks, he was inspired to write his first political song, "Salvador Death Squad Blues” (“Nightwatchman Speaks \#2”). Punk music offered the young Morello a low barrier of entry, and the commitments to social change present in the music and personas of the The Clash and Sex Pistols granted him permission (or even extended an invitation) to follow their example and participate in similar work.

Morello's experience of being radicalized through punk music connects to Ani DiFranco's assertion that punk fits in squarely with the tradition of folk musiccommunity-based, sub-corporate music that delivers a populist message and/or critique of society through voicing the shared, lived experiences of common citizens. The simplicity of punk recalls Oscar Brand's discussion of the "simple noise" of folk, and the punk aesthetic shares similarities with R. Serge Denisoff's concept of "folk consciousness." In the same way folk musicians might look and sound anachronistic as a political statement against the status quo, so too does the loud, angry, and brash image and sound of a punk musician make plain the opinion that "something is wrong" with business as usual. Through image, music, and lyrics, folk and punk musicians alike use their ethos and art as public pedagogy, sketching out their perspectives on society and relying heavily on 
collective action frames to persuade listeners to adopt their ways of viewing the world.

Another significant aspect that drew Morello to punk music was the do-it-yourself ethic that created a "use whatever you have" perspective in that community, something that he has continued to promote in both his musical and activist work. He recounts how he, as a teenager, practiced guitar for hours each day in his mother's basement with a small Fender amp propped up on a chair; when he and his high schools friends were able to see The Clash perform in Chicago, there stood his hero, frontman Joe Strummer, playing through the exact same amplifier, also on a chair (D'Ambrosio). He explains that seeing Strummer's amp on that chair felt like a political statement, that it thumbed a nose at the arena rock bands with their walls of Marshall amplifiers and speaker cabinets. This planted a notion that he would only later be able to articulate, that all music is ultimately political: "Whether it's bread and circuses diverting people from what needs doing or songs about George Dubya Bush. As Howard Zinn says, 'You can’t be neutral on a moving train"” ("Playing 6-String Politics").

By the time he graduated high school, Morello was embracing and embodying the ideals of Castro, Guevara, and Chomsky, writing polemics for his school's underground newspaper, and ready to "fight the man" through music. This led him first to Harvard for a degree in political science, then to Los Angeles the day after graduation to pursue music full-time. Morello quickly discovered that it took a lot more money to survive, let alone thrive, in California. Within days, he found himself broke and looking for work. He took a variety of positions - ranging from temporary labor jobs to male stripper to scheduling secretary for Senator Alan Cranston—while he worked toward his musical goals. Despite an early interest in participating in politics, Morello's time with Cranston squashed any 
curiosity the musician might have had about his ability to work in that environment, based on two significant realizations. First, he observed that Cranston spent every waking moment asking rich people for contributions, and their money always came at a price. More personally, he recalls a day in which he needed to answer the phone during a receptionist's lunch, and a constituent called Cranston's office with a complaint: Mexicans were moving into her neighborhood. After she concluded her rant, Morello told the woman, "You're a damn racist, and you can go to hell." He hung up on her, believing he had done the right thing, but much to his disappointment, he received numerous admonitions from everyone in the office for two weeks. He concluded that, "If I'm in a job where I can't tell racists to go to hell, I'm not in the right job" (Adlercast). Clearly, Morello was already committed to practicing parrhesia, but he was discovering that without a platform, his fearless speech was not going to lead to paideia.

Eventually, Morello signed to Geffen Records with a band called Lock Up, but turbulence between the band and label would lead to their fast demise. Morello's unique approach to the electric guitar, however, was beginning to emerge. His devotion to practice was paying dividends in terms of his technical prowess, and his search for new sounds and expressions led him to consider other ways the guitar might make noise. In addition to the punk music that sparked his imagination as a teenager, hip-hop was increasingly bringing the same kind of alternative news to large audiences in the way Morello had admired in The Clash. Morello has frequently cited Public Enemy's 1990 release, Fear of a Black Planet, as one of his most significant musical and political influences. In addition to the beats and rhymes in hip-hop, Morello became intrigued with the subversive sounds of record scratches, samples, and sound effects, leading him to 
merge the heavy riffs and screaming leads of hard rock with the sounds of hip-hop in a style that remains to this day entirely his own. Between guitar modifications, effects pedals, and unconventional methods of playing, Morello could make his guitar sound like a DJ scratching a record, a synthesizer, a police siren, a car crash, and so on. When he found Zach de la Rocha freestyle rapping in the LA club circuit, Morello was impressed with de la Rocha's angry but informed lyrics and urged him to start a band. Morello found a drummer while de la Rocha recruited a bassist, and Rage Against the Machine officially formed in 1991, eventually signing with Epic Records the following year.

In 1992, the band released their self-titled debut album, featuring a rap metal hybrid sound that no one had ever heard before, every song an overt political argument. Morello's flamboyant guitar work was equally matched by de la Rocha's fierce lyrical delivery, which ranged from whispers to growls to primal screams throughout the entire album. Rage Against the Machine sold over three million copies, arguably becoming the most progressively (and aggressively) political chart-topping record in the history of recorded music. Audiences around the world responded enthusiastically to the riotous sound and performances, and a large percentage found in Rage what Morello had found in The Clash and Public Enemy: an alternative source of information regarding social issues around the world and the band's indictment of the perpetrators of those abuses. As the band's fame grew, so did their notoriety, leading to numerous clashes with local authorities at various cities around the world—sometimes even before the band's arrival. Citing Rage's numerous affiliations and affinities with subversive groups around the globe, their pull-no-punches lyrics, and the band members' participation in countless protests, marches, and acts of civil disobedience, parents, politicians, and police had their 
hands full trying to keep the band out of their cities and Rage's music out of the hands of their children.

Over the next eight years, the band slowly released two more studio albums, both reaching multi-platinum status, but both efforts were reported to have been accompanied by significant labor pains. In October of 2000, de la Rocha released a statement announcing his departure from the band, and a final studio album of cover songs, Renegades, followed after the band's dissolution. The remaining three members eventually joined with singer Chris Cornell, recently departed from the Seattle grunge band Soundgarden, to form Audioslave, who, despite great commercial success, lacked the political punch of Rage. Two albums followed, both with significantly lower sales, and by 2007, Audioslave disbanded.

During the years of Audioslave, Morello covered a lot of familiar territory musically, but he was frustrated with the largely apolitical lyrical content of the band's songs. Because of this, he began to feel less connected with his audience and farther away from his big picture, activist goals. Noting in particular one summer festival in which he was surprised to see several white power and Nazi tattoos in the audience, despite the fact that every band on the festival billing was a mixed-race band, he decided to seek out new agencies for more intentional expressions of his politics (Rollins). One result of this was the formation of the non-profit activist organization Axis of Justice with System of a Down singer Serj Tankian, and another came in the form of an alter ego, The Nightwatchman. While Audioslave toured the U.S., Morello began scanning local newspapers for open mic nights at small clubs and coffeeshops, and on his nights off or even after Audioslave shows, he would take his acoustic guitar to perform two or three 
old protest and labor songs that spoke to his conscience. The pseudonym granted him a level of anonymity his own name would not, and he discovered that there was enormous power in those small rooms that he simply did not feel in the same way in the 10,000 -seat arenas in which Audioslave was booked night after night. Of this awakening, he says, "I felt a visceral connection to the audiences, even on those nights where no one was coming to see or hear me. When it went well, it really felt like everyone's soul in the room was at stake. And it really felt like I was being heard for the first time. And this was the most complete and honest me as an artist that I'd ever experienced" (Moyers). What had begun as a disguise turned out to be the emergence of an increasingly truthful selfrepresentation, and The Nightwatchman began making plans to write, record, and release original songs that spoke to current issues in a much more personal but no less political way.

Like folk musicians before him, Morello relies on collective action frames as his primary means of persuasion. As such, his song lyrics frequently construct injustice frames as a way of connecting societal problems to the systems of power, money, and greed that run corporations and governments. Speaking about receiving the 2011 Musician of the Year award from the progressive magazine, The Nation, Morello says, "That's the work the Nightwatchman was born for, and whether it's supporting the union efforts in Wisconsin and across the Midwest, the Occupy movement globally, or releasing records like World Wide Rebel Songs, that's what I'm in this for" ("Nightwatchman Speaks \#9"). And yet, for Morello, giving the voiceless a voice does not exactly mean speaking for them in the way one might speak in place of another (which seems to be the major disconnect between the public and Bob Dylan in their 
attribution of "spokesman"). Instead, Morello gives voice to the plight of others so they may be heard. To use a metaphor in line with Morello's world, he functions less like a microphone and more like an amplifier. In a 1993 interview, Morello denies representing the views of alternative American youth with a very Dylanesque answer, effectively saying that he doesn't speak for them because he doesn't know what they think. Of Rage, he says, "All we try to do is represent our own ideas well, and in the music and the words, tell the truth. That's basically it. ... If people are drawn to that, fine.... By doing that, we represent everybody" (ZapatistaDiF, "What Is the Machine?"). This perspective aligns with the analysis in this chapter's introduction: Morello believes those who pay attention will be drawn to the truth he attempts to present in his music. Put another way, connecting to West's idea of parrhesia, Morello suggests that the rhetorical power of political music rests in its bold truth-telling, and it is precisely that quality in the lyrics that will transform listeners into participants.

Perhaps the reason Morello has maintained this model of songwriting is also autobiographical. When asked if he believes music is an appropriate vehicle for social action, he quickly answers, "Oh, absolutely. For one, it worked for me. Bands like The Clash and Public Enemy gave me insights and perspectives and inspired me in ways that a textbook never did" (ZapatistaDiF, "Husltfred"). Then, speaking to his own experience that guides his version of rhetorical education, he concludes:

It has to begin with yourself. For example, during the Black Power struggles, the first line of attack was that blacks had to confront within themselves the attitudes they held within themselves that contributed to their own subordination. And the same with the Women's Movementwomen had to combat the attitudes within themselves that contribute to their own subordination. The same is true of workers and students as well. 
Following the folk singer as public pedagogue model established by Guthrie and revised by so many since, Morello constructs collective frames to highlight injustice, identifying victims and villains within the dominant structures of society. As the following sections describe more explicitly, Morello's collective action frames depend on this relationship between injustice and identification to create the type of agency described by Gamson, which depends on a sense of empowerment through action. Although Gamson defines agency in affective terms (that is, feeling like something can be done), a Burkean definition of agency as a vehicle for action seems more appropriate and robust for considering the rhetorical effectiveness of folk music.

“The Black Woody Guthrie": Identity and Agency

Of all the people Morello describes in his music and commentary, the person(a) he describes most frequently and thoroughly is actually himself. Previous chapters demonstrate the integral role authenticity plays in the construction, performance, and uptake of a public pedagogue, and thus Morello's own personal ethos is a significant part of his identity as an activist musician. Although he established his musical and activist credibility while in Rage Against the Machine, his choice to alter his style and approach as The Nightwatchman is significant and begs an important question: what does the folk music idiom allow Morello to accomplish that his previous projects did not? Through the construction of this alter ego, Morello signals a shift in the way his music and activism might be perceived, and his rebranding makes explicit his intentions to carry on the work of folk singers like Guthrie, Dylan, and DiFranco. 
Morello took the moniker of The Nightwatchman from the story of Secretariat, the Triple Crown-winning racehorse. When the highly anticipated horse was being born, it was the nightwatchman who stayed with the mare through the night to ensure her safety, and it was he who called out into the darkness when the foal was ready to be born (Scanlan 87). Adopting this name for this incarnation of his musical identity signals a rhetorical repositioning of Morello's music, declaring the nature of the role he wants to play for the vulnerable citizens of the world and the fragile revolutions and movements that would lead to their freedom. As The Nightwatchman, Morello places the ethical underpinning of his work at the forefront of his activity, suggesting that his music is not his end but rather his means. Considering this with his comment about feeling as if souls are at stake only adds to the urgency of his message; his concern for citizens extends beyond the physical to the metaphysical, and his invocation of the soul turns his role into a religious one. He sees the Nightwatchman as a caretaker and an evangelist —or perhaps something like the Christian idea of a "good shepherd." Like Guthrie, Morello exhibits an ideal representation of Roberts and Steiner's definition of a critical public pedagogue, who "both serves and leads a source of social, cultural, and political critique" (26, emphasis mine). Since discovering this facet of himself, Morello has said that, increasingly, he is less certain "which persona is more me" (Rolling Stone). (A selfprofessed comic book nerd, Morello may be invoking the long-standing debate about superheroes with alter egos, such as wondering whether Batman or Bruce Wayne is the hero's true disguise.)

Because Morello’s music aims to empower marginalized people, his varied oeuvre may therefore be scrutinized as a form of rhetorical education. Jessica Enoch's 
definition of rhetorical education mentions strategies, language, and behavior that leads to civic engagement, and the programs she and others examine feature tangible techniques and tools, such as learning to read, understanding voter application forms, and so on. However, Morello's songs contain none of this. There are no explanations, for example, of how a picket line works, or how to register for healthcare, or how to pressure politicians. Instead, it seems that Morello's most frequent goal is to inspire anger, much like the fed up Howard Beale in the film Network, who implores his audience to shout to the world, "I'm mad as hell, and I'm not going to take it anymore!" Lyrics like "whatever it takes," "give them hell every time," and "you've got to rise to power" (from "Whatever It Takes," "Union Town," and "Rise To Power," respectively) offer nothing in terms of concrete action plans, and, if taken literally, might inspire the kind of action Morello might not wish to be on record as endorsing.

For example, over the course of The Nightwatchman's four albums, Morello seems to vacillate between peaceful and violent revolution, working out his own thoughts and feelings—again, drawing on his own personal experiences in a public way—and resonating with the percentage of his audience who wonder which methods of resistance are appropriate responses to the violence and coercion they face on a daily basis, often from authority figures. In "One Man Revolution,” Morello includes a bit of his own personal history, singing, "Found a noose in my garage / Now how "bout that / So tonight I'm in the bushes / With a baseball bat." The narrator's action after being threatened with a lynching is not to call the cops but to lie in wait should his aggressors return. The speaker stops short of hunting down the characters for retribution, but he makes clear his intent to mete out vigilante justice should the opportunity arise. In an interview, Morello 
describes both the song's origin and his continued reevaluation of pacifism versus militant resistance:

One of the things that I, in the Nightwatchman catalogue, that I deal with a lot is pacifism versus active resistance to oppression. And you know, I grew up, you know, despite some of the radical politics in my household, very much a pacifist. And, you know, when I entered Harvard University, I was discussing with some friends then who were of a more radical bent than myself. And we were discussing the incident when I was 13 years old of having the noose in the family's garage. And they were challenging my pacifist leaning, saying, you know, like, "How did you feel about that?" And I was terrified for months afterwards. They said, "Well, how would you feel if, you know, the Klan were coming up your family's driveway with a noose with - not knowing what their intentions might be, you know, and at that point, do you feel it's best to turn the other cheek? Or would you rather that me and my friends were in the bushes with baseball bats?" And that's a - I've turned that over, you know, on the course of four records, that is a recurring theme. And not - and some days I fall on one side of the line, on some days, the other. (Moyers)

Clearly, Morello reveals an inclination toward Hammurabi's Code, fighting fire with fire, taking an eye for an eye. At the same time, he shows a preference for peace-after all, the entire reason The Nightwatchman exists is to ensure safety, justice, and harmony. Rather, far from actually inviting people to grab baseball bats, torch buildings, or kill their military superiors, Morello's advice should be understood in the context of both musical and religious traditions.

To quickly revisit R. Serge Denisoff's distinction between magnetic and rhetorical songs, the magnetic song "appeals to the listener for the purposes of attracting the nonparticipant listener to a movement or ideology," while the rhetorical song attempts "to identify and describe some social condition, but . . offers no explicit ideological or organizational solutions, such as affiliation with an action or a movement" (6). Thus, identification and amplification in Morello's lyrics perform a rhetorical function insofar as they "identify and describe some social condition," while the anger he conveys and 
attempts to inspire performs a magnetic function, with righteous indignation perhaps being the ideology to which Morello wants to attract his audience. Again, Morello appears to recognize the affordances and limitations of music in terms of inspiration versus information: "There's something in music in particular that speaks to the reptilian brain in people, that when it's the right combination of rhythm and harmony-and the right lyrical couplet — really feels like the truth in a way that a written screed can't" (Irving Ferkleheimer). In this sense, Morello demonstrates how music can add a precognitive or precommunicative aspect to framing, shaping perception through association and affect.

When Morello refers to "the right combination of rhythm and harmony - and the right lyrical couplet," he makes an implicit argument about the importance of craft. Despite the radically progressive politics of Rage Against the Machine, all four of their albums were certified platinum, and their virtuosity as musicians is widely lauded. Their success has led to ample criticism, as well, as Morello in particular has been accused more than once of being a part of the $1 \%$ at which he fires his most pointed barbs. However, Morello has explained the commercial success of his music, despite its radically left content, by arguing that the music had to be excellent to be taken seriously. In a conversation with documentarian Michael Moore at the 2014 Traverse City Film Festival, Moore and Morello discuss the heavy-handedness of so much creative activism as poor art in service of activism, whether music, movies, fiction, or any other medium (UpNorth TV). The failing, Morello argues, is not in the intention but in the execution, that artists must make great art, or people will not care about the message. This does leave room for people like Paul Ryan to end up listing Rage Against the Machine among 
their favorite bands, but Morello often reminds interviewers that "the art has to come first so that the politics can be heard" ("The Nightwatchman Speaks \#9"). Refining labor organizer John L. Lewis' claim that “A singing army is a winning army,” Morello emphasis the importance of quality, noting that "Every successful movement has a great soundtrack" (Horton 4; Flanary). By claiming the art must come first, Morello does not mean that the message is secondary, but rather that the message's vehicle must be attractive enough to draw listeners so that the message itself becomes credible.

Acknowledging that good music employs appeals of pathos, Morello understands the rhetorical function of his music, insisting that "what music can do is it can help steel the backbone of those in the midst of a struggle and help put wind in the sails of social justice movements" (Democracy Now). In particular, he finds that folk music offers a kind of "heaviness" that depends on honest and raw simplicity, observing that "the right turn of phrase and the right couplet can cut to the core of your heart in a way that a searing, you know, guitar solo sometimes can't"' (Moyers). In light of Roberts and Steiner's servant-leader description of a critical public pedagogue, Morello's comments suggest that musicians engaged in this type of activist work must also cultivate an appropriate ethos, one that remains true to the artist's own self but is equally committed to the public good.

The second, and perhaps more satisfying way to interpret Morello's approach is found in the rhetorical form of the jeremiad. A theme that stretches across the last century of vernacular music is a reckoning for the guilty, which likely comes out of the faithbased spirituals of the past centuries that are grounded in an eschatological frame. Referring to the Old Testament prophet Jeremiah, the jeremiad became a popular 
rhetorical treatment in social movements, particularly by African Americans. The jeremiad typically follows a specific format that (a) invokes a promise or covenant, (b) observes or describes how that promise or covenant has been broken, and then (c) casts a vision of the judgment that will befall those who fail to restore or redeem the fracture. As David Howard-Pitney observes, "The American jeremiad is a rhetoric of indignation, expressing deep dissatisfaction and urgently challenging the nation to reform" (5).

Viewed from this angle, when Morello's songs describe violent retribution from the oppressed, he is not literally advocating that sort of action; he is instead drawing on a familiar rhetorical frame, providing a context for his politics that allows listeners to understand the gravity of his message.

For example, in the provocatively titled "Maximum Firepower," the lyrics use violence, at least metaphorically, to deliver action:

Kiss the ring if the Queen will let you But come over the fence and the dogs will get you On a rope hung the traitor, on a hook hung the meat You and me are missing persons 'til we're counted in the streets So seize the time and storm the tower And come correct, with Maximum Firepower

For the sins of the fathers the son he must pay The Nightwatchman giveth and he taketh away Thought hard about this next line, pretty sure it's true If you take a step towards freedom, it'll take two steps towards you So mister, I ain't scared, and mister, I ain't worried Cause on that lonely stretch of blacktop, I sit as judge and jury

The above lyrics draw heavily on biblical imagery and use the framework of a jeremiad, although the first part - a reminder of the original promise - is omitted. Morello points to the ruling powers with "comply or die" attitudes as the perpetrators of suffering. The omission of the first part of the jeremiad, in this context, bears no significant impact on the message of the song, perhaps because Morello operates from a 
foregone conclusion that those in authority have a responsibility to care for and protect all their citizens and, more accurately, to empower them to care for themselves. In fact, that omission might add rhetorical force to the song in that it suggests a perspective that is so fundamental it does not require explanation. The lyrics speak to the betrayal of that trust via the distance created between the "queen" and the subjects: "Kiss the ring if the Queen will let you / But come over the fence and the dogs will get you." Finally, though abstract, the narrator completes the jeremiad with the prophetic warning of punishment, proposing a coup: "Sieze the time and storm the tower / And come correct, with Maximum Firepower."

In the next verse, the narrator again plays the part of the vigilante outlaw on his liberation quest, observing with the first line that the problem is a systemic one that passes from power to power as if from father to son. Continuing in biblical themes, the language here comes from the Old Testament, used a few times during the Israelites' journey through the wilderness. In Exodus 34:6-7, when God commands Moses to create new stone tablets for the law after Moses broke the previous in anger at the Israelite's disobedience, the text reads: "Then the Lord passed by in front of him and proclaimed, 'The Lord, the Lord God, compassionate and gracious, slow to anger, and abounding in lovingkindness and truth; who keeps lovingkindness for thousands, who forgives iniquity, transgression and sin; yet He will by no means leave the guilty unpunished, visiting the iniquity of fathers on the children and on the grandchildren to the third and fourth generations"' (New American Standard Bible). By invoking this passage (and others that convey similar sentiments), Morello aligns his work with God's and, referring to the broken covenant of those in power, warns of severe consequences. He continues using 
biblical imagery to effectively argue that his is the side of righteousness, again taking on the role of "the Lord" (this time from the book of Job), making the connection all the more obvious with King James language: "The Nightwatchman giveth and he taketh away." Morello has often portrayed his work as a type of religious conviction of righteous work, once joking, "If they don't have a healthy FBI file on you, you're not doing God's work!" (MySpace). Therefore, similar to Martin Luther King, Jr. referring to the symbolic action of the March on Washington as coming to "cash a check," the jeremiad form in Morello's music does not prescribe concrete suggestions but instead fosters both dissatisfaction and solidarity through the rhetorical framing of injustice and building collective identity and agency.

Morello's frames, then, appear to depend on two necessary components: driven by an intense care of people, Morello creates the best art he can to attract as many as possible. Fashioning himself as "the black Woody Guthrie," Morello invokes more than the simple noise of folk; he draws on the role Guthrie created for future folk singers: a celebrity town crier. Interestingly, however, Morello also manages to blend Guthrie with Dylan by using the latter's approach to drawing inspiration from his own personal life. Dylan describes moving away from "finger-pointing songs" toward mining his personal history, thoughts, and feelings for material as he approached his departure for folk, ultimately finding those later songs more satisfying, and staying with that model for the rest of the career. At the time, many saw this as outside the boundaries of folk, as critics took him to task for this shift in songwriting on Another Side of Bob Dylan. But Morello combines folk's simple chord structures and melodies with personal lyrics, insisting that the politics begin with the person: 
I go to protests, so I'm branded as a political artist - a good deal of the material on those records is very, very personal. And it's, some of it's politics with a lower case "p." Some of it could hardly be described as politics at all. It's sort of, you know, an unearthing of the dark, shining a light on the dark recesses of that tortured suburban psyche that feels like, in order to be true to the political stuff, I feel I have to be just true to myself in making that music and to not conceal those things. (Moyers)

As with the other artists in this study, Morello's public pedagogy offers a type of rhetorical education by starting at the level of the individual. He asserts the need for the art to be good to attract listeners as step one, and then describes delivering a valuable messages as step two. And certainly, cultivating the proper ethos that demonstrates an authentic commitment to the public good enables step two. Turning to folk music and comparing himself to Guthrie symbolically rebrands his musical mission. If, as DiFranco argues and the previous chapter attempts to demonstrate, all vernacular music has the potential to function as folk music, Morello's move toward the folk idiom seems an attempt to make explicitly clear to his audience that his work should be understood as an extension of that musical legacy.

Musical Activism 2.0

One of the well-known characteristics of Woody Guthrie was his "rambling," getting out to where the masses were and participating in direct action. Similarly, Morello as The Nightwatchman has developed a sort of omnipresence in terms of traveling around the world, both physically and virtually, to go where he feels needed. He notes that one of the things that drew him to folk music is the freedom of following the causes as they happen:

With The Nightwatchman, it's guerilla warfare. It's sniping at the fascists from the sidelines and from the rooftops, and I like how mobile I can be, too. Like for example when the union uprising was occurring in Madison 
in February, I saw that one day on TV and I was there, playing in front of 100,000 people in the freezing cold on the steps of the capitol building the next day. (Smiley)

Though not drawing arenas as he had with Rage and Audioslave, this immediacy of response allows Morello to connect his music directly to the people and events in new and much more intimate ways, which fosters stronger connections between his art and activism and allows him to tailor his sets and songs to fit the needs of situations more effectively. If considering agency as the vehicle that permits action, Morello combines the portability of folk music with modern-day travel and technology to increase agency, both for himself and his audiences.

In recent years, the debate over the liberatory nature of Web 2.0 has seen scholars and theorists take polarizing views. On one side are arguments about how new technologies provide a kind of democratic intervention for individuals to produce content in a participatory culture, that anyone with even a modest computer can become a "prosumer" who can leverage the power of the Internet to gain a voice. On the other side are warnings that Web 2.0 has come and gone, that the exciting, level playing field once greatly anticipated has been fully absorbed by capitalism, that corporations govern not only the type of information and production we create and share but also the way that we create and share it. Remembering the old adage that "there's no such thing as a free lunch," it is important to recognize how the corporations that run these platforms have found lucrative ways to monetize free information and interaction, and users' blind participation in using such platforms may be construed as complicity with corporate policies and practices.

In speaking toward the more democratizing aspects of web 2.0, scholars like Henry Jenkins and Frank Farmer have examined how select groups use fan-fiction, 
podcasts, anime music videos, and remixes to subvert dominant narratives, discussing such ideas as virtual counterpublics and the ways subcultures find solidarity and strength in online forums. At the same time, citizens in developed countries are confronted with the reality that social media often dominates daily life in much less exciting ways. As Dutch theorist Geert Lovink describes, these "networks without a cause" have lulled the public into somnolence, and rather than moving toward a utopian, Habermasian public online, Lovink argues that users are sleepwalking into an endless sea of links, Buzzfeed lists, petitions, hashtags, and memes (9). Building on Lovink, Franco Berardi notes the acceleration of information that similarly leads us away from autonomy, taking us instead toward "automation in the processes of interpretation and in the processes of social construction, so that we are taken in a frenzy of 'friending,' 'liking,' and 'commenting,' as we are unable to create an autonomous sphere of expression in our info-saturated lives (44). And yet, the Internet is increasingly become a headquarters for many activist movements, both temporary and sustained. The ALS Ice Bucket Challenge, \#BlackLivesMatter, and countless other issues go viral and become a part of international conversations, prompting many to gain awareness of issues and, in many cases, directly participate in them.

New topics and campaigns crop up with increased frequency, and intense public pressure can be driven toward issues that capture the attention of enough people. This process is consistent with Michael Warner's discussion of the emergence of publicsgroups of people create discourse with, about, and around public texts in circulation — but the technologies of Web 2.0 allow these publics to be created significantly faster than even a decade ago. These particular publics — what I would call "fast publics"—form 
almost instantly, with texts generally being shallow enough to understand immediately (and, as Lovink and Berardi would likely warn, easily misunderstood with nuances being overlooked and oversimplified) and often disperse as quickly. They are ephemeral in that the circulating texts and public interest disappear quickly. For example, a few weeks after social media became outraged about the killing of Cecil the Lion (in July, 2015), for instance, the dentist who was viciously vilified for shooting the animal was all but forgotten on social media (along with Cecil). The fast public dissipated, and its constituents turned to other issues, forming new assemblies of other fast publics.

Fast publics intensify in strength when coupled with Dayan and Katz's concept of "media events" as described in the previous chapter, in which a large viewing public gathers to observe "high holidays of mass communication" (1). In the days when broadcast and then cable television were the most immediate and primary sources of viewing media events, coverage of large-scale events was deemed worthy or not by executives in a boardroom. With current social media and Web 2.0 platforms, however, not only can a lone, average citizen find, curate, and share endless hours of content, she can quite easily produce it. The very idea of a viral video allows the possibility that individuals can participate in the creation of media events, and the asynchronous-butinstant aspect of online media-sharing platforms subverts the concept of a mass communication "high holiday."

Of course, the argument remains that a video must participate in a corporate platform if it has any chance of going viral. At the same time, users have demonstrated multiple, tactical ways dominant systems can be turned on themselves. In 2014, the New York police department, in an attempt to combat a decline in public opinion of the police 
force, began a hashtag campaign called \#myNYPD, in which citizens were invited to share images of their positive interactions with police on social media, using the hashtag provided. The campaign was a spectacular failure, as images poured in of police overreaching their authority, wrestling black women to the ground, pepper-spraying peaceful protestors, and beating black men with nightsticks, each image posted with the \#myNYPD hashtag. The project was immediately and completely wrestled out of the hands of those who put it in place, providing an ideal example of not only the way that content can become public domain on the Internet but also, more importantly, how average users can participate in a type of digital activism through ad hoc publics.

This type of digital activism has received its share of criticism, garnering the terms "slacktivism" or "armchair activism." (Recall Bob Dylan's admonition, too, that listening to a protest song is not the same as protesting.) Perhaps the clearest distinction between this sort of digital activism and a legitimate social movement is organization. Lovink argues that if networks are here to stay, "we must therefore take them more seriously and radicalize their shape." He maintains that "networks are seen as secondary, informal platforms for interpersonal expression," and that this view of network organization reinforces thinking about networks as merely tools, rather than environments that shape human interaction and behavior. (166) Instead, Lovink suggests that we flip our thinking - rather than network organizations, we should gain a better understanding of organized networks, or what he refers to as "orgnets." He explains, "Whereas network organizations are more loosely connected and form slightly noncommittal ties, aimed at 'recharging the batteries' through information sharing and inspirational talks, the term 'organized networks' is more transformative by moving the 
production of culture onto the Net, and so changing the very mode of organization itself" (166).

Lovink's view of orgnets does not avoid the tension between decentralization and institutionalization, but it instead focuses on it. Through a concerted effort, activists, artists, programmers, scholars, journalists, and others could align their work through informal networks. Unlike network organizations that create weak connections, organized networks "seek stronger bonds within smaller units that emerge out of peer-to-peer encounters" (167). The burden is then on the activist to create structures that can facilitate and coordinate collaborative work on cultural, political, and educational projects. Nevertheless, Berardi remains dubious regarding the usefulness of web 2.0 in the service of digital activism as an end in itself, arguing,

We should never forget that just after midnight on 28 January 2011, Egypt, a country in which more than 20 million people were following the events of Tahrir Square online, was essentially cut off from the Internet. The next day, the number of people gathering in the streets of every city in the country exploded, and the revolt became an irrepressible revolution; pulling a country of 82 million people ... offline created the largest flashmob ever. (45)

For the activist in a digital age, avoiding social media is not an option, and it makes sense that the nature of fast publics is an ideal avenue for activist work in societies so thoroughly integrated with Web 2.0 platforms. Paying heed to theorists like Lovink and Berardi prompts two significant points. First, activists should seek to employ social media along the lines of an "orgnet," which is to say the organization should develop a strong network of complementary organizations and multiple platforms that allow average users to participate directly with the organization's efforts. Second, activists should remember the rhetorical power of mobilizing bodies in physical spaces. For 
musicians in particular, this is particularly salient, given the incredible affordances of group singing and crowd dynamics.

In the case of Tom Morello and his harnessing of social media, he demonstrates a robust pairing of organized networks with mobilizing people in both virtual and physical environments. Even more than the freedom granted by only requiring a guitar case and a plane ticket, Web 2.0 technologies have enabled an entirely new level of direct engagement with audiences that someone like Woody Guthrie could likely not have ever imagined. Additionally, the multiple content platforms available to Morello have allowed him to expand his rhetorical education pedagogy well beyond his music. Through a concerted, multi-pronged effort, he has developed his own methods of producing and distributing his music, engaging in dialogue with his audience, tapping into mainstream outlets when he chooses, connecting listeners with activist organizations in their own communities, and organizing and mobilizing participants in direct action efforts.

The Nightwatchman's YouTube channel features a series of over 50 videos, typically about 10 minutes each, called "The Nightwatchman Speaks," in which Morello answers questions he receives through his website. Handpicking the questions he answers allows him to purposefully craft each show into a combination of entertainment and information, giving him an opportunity to contextualize much of his work within personal experiences, his ideological perspectives, and current events. The videos might be construed as a kind of mashup between "Woody Sez," a column Guthrie wrote for The Daily Worker, and Franklin Delano Roosevelt's "Fireside Chats," and yet unlike both of those, the YouTube platform is significantly more intimate as recorded with a webcam, provides a means of interaction directly with viewers, and is infinitely rewatchable. 
Additionally, through his organization, the Axis of Justice, Morello and company provide a vast array of resources with tangible information for those looking to act. Of the organization, Morello explains,

We offer everything from providing firsthand help to kids who are physically or sexually abused to offering kids ways that they - in their community, that day - can hook up with organizations fighting for causes they believe in. Everything from environment, to labor issues, to stopping this international cycle of violence. ... It's the most exciting political endeavor I've ever been a part of. (Davis)

Through the Axis of Justice website, visitors can browse news articles, book recommendations, and event schedules, all curated by Axis of Justice team members. Even more significantly, the site provides an interactive feature that allows users to connect with causes in which they are interested by entering their location to find local organizations actively engaged in that work. This gives people not only resources for finding fast help for things they might need, but it also allows them to participate in activism in tangible ways, having been inspired by the rhetorical force of the music that drove them to the organization's site. That Morello proves interested and able to provide this information freely through the Internet actually helps clarify Morello's perspective on rhetorical education through music, that perhaps songs are not where this type of learning should (or maybe even can) occur, and thus he seems to allocate the emotion to the music and the information to the organization.

But what is perhaps most interesting about Morello's use of technology is the way he harnesses social media to organize and mobilize people in physical spaces. On the afternoon of April 30, 2012, Morello posted the following to his Twitter page: "I'm putting a new band together and ur in it. Our 1st rehearsal is tomm noon @ Bryant Park in NYC. Looking for about 10,000 guitar players.” The following day, International 
Workers Day, hundreds of participants showed up to march, play, and sing in service of reinvigorating the Occupy Wall Street Movement. Walking the streets of New York, singing old and new protest songs, Morello and his "new band" made their way to Union Square, where the day's events culminated in a free concert and rally featuring Morello and other musicians and speakers. The same day, Morello released a documentary on the Internet called World Wide Rebel Tour with 42 different instantiations and in 30 different languages, featuring performances from his latest solo album with unique content for different countries. As he explained in a brief interview with Fuse TV at the event, "Today is going to be a big May Day throwdown for Occupy Wall Street and the million guitar march.... It's a celebration about being really pissed off, and we're going to have a great time." As they marched, the crowd sang one of Morello's original songs of protest alongside more familiar anthems, including "Which Side Are You On?" "We Shall Not Be Moved," and "This Land Is Your Land." The event was declared by many to be enormously successful, and Morello was quick to give credit to his musical forebear; as he introduced "This Land Is Your Land," he shouted to the crowd, "This next one was written by the great rebel Woody Guthrie! If he was alive today, he would be headlining this event!" (Flanary). Since Morello was headlining the event, his invocation of Guthrie is a clear act of frame extension that describes who he (Morello) is, what he is doing, and how the public should interpret his music and commitments.

While the circulation of memes, tweets, and hashtags represent exactly the kind of shallow, uninformed textual circulation experts like Lovink and Berardi warn against, they nevertheless resonate with the most effective rhetorical features of folk music. A song like "We Shall Overcome," for instance, provides almost nothing in the way of 
information, evidence, argument, or action, and yet it was arguably the most important song in the Civil Rights Movement. Viewed in light of fast publics and social media, one might consider how the simple noise of folk music translates to Web 2.0, such as considering the rhetorical effects of something like \#WeShallOvercome. Perhaps the shallow, pithy hashtag, meme, or tweet is also a form of simple noise that merits interrogation along the lines of the folk tradition. If so, then Morello appears to be positioned as "Woody Guthrie 2.0," modeling the same consciousness with an updated skin, and demonstrating the work of a folk musician enacting rhetorical education through public pedagogy at the cutting edge of technology.

Harnessing social media as he has, Morello represents an emerging epoch in the lineage of activist folk musicians, and he also offers a way of conceiving of this tradition as a loop rather than links in a chain. Following Guthrie so closely, from his songwriting approach to the inscriptions on his guitar, Morello seems to have been able to realize Guthrie's ideals of a proletarian champion perhaps even more fully than Guthrie ever did, thanks to these technologies. Because of direct access to platforms, Morello does not need corporate sponsors, large record labels, broadcast networks, expensive recording equipment, or underwriting by government agencies - all technologies and structures that Guthrie depended on to deliver his message. Instead, Morello is able to tap into the existing infrastructures of the Internet to deliver content around the world, to interact with fans and fellow activists, to organize events in both virtual and physical environments, to release new music, and to deliver sophisticated mechanisms for activism to interested people around the planet. 
Morello's collective action frames draw on multiple forms of vernacular music to carve out the ideological and political space in which he constructs his musical platform. Emphasizing the rhetorical effects of music, he employs his celebrity status to weigh in on various issues, both creatively and critically, pointing out social problems while identifying victims and villains. Leveraging the fast publics of digital social media allows him to construct his own fast publics in both virtual and physical spaces, building solidarity while increasing agency by providing legitimate, concrete actions for ordinary citizens to participate in social causes. For scholars, Morello offers a rich case study as a critical public pedagogue enacting rhetorical education through a collective action frame. For activists, Morello exemplifies activism 2.0, connecting directly with disaffected people through technology, responding immediately to issues and causes around the world, and mobilizing enormous numbers of people in a matter of hours. For musicians, Morello synthesizes some 80 years of folk singers working as public pedagogues to demonstrate how collective action frames can be amplified and extended to bridge and transform issues, individuals, and publics. Through the continued study of such social action, scholars, activists, and musicians alike can continue to mine popular culture for its pedagogical and rhetorical affordances to conduct more incisive and effective forms of activism in the 21 st century. 


\section{CONCLUSION}

\section{Dangerous Times Demand Dangerous Music}

Although this project considers a nearly century-long legacy of folk musicians working for social change (with musical and activist roots reaching even farther back than that) the ripples in this rhetorical pond can still be easily observed in present-day culture. At the time of this writing, two headlines in particular demonstrate the continued relevance of this examination. On June 22, 2016, Democrat leaders staged a sit-in in the House of Representatives to call for a vote on stricter gun control measures in the wake of a devastating mass shooting, in which 49 people were murdered at a gay night club in Orlando, Florida. While both Democrat and Republican representatives were still in the chamber, a spontaneous chorus broke out. Live-streaming videos instantly popped up and circulated through social media outlets. In a video posted to YouTube, a CNN commentator observes,

So what they're doing is singing "We Shall Overcome" on the House floor and changing some of the words. Can't pick out exactly what their singing - maybe the folks at home can - but again, singing "We Shall Overcome," which was sung many times during the Civil Rights movement and is also sung during Black History Month in celebrations and in churches. And of course this is all being led by Civil Rights icon John Lewis, who started all of this. (CNN)

The 42-second video posted to YouTube by CNN neatly encapsulates the rhetorical and pedagogical dimensions of this dissertation, demonstrating the adaptability and relevance of folk music in collective action, the power of rhetorical framing, and the 
role of media in organizing and animating publics. The use of tactics effective in the Civil Rights movement- the sit-in and the song-exemplify frame extension, in which Lewis and others draw on existing frames but extend their boundaries to include new topics and publics of similar concern. Although the commentator could not hear the revised lyrics, viewers posted comments on Twitter and YouTube indicating the new verse: "We will pass a bill someday." The changing of words in the song, an affordance of the "simple noise" of folk songs, allowed the participants to speak directly to the moment. The song served as much more than an object or artifact, but as an activity. Merely calling it a "text" undermines the discursive circulation that caused this fast public to emerge, both in the House and online.

As a framing activity, this impromptu chorus highlights the type of work they believed they were doing, effectively linking their call for gun control measures with human rights issues that have punctuated American history for the past several decades. Stephen Schneider recounts how, when police raided the Highlander Folk School ${ }^{5}$ in 1959, Highlander staff members and participants stood fast and sang "We Shall Overcome" as "an act of defiance" (142). Fifty-seven years later, the song continues to be sung no less defiantly. As a rhetorical model of resistance, the frame appears to have been effective and persuasive, as footage from outside the Capitol building from two hours later shows more politicians, including former Speaker Nancy Pelosi, leading a gathered crowd in singing "We Shall Overcome" as well. Responses to these demonstrations were greatly mixed—not everyone was moved or persuaded—but what remains significant is that this frame was employed and understood.

\footnotetext{
${ }^{5}$ It was at the Highlander Folk School where Pete Seeger joined Highlander staff to revise "We Shall Overcome" into the version that became popular during the Civil Rights movement.
} 
Videos of these events were streamed and posted—and still remain—online, allowing continued and repeat viewing and discussion. And when current House Speaker Paul Ryan (whom Morello lambasted for missing the point of his own music in chapter four) closed the session despite the continued activity and the CNN cameras were turned off, representatives and aides pointed their phones at the group in the House floor and livestreamed the sit-in on Facebook and Periscope, allowing the public to view the action in real-time through the Internet. The "media event" (Katz and Dayan) continued without interruption, despite the fact that the mainstream media turned off their cameras. The revolution may not be televised, but chances are good it will be livestreamed.

In a completely different example of vernacular music as social protest, a mysterious website appeared in late May 2016, featuring a countdown clock to June 1 and the cryptic message, "Clear the way for the Prophets of Rage" (Prophets of Rage). Word quickly spread that Rage Against the Machine guitarist Tom Morello and Public Enemy frontman Chuck D were planning a new project, and on June 1, the website announced the formation of a new project, Prophets of Rage, featuring Morello, Chuck D, and Cypress Hill rapper B-Real. With the backing band Brad Wilk and Tim Commerford (drummer and bassist from Rage Against the Machine, respectively) and turntablist DJ Lord, the Prophets of Rage announced a summer tour that would feature songs by all three involved bands as well as new song called "The Party's Over," referring to the 2016 election season. Morello, who conceived the project, explains the group's mission:

Dangerous times do demand dangerous songs. This historical moment is really unprecedented. Both the country and the world are on the brink of the abyss. And we thought it was wholly irresponsible of us to be sitting on the sidelines when we have a catalog of material like we do between 
the three of us to go out and fight the power, to take the power back, to bring the noise, to rise up $^{6}$. . It's a historical necessity. The last time Rage played in LA, we out-drew Trump, Clinton and Bernie Sanders by about a margin of three times. This is not just music, this is a movement. ("Prophets of Rage Reveal Lineup")

Like the spontaneous chorus on the House floor, this calculated collaboration and tour continues Morello's public pedagogy with all the same features of rhetorical framing described by William Gamson: injustice, identity, and agency. His explanation above for the group's exigence evokes Lloyd Bitzer's "rhetorical situation," describing how the music exists as a response to the current political climate in the U.S. When Morello refers to "dangerous music," he poses an argument that their songs are an effective form of discourse and collective action that can bring about radical social change ${ }^{7}$. Their summer tour begins on July 19, 2016, in Cleveland, Ohio, and when asked about the timing and location, Morello quips,

Well, there's a thing called the Republican National Convention in July, and that will be a perfect place for a band like Prophets of Rage to cause a ruckus, and we will be there on the streets, in the field. We have a venue and there may be venues that will be spontaneous venues, it's hard to say. This is the kind of thing you don't broadcast to the local authorities prior to arrival. (Bloomberg)

Although the media refer to Prophets of Rage as a supergroup, Morello insists, "I don't look at it like a super group. I look at it like it's an elite task force of revolutionary musicians come together at a historical moment to stir shit up" ("Prophets of Rage Reveal Lineup").

\footnotetext{
6 "Fight the Power," "Take the Power Back," "Bring the Noise," and "Rise Up" are song titles by the groups represented in Prophets of Rage.

${ }^{7}$ Recall Woody Guthrie's similar sentiments in Pastures of Plenty from chapter one: "If the fight gets hot, the songs get hotter. If the going gets tough, the songs get tougher."
} 
Morello's continued use of music to "cause a ruckus," combined with his running commentary of what he is doing and why he is doing it, demonstrates a continued commitment to the ideals championed by Guthrie. At every opportunity, Morello reminds the public that he is the very model of a modern public pedagogue, reinforcing the sincere and authentic public persona he has been cultivating for over 20 years. On June 10, 2016, he appeared on Bill Maher's "Overtime," an extended segment of "Real Time with Bill Maher" that is shown on YouTube after Maher's HBO show ends each broadcast. Even Morello's appearance underscores his commitments, as he wore his trademark plain tshirt, jeans, and a ball cap — only this time, instead of an IWW hat, he wore a bright red cap with white lettering that reads, "MAKE AMERICA RAGE AGAIN." Parodying Republican presidential nominee Donald Trump's campaign slogan, "Make America great again," the hat itself reveals yet another frame, pitting Morello's music against the politician's campaign as a viable response, and marking out the territory of what he thinks his music can accomplish, as well as how Morello should be regarded in opposition to Trump.

This attention to persona seems particularly important in that Morello still reinforces it as actively as ever. Interestingly, the segment even begins with acknowledging that Morello is indeed a public figure and successful musiciannecessary equipment in the platform he has been constructing since he began. Maher begins by asking, "Tom, how do you keep ticket prices to your shows affordable?" This question seems out of place among the rest of the political discussion, but it reveals an interrogation into Morello's ethos, implicitly noting that many rock bands' ticket prices 
have risen to such an extent that the working class can no longer afford them ${ }^{8}$. Morello replies flatly, "By insisting," before breaking into laughter and shrugging. "I mean, that's it." Maher returns, "Well, but also by being popular, because enough people come out." Morello then explains that the first three shows of the tour (technically pre-tour shows in Los Angeles) were \$20 tickets that the band gave away. He agrees when Maher notes that a rock music tour is expensive, but then explains, "You have to absorb some of that cost and then make that a part of the thing you're doing" (Real Time). In this way, Morello reminds Maher and the audience that his musical goals are sub-corporate, and that he accepts the personal cost as a part of his activist framework.

These two current examples could not make clearer the relationships between music, musicians, and media. As public figures, John Lewis and Tom Morello both used music and rhetorical framing to decry injustice, build collective identity, and offer agency in service of social change. In so doing, they reinforced their own identities as critical public pedagogues, and the media that circulated their discourse facilitated the publics that emerged as a result. As critics and commenters have since argued, we have yet to see any results from their efforts, which might call into question Lewis' assertion decades ago that "A singing army is a winning army." After all, votes on gun measures failed to pass after the sit-in. However, there were votes. Despite not accomplishing what they ostensibly wanted, Lewis still framed the sit-in as successful, as moving the conversation forward, however incremental.

\footnotetext{
${ }^{8}$ While in Rage Against the Machine, Morello and the band repeatedly and proudly declared that tickets to see Rage would never cost more than \$20.
} 
Assessing the Effectiveness of Rhetorical Framing

This raises one of the most popular questions surrounding analyses of social movements and collective action: how does one measure success? While certainly an important question for activists, this is the wrong question for a rhetorical study like this. Success is hard if not impossible to measure, and for many individuals, attitudes and ideas change slowly and through a variety of sources in their hearts and minds. What is much more observable, however, is the fact that public figures continue to revisit these tactics again and again. Musicians still understand their pedagogical role, and they continue returning to this replicable model of musical activism. Just as the singing of "We Shall Overcome" that began in the House of Representatives led to a group of gathered politicians and citizens on the Capitol steps singing the same song a few hours later, musicians have been emulating and invoking Woody Guthrie, along with a long line of other musicians in the same traditions, ever since the 1930s. Moreover, not only is Guthrie's public pedagogy replicable, the collective action frames he introduced have proven portable and adaptable, seen through the exemplars in this project.

So persistent are this frames, in fact, that they have been employed by musicians outside of the sub-corporate, vernacular music spaces described by Ani DiFranco in her reclamation of folk music. Although all popular music styles share some of the same branches with folk in the musical family tree, some of the world's biggest musical celebrities (many of whom could hardly be considered sub-corporate) have been able to assemble sincere personas and platforms of authenticity that define their work as public pedagogy. For example, U2 contributed a song to the 2013 Nelson Mandela biopic, Long Walk to Freedom. Similarly, singer John Legend and rapper Common collaborated on the 
song "Glory" for the 2014 film, Selma. And Bruce Springsteen continues to revisit the commitments of The Seeger Sessions in his albums, including his 2014 album High Hopes - which, incidentally, prominently features Tom Morello on lead guitar. These examples again highlight the relationships between music, musicians, and media, offering another set of framing markers to not only understand the art and issues but the performers and their commitments. Because of the highly-circulated media that bring us the sounds and images of these musicians, it becomes we the public who examine these texts and participate in the discourse that determines which artists might be considered critical public pedagogues — which artists are sincere, and which are merely opportunistic. No matter the message of a song, it consistently falls to an assessment of the public figure that causes a public to decide who is sincere, and that seems to be the biggest indicator of a song's effectiveness or uptake in collective action.

Therefore, the case studies in this project provide us with a lens for analyzing how songs move from being artifacts to public pedagogy, from being merely sonorous to sonic rhetoric. Moreover, these chapters reveal that rhetorical effects of songs do not appear to be inherent in the songs themselves, but in the embedded activities in which these songs participate. The public pedagogue uses her music to construct collective action frames, but she must also cultivate a relationship with the technologies that mediate and circulate public discourse in order for her to become a public figure and for her music to become public texts in the first place. And most importantly, if her music is to have any lasting impact in popular culture by participating in social change, she must fashion herself in the image of a critical public pedagogue. That is, she must actively develop a public persona that resists dominant, corporate narratives while framing the social problems her 
music addresses as consequences of injustice that are capable of being rectified. To do this, she must foster collective identity within her audiences and leverage her own mediated image to offer her public(s) a model of, in Cornel West's language, tragicomic hope.

"This Machine Kills Fascists"

The type of public pedagogy discussed by critical theorists like Henry Giroux and Peter McLaren focuses on exposing oppressive, often implicit forms of neoliberalist ideologies in popular culture. Through their lenses, popular culture frequently reveals underlying arguments that reinforce rather than resist dominant power structures. As much as such critiques are necessary and valuable in understanding both how extrainstitutional learning occurs via culture and how popular public texts inform and persuade publics, this direction of scholarly inquiry leaves little room for the producers of popular culture to enact the type of critical public pedagogy described in this dissertation. A conspiratorial perspective of public pedagogy can point out pitfalls and warn of snakes in the grass, so to speak, but it is ultimately more debilitating than liberating. Thus, the addition of new and perhaps more useful models of public pedagogy should be seen as complementary rather than contradictory, offering replicable examples of activism via popular culture that can in fact combat the more insidious elements of culture on its own turf.

This project orients itself around the public pedagogy of music — and only a particular subset of music at that—but the activities described herein can be exported to numerous other scenarios. The concepts of parrhesia and rhetorical framing are certainly 
not bound to music or even just the arts, but can apply to any form of public discourse. Thus, any individual or group may approach their own work as potentially activist, capable of producing the dynamics that foment social change. At this moment, most Americans could name authors, poets, athletes, film directors, actors, politicians, scientists, evangelists, teachers, scholars, and a host of other public figures who espouse the values that would resonate with the case studies in this dissertation, and in each case, an analysis would reveal the specific framing activities those individuals engage in to convey their commitments that comprise an authentic persona.

This is not to argue that celebrities are the only demographic capable of bringing about social change - this model I have been describing is scalable, to an extent—but in order to have public pedagogy, there must be a public, and in order for there to be collective action, there must be a collective. And, as Nancy Fraser, Michael Warner, Gerard Hauser and other scholars of publics remind us, publics are never discrete. We inhabit multiple, overlapping publics that can exist in opposition to each other. As Bob Dylan and even Paul Ryan prove, public texts can circulate among publics whose discourse may be entirely different than the intentions of the texts' authors. However, this seems to only reinforce the importance of framing, and it should be obvious at this point that a public figure who can achieve frame resonance stands a very good chance of mobilizing participants to her desired effect.

So, although any public figure may be poised to enact rhetorical education through public pedagogy, music nevertheless remains a uniquely powerful medium with specific affordances to help achieve frame resonance. The embodied, participatory act of music-making and the affective, personal way music stirs emotion and builds collective 
identity is so woven into the human experience that one is hard-pressed to find another human activity that achieves what it does quite like it does. The concepts, frameworks, and questions raised in this dissertation therefore extend well beyond the field of rhetoric into a variety of arts and sciences, but certainly would be predominantly useful in the humanities and social sciences. Simultaneously, digital media dominates popular culture now in ways that we are scrambling to understand, and the literacy practices we use to create and consume new media texts is only changing faster. The closer our media allow us to simulate reality, the more invisible our practices become, and the harder it is to recognize the multiple layers, screens, and filters through which we observe the world around us. Furthermore, the speed at which we receive information is at odds with many of our previous ways of understanding and assessing ideas and events, much like trying to count individual blades of grass as we speed past them on a highway. But rather than decry the reality of life in 2016, the critical public pedagogue embraces and critiques it with the very tools that complicate it. And although the master's tools may never dismantle the master's house, perhaps they can nevertheless make some much needed modifications. Maybe the shallow texts of hashtags and tweets are exactly what activism in the 21 st century needs, and maybe fast publics will help accelerate social change. The direction of that change, however, is never guaranteed, so it falls to those of us who care about paideia to practice parrhesia, and to participate in the discourse of our many publics.

Woody Guthrie's famous inscription, “THIS MACHINE KILLS FASCISTS,” still remains a provocative statement, but it also belies the true mechanism of protecting radical democracy from its enemies. Reportedly an expression that fighter pilots printed 
on their planes in World War II, the phrase occludes the relationships between the plane, the pilot, the munitions, and the mission. Likewise, it was not Guthrie's guitar that radicalized people and fostered collective action. It was the relationship of the music, the musician, the media, and the message, all working together in concert - that was the mechanism by which people's hearts and minds have been organized, animated, and mobilized. That was and continues to be the machine that fights for freedom. 


\section{REFERENCES}

“21 for the 21st.” Ms. September/October 1997: 102-111. Print.

Ackerman, John M., and David J. Coogan, eds. The Public Work of Rhetoric: Citizenscholars and Civic Engagement. Columbia: University of South Carolina, 2010. Print.

Adlercast. "Tom Morello Pt 2 - The Obama Effect, Drowning George Bush." YouTube. YouTube, 2 Mar. 2009. Web. 28 June 2016.

Amburn, Ellis. Pearl: The Obsessions and Passions of Janis Joplin. New York: Little, Brown \& Co., 1992. Print.

Amos, Deborah. “21st-Century Troubador.” ABC News, 2002. Television.

“The Angry Young Folk Singer.” Life Apr. 1964: 109-117. Print.

Angyal, Chloe. "The Hairpin Rom Com Club: My Best Friend's Wedding." The Hairpin. N.p., n.d. Web. 25 Mar. 2016.

Asen, Robert. 'Seeking the 'Counter,' in Counterpublics." Communication Theory 10.1995 (2000): 424-446. Print.

Attali, Jacques. Foreword. Music and Marx: Ideas, Practice, Politics. By Regula Burckhardt Qureshi, ed. New York: Routledge, 2002. Print.

Benford, Robert D. “An Insider's Critique of the Social Movement Framing Perpective.” Sociological Inquiry 67.4: 409-430. Print. 
Berardi, Franco "Bifo." "The Paradox of Media Activism: The Net Is Not a Tool, It's an Environment." Uncommon Grounds: New Media and Critical Practices in North Africa and the Middle East. Ed. Anthony Downey. New York: Palgrave Macmillan, 2014. 39-46. Print.

Bloomberg Politics. "The Supergroup That Wants to Make America Rage Again.” Bloomberg Politics. Bloomberg.com, 2 June 2016. Web. 28 June 2016.

"Bob Dylan and the NECLC." corliss-lamont.org. N.p., n.d. Web. 17 Aug. 2015.

Boler, Megan. Feeling Power: Emotions and Education. New York: Routledge, 1999. Print.

Brand, Oscar. The Ballad Mongers: Rise of the Modern Folk Song. New York: Funk \& Wagnalls, 1967. Print.

Burdick, Jake, and Jennifer A. Sandlin. "On the Politics and Ethics of Researching Critical Public Pedagogies." Sandlin, Schultz, and Burdick 116-124.

Burlingham, Bo. "Don’t Call Her an Entrepreneur." Inc. Magazine Sept. 2004: 97-102. Print.

Cassuto, Leonard. "Woody Guthrie at 100." The Chronicle of Higher Education Oct. 2012. Web. 27 June 2016.

CNN. "House Democrats Sing 'We Shall Overcome” during...” YouTube. YouTube, 22 June 2016. Web. 28 June 2016.

Coker, Hillary Crosley. "Ani DiFranco Issues a Real Apology for Plantation Event.” Jezebel 2 Jan. 2014. Web. 25 Mar. 2016.

Comingore, Aly. "Ani DiFranco Talks Past, Present, and Future Projects." Santa Barbara Independent 3 Apr. 2008. Web. 25 Mar. 2016. 
Crowe, Cameron. Liner Notes. Biograph. Columbia, 1985: n. pag. Print.

Crowley, Sharon. “Composition Is Not Rhetoric.” Enculturation 5.1 (Fall 2003): n. pag. Web. 27 June 2016.

D’Ambrosio, Antonino, dir. Let Fury Have the Hour. SnagFilms, 2012. Film.

Davis, Timothy C. "Rage for Justice.” Mother Jones January/February 2003. Web. 9 Oct. 2015.

Dayan, Daniel, and Elihu Katz. Media Events: The Live Broadcasting of History. Cambridge, MA: Harvard University Press, 1992. Print.

Deans, Thomas, Barbara Roswell, and Adrian J. Wurr, eds. Writing and Community Engagement. New York: Bedford/St. Martin's, 2010. Print.

De Mille, Agnes. Foreword. The Ballad Mongers: Rise of the Modern Folk Song. By Oscar Brand. New York: Funk \& Wagnalls, 1967. Print.

Democracy Now. "Guitarist, Activist Tom Morello: 'Music Can Help Steel the Backbone of Those in the Struggle."” Democracy Now. Democracynow.org, 21 May 2012. Web. 9 Oct. 2015.

Denisoff, R. Serge. The Sounds of Social Change: Studies in Popular Culture. Chicago, IL: Rand McNally \& Co., 1972. Print.

DiFranco, Ani. “32 Flavors.” Not a Pretty Girl. Righteous Babe Records, 1995. CD.

---. “Fixing Her Hair.” Imperfectly. Righteous Babe Records, 1992. CD.

---. “Fuel.” Little Plastic Castle. Righteous Babe Records, 1998. CD.

---. "In Or Out.” Imperfectly. Righteous Babe Records, 1992. CD.

---. “Literal.” Verses. New York: Seven Stories Press, 2007. 11. Print.

---. “Not So Soft.” Not So Soft. Righteous Babe Records, 1991. CD. 
---. “Open Letter from Ani DiFranco to Ms. Editors.” MTV. N.p., n.d. Web. 25 Mar. 2016.

---. “Origami.” Educated Guess. Righteous Babe Records, 2004. CD.

---. "Serpentine." Evolve. Righteous Babe Records, 2003. CD.

---. "The True Story Of What Was.” Educated Guess. Righteous Babe Records, 2004. CD.

---. “To The Teeth.” To the Teeth. Righteous Babe Records, 1999. CD.

---. Trust. USA: Righteous Babe Records, 2004. DVD.

---. Verses. New York: Seven Stories Press, 2007. Print.

Donnelly, Theresa. "Public Speaking: Ani DiFranco." The Public 28 Jan. 2015. Web. 25 Mar. 2016.

Doxtader, Erik. "In the Name of Reconciliation: The Faith and Works of Counterpublicity." Counterpublics and the State. Ed. Robert Asen and Daniel C. Brouwer. Albany: State University of New York Press, 2001. Print.

Dylan, Bob. “All I Really Want To Do.” Another Side of Bob Dylan. Columbia, 1964. Music recording.

---. “Blowin' In The Wind.” The Freewheelin' Bob Dylan. Columbia, 1963. Music recording.

---. Chronicles. New York: Simon \& Schuster Paperbacks, 2004. Print.

---. “A Hard Rain's A-Gonna Fall.” The Freewheelin' Bob Dylan. Columbia, 1963. Music recording.

---. "It Ain’t Me, Babe." Another Side of Bob Dylan. Columbia, 1964. Music recording. 
---. "It’s All Over, Baby Blue.” Bringing It All Back Home. Columbia, 1965. Music recording.

---. "Maggie's Farm.” Bringing It All Back Home. Columbia, 1965. Music recording.

---. "Restless Farewell." The Times They Are A-Changin'. Columbia, 1964. Music recording.

---. "Song to Woody." Bob Dylan. Columbia, 1962. Music recording.

Enoch, Jessica. Refiguring Rhetorical Education: Women Teaching African American, Native American, and Chicano/a Students, 1865-1911. Carbondale: Southern Illinois University Press, 2008. Print.

Eyerman, Ron, and Andrew Jamison. Music and Social Movements: Mobilizing Traditions in the Twentieth Century. New York: Cambridge University Press, 1998. Print.

FaceCulture. "Interview Ani DiFranco (part 5).” Online video clip. YouTube. YouTube, 8 Feb. 2011. Web. 25 Mar. 2016.

Farmer, Frank. After the Public Turn: Composition, Counterpublics, and the Citizen Bricoleur. Logan, UT: Utah State University Press, 2013. Print.

Filene, Benjamin. Romancing the Folk: Public Memory and American Roots Music. Chapel Hill, NC: University of North Carolina Press, 2000. Print.

Fine, Marshall. "Bob Dylan, Corporate Shill.” Huffington Post. Huffington Post, 4 Feb. 2014. Web. 27 June 2016.

Flanary, Patrick. “Tom Morello Occupies Wall Street: ‘Every Movement Has a Soundtrack." Billboard 13 Oct. 2011. Web. 9 Oct. 2015. 
Flower, Linda. Community Literacy and the Rhetoric of Public Engagement. Carbondale: Southern Illinois University Press: 2008. Print.

FORA.tv. "Idea Framing, Metaphors, and Your Brain - George Lakoff" Online video clip. YouTube. YouTube, 16 Jul. 2008. Web. 29 Apr. 2016.

Fraser, Nancy. "Rethinking the Public Sphere: A Contribution to the Critique of Actually Existing Democracy." Social Text 26.25 (1990): 56-80. Print.

Frith, Simon. Taking Popular Music Seriously: Selected Essays. Burlington, VT: Ashgate Publishing Company, 2007.

Frow, John. Genre. New York: Routledge, 2005. Print.

Fuse (FM). "Tom Morello at Occupy Wall Street: May Day Guitarmy.” YouTube. YouTube, 1 May 2012. Web. 9 Oct. 2015.

Gammond, Stephen, dir. Woody Guthrie: This Machine Kills Fascists. Snapper UK, 2005. Film.

Gamson, William A. "Constructing Social Protest." Social Movements and Culture. Eds. Hank Johnston and Bert Klandermans. Minneapolis: University of Minnesota Press, 1995. Print.

Garman, Bryan K. A Race of Singers: Whitman's Working-Class Hero from Guthrie to Springsteen. Chapel Hill: University of North Carolina Press, 2000. Print.

Giroux, Henry A. Breaking in to the Movies: Film and the Culture of Politics. Malden, MA: Blackwell Publishers Inc., 2002. Print.

Giroux, Henry A. "Cultural Studies and the Politics of Public Pedagogy: Making the Political More Pedagogical.” Parallax 10.2: 73-89. Print. 
Glenn, Cheryl, Margarat Lyday, and Wendy Sharer, eds. Rhetorical Education in America. Tuscaloosa: University of Alabama Press, 2004. Print.

Grossberg, Lawrence. We Gotta Get Out of This Place: Popular Conservatism and Postmodern Culture. New York: Routledge, 1992. Print.

Guthrie, Woody. "Beaumont Rag.” Library of Congress Recordings. Rounder Records, 1988. Print.

---. Born to Win. Ed. Robert Shelton. New York: Macmillan, 1965. Print.

---. “Do Re Mi.” This Land Is Your Land: The Asch Recordings, Volume 1. Smithsonian Folkways Records, 1997. CD.

---. "I Ain't Got No Home.” The Asch Recordings, Volume 3: Hard Travellin'. Smithsonian Folkways Records, 1998. CD.

---. “Pastures Of Plenty.” This Land Is Your Land: The Asch Recordings, Volume 1. Smithsonian Folkways Records, 1997. CD.

---. “Rye Whiskey.” Library of Congress Recordings. Rounder Records, 1988. Print.

---. "The Sinking of the Reuben James." This Land Is Your Land: The Asch Recordings, Volume 1. Smithsonian Folkways Records, 1997. CD.

---. "This Land Is Your Land." This Land Is Your Land: The Asch Recordings, Volume 1. Smithsonian Folkways Records, 1997. CD.

---. "Wallace-Taylor Train," based on "Farmer-Labor Train.” Long Ways to Travel: The Unreleased Folkways Masters. Smithsonian Folkways Records, 1994. CD.

---. Woody Sez. New York: Grosset \& Dunlap, 1975. Print. 
Guthrie, Woody, and Alan Lomax. Letter from Woody Guthrie to Alan Lomax, September 19, 1940. 19 Sep. 1940. Manuscript/Mixed Material. Retrieved from the Library of Congress, <https://www.loc.gov/item/afcwwgbib000004>.

Guthrie, Woody, Dave Marsh, and Harold Leventhal. Pastures of Plenty: A Self-Portrait. New York: HarperCollins, 1990. Print.

Habermas, Jürgen. The Structural Transformation of the Public Sphere: An Inquiry into a Category of Bourgeois Society. Trans. Thomas Burger. Cambridge, MA: MIT Press, 1989. Print.

Hajdu, David. Positively 4th Street: The Lives and Times of Joan Baez, Bob Dylan, Mimi Baez Fariña, and Richard Fariña. New York: North Point Press, 2001. Print.

Harburg, Yip. "I've Got A Ballot," based on "I've Got A Sixpence." Election Songs of the United States. Smithsonian Folkways Records, 2004. CD.

Hauser, Gerard A. Vernacular Voices: The Rhetoric of Publics and Public Spheres. Columbia, SC: University of South Carolina Press, 1999. Print.

Haynes, Todd, dir. I'm Not There. Killer Films, 2007. Film.

Hedin, Benjamin, ed. Studio A: The Bob Dylan Reader. New York: W.W. Norton \& Company, Inc., 2004. Print.

Hentoff, Nat. “The Cracklin', Shakin', Breakin' Sounds.” The New Yorker 1964: 64. Print. Hentoff, Nat. "Interview: Bob Dylan." Playboy March 1966: 41-46. Print. Hochman, Steve. “DiFranco Joins ‘Best Friend's Wedding' Party.” Los Angeles Times 8 June 1997: n. pag. Print.

Horton, Zilphia. Labor Songs. Atlanta: Textile Workers Union of America. Box 69, Folder 8. HREC Records, 1939. Print. 
Howard-Pitney, David. The African American Jeremiad: Appeals for Justice in America. Philadelphia: Temple University Press, 2005. Print.

Irving Ferkleheimer. "Keith Talks to Tom Morello of Rage Against the Machine - 201110-13 Countdown with Keith Olbermann.” YouTube. YouTube, 17 Aug. 2012. Web. 28 June 2016.

Jenkins, Henry. Convergence Culture: Where Old and New Media Converge. New York: New York University Press, 2006. Print.

Jeremy. "With the NFL Controversy, I Wonder, Is Ani Even a Fan?" Google Groups. N.p., n.d. Web. 25 Mar. 2016.

Johnson, Nan. "Parlor Rhetoric and the Performance of Gender in Postbellum America." Glenn, Lyday, and Sharer 107-128.

Kat. “Kat's Korner: Ani DiFranco's Embarrassing Odor.” The Common Ills. N.p., n.d. Web. 25 Mar. 2016.

Kates, Susan. "Politics, Identity, and the Language of Appalachia." Glenn, Lyday, and Sharer 74-86.

Kaufman, Will. Woody Guthrie, American Radical. Urbana, IL: University of Illinois Press, 2011. Print.

Keast, James. “Ani DiFranco: The L'il Folksinger That Could.” Exclaim! 1 Jan. 2006. Web. 25 Mar. 2016.

Klein, Joe. Woody Guthrie: A Life. New York: Dell Publishing, 1980. Print. Kun, Josh. Audiotopia: Music, Race, and America. Berkeley: University of California Press, 2005. Print. 
Kuypers, Jim A. Bush's War: Media Bias and Justifications for War in a Terrorist Age. Lanham: Rowman \& Littlefield Publishers, Inc., 2006. Print.

"Kyle Meredith with... Ani DiFranco." The Speed of Sound. Louisville Public Media. WFPK, Louisville. 22 Jun. 2016. Radio.

Logan, Shirley Wilson. Liberating Language: Sites of Rhetorical Education in Nineteenth-Century Black America. Carbondale: Southern Illinois University Press, 2008. Print.

Long, Elenore. Community Literacy and the Rhetoric of Local Publics. Anderson: Parlor Press, 2008. Print.

Lovink, Geert. Networks without a Cause: A Critique of Social Media. Malden: Polity Press, 2011. Print.

Maistros, Louis. "The Curious Case of Ani DiFranco.” Relix Apr. 2012. Web. 25 Mar. 2016.

Mathieu, Paula. Tactics of Hope: Street Life and the Public Turn in English Composition. Portsmouth, NJ: Boynton/Cook Publishers, Inc., 2005. Print.

McClure, Michael. "Bob Dylan: The Poet's Poet.” Rolling Stone 1974: n. pag. Print. Morello, Tom. "Alone Without You." Alone Without You - Single. New West Records, 2007. MP3.

---. “Branding Iron.” World Wide Rebel Songs. New West Records, 2011. MP3.

---. "Maximum Firepower." One Man Revolution. New West Records, 2007. MP3.

---. "One Man Revolution.” One Man Revolution. New West Records, 2007. MP3.

---. “Rise To Power.” The Fabled City. New West Records, 2008. MP3.

---. "Stray Bullets.” World Wide Rebel Songs. New West Records, 2011. MP3. 
---. “Tom Morello: The Nightwatchman Speaks \#2.” Online video clip. YouTube. YouTube, 6 June 2011. Web. 9 Oct. 2015.

---. “Tom Morello: The Nightwatchman Speaks \#9.” Online video clip. YouTube. YouTube, 9 Mar. 2012. Web. 9 Oct. 2015.

---. "Tom Morello: 'Paul Ryan Is the Embodiment of the Machine Our Music Rages Against." Rolling Stone 16 Aug. 2012. Web. 9 Oct. 2015.

---. “Union Town.” Union Town. New West Records, 2012. MP3.

---. "Whatever It Takes." The Fabled City. New West Records, 2008. MP3.

Morello, Tom (tmorello). "I'm Putting a New Band Together and Ur in It. Our 1st Rehearsal Is Tomm Noon @ Bryant Park in NYC. Looking for about 10,000 Guitar Players.” 30 Apr. 2012, 11:41 a.m. Tweet.

Moyers, Bill. “Tom Morello, Troubadour for Justice.” Moyers \& Company. Billmoyers.com, 18 May 2012. Web. 9 Oct. 2015.

MySpace. "Artist on Artist: Tom Morello \& Michael Moore.” Online video clip. MySpace. MySpace, 23 Apr. 2007. Web. 9 Oct. 2015.

Lumet, Sidney, dir. Network. Metro-Goldwyn-Mayer, 1976. Film.

New American Standard Bible. La Habra: The Lockman Foundation, 1995. Print.

"Northern Folk Singers Help Out at Negro Festival in Mississippi." New York Times 7 July 1963: 43. Print.

Obejas, Achy. "Both Sides Now." The Advocate Dec. 1997: 26. Print.

“Oral Histories.” American Roots Music. PBS.org. PBS, n.d. 27 June 2016.

Pancratz, Paige. "The Talented Ms. DiFranco." Colorado Springs Independent 27 Apr. 2000: n. pag. Web. 25 Mar. 2016. 
Pennebaker, D. A., dir. Dont Look Back. USA: New Video, 1967. Film.

Petrusich, Amanda. "Bruce Springsteen, We Shall Overcome: The Seeger Sessions." Pitchfork 23 Apr. 2006. Web. 28 June 2016.

"Playing 6-String Politics." The Gazette. CanWest MediaWorks Publications Inc., 24 Apr. 2007. Web. 28 June 2016.

Prophets of Rage. Prophets of Rage - Take the Power, 2016. Web. 28 June 2016.

"Prophets of Rage Reveal Linup, Announce First Show on Kevin \& Bean.” KROQ. CBS Local Media, 31 May 2016. Web. 28 June 2016.

Rao, Mallika. “Ani DiFranco Is 'Remarkably Unapologetic' About Slave Plantation Retreat.” The Huffington Post 23 Jan. 2014. Web. 25 Mar. 2016.

Real Time with Bill Maher. "Real Time with Bill Maher: Overtime - June 10, 2016 (HBO).”YouTube. YouTube, 10 June 2016. Web. 28 June 2016.

righteousbaberecs. "Utah and Ani on Folk Music." Online video clip. YouTube. YouTube, 25 Feb. 2009. Web. 25 Mar. 2016.

Roberts, Patrick A., and David J. Steiner. "Exploring the Normative and Political Challenges of Radical Democracy." Handbook of Public Pedagogy: Education and Learning Beyond Schooling. Ed. Jennifer A. Sandlin, Brian D. Schultz, and Jake Burdick. New York: Routledge, 2010. Print.

Rodnitzky, James L. “The Mythology of Woody Guthrie.” American Popular Music: Readings from the Popular Press Volume II: The Age of Rock. Ed. Timothy E. Scheurer. Bowling Green, OH: Bowling Green State University Popular Press, 1989. 13-23. Print. 
Rolling Stone. “Tom Morello - Interview.” YouTube. YouTube, 15 Sep. 2011. Web. 28 June 2016.

Rollins, Henry. “The Henry Rollins Show \#314: Serj Tankian, Tom Morello/Amen.” Online video clip. festivalgenius. Independent Film Channel, 13 July 2007. Web. 9 Oct. 2015.

Roscigno, Vincent J., and William F. Danaher. The Voice of Southern Labor: Radio, Music, and Textile Strikes. Minneapolis: University of Minnesota Press, 2004. Print.

Rosenbaum, Ron. “Interview: Bob Dylan.” Playboy January 1978:

Rothschild, Matthew. “Ani DiFranco.” The Progressive May 2000: n. pag. Web. 25 Mar. 2016.

Roy, William G. Reds, Whites, and Blues: Social Movements, Folk Music, and Race in the United States. Princeton: Princeton University Press, 2010. Print.

Sandlin, Jennifer A., Michael P. O’Malley, and Jake Burdick. "Mapping the Complexity of Public Pedagogy Scholarship: 1894-2010.” Review of Educational Research 81.3 (2011): 338-375. Print.

Savage, Glenn. “Problematizing ‘Public Pedagogy' in Educational Research.” Sandlin, Schultz, and Burdick 103-115.

Scanlan, Lawrence. The Horse God Built. New York: Thomas Dunne Books, 2007. Print. Scherman, Tony, and David Dalton. Pop: The Genius of Andy Warhol. New York: Harper, 2009. Print. 
Schneider, Stephen. You Can't Padlock an Idea: Rhetorical Education at the Highlander Folk School, 1932-1961. Columbia: University of South Carolina Press, 2014. Print.

Scorsese, Martin, dir. No Direction Home: Bob Dylan. USA: Public Broadcasting Service, 2005. Film.

Shelton, Robert. "Interview with Abe and Beatty Zimmerman." Isis: A Bob Dylan Anthology. Ed. Derek Barker. London: Helter Skelter, 2001. 12-25. Print.

Sheridan, David M., Jim Ridolfo, and Anthony J. Michel. The Available Means of Persuasion: Mapping a Theory and Pedagogy of Multimodal Rhetoric. Anderson, SC: Parlor Press, 2012. Print.

Smetana, Vincent. “Opening Title Sequence: My Best Friend's Wedding.” Cinesnatch. N.p., n.d. Web. 25 Mar. 2016.

Smiley, Tavis. "Musician-Activist Tom Morello." Tavis Smiley. The Smiley Group, Inc., 6 Oct. 2011. Web. 9 Oct. 2015.

Smith, Larry David. Writing Dylan: The Songs of a Lonesome Traveler. Westport, CT: Praeger Publishers, 2005. Print.

Smith, Martin. "Picket Lines and Songs of Protest." Socialist Review July/August 2007. Web. 9 Oct. 2015.

Snow, David A., and Robert D. Benford. "Ideology, Frame Resonance, and Participant Mobilization." International Social Movement Research 1.1 (1988): 197-217. Print. 
Snow, David A., E. Burke Rochford, Jr., Steven K. Worden, and Robert D. Benford. "Frame Alignment Processes, Micromobilization, and Movement Participation." American Sociological Review 51 (1986): 464-481. Print.

Turino, Thomas. Music as Social Life. Chicago: University of Chicago Press, 2008. Print. UpNorth TV. "TCFF Panel 2014 One-on-One Conversation with Michael Moore and Tom Morello.” 21 Aug. 2014. Web. 9 Oct. 2015.

Warner, Michael. Publics and Counterpublics. Brooklyn: Zone Books, 2002. Print. Weissman, Dick. Which Side Are You On?: An Inside History of the Folk Music Revival in America. New York: The Continuum International Publishing Group, Inc., 2005. Print.

West, Cornel. Democracy Matters. New York: Penguin Books, 2004. Print.

Zagone, Robert N., dir. Dylan Speaks: The Legendary 1965 Press Conference in San Francisco. USA: Eagle Rock, 2006. DVD.

ZapatistaDiF. "Tom Morello Interview + Know Your Enemy - Hulstfred 6/12/97." YouTube. YouTube, 21 Dec. 2007. Web. 28 June 2016.

ZapatistaDiF. “Tom Morello Interview - 'What Is the Machine?"” YouTube. YouTube, 6 Oct. 2007. Web. 28 June 2016. 


\section{CURRICULUM VITAE}

\section{HARLEY FERRIS}

Department of English

University of Findlay

1000 N. Main Street

Findlay, OH 45840

\section{EDUCATION}

Ph.D. Rhetoric and Composition. University of Louisville. 2016.

M.A. English. University of Louisville. 2012.

B.A. English. Jacksonville University. 2010.

\section{EMPLOYMENT}

Assistant Professor

University of Findlay. 2016-present.

Graduate Teaching Assistant

University of Louisville. 2011-2016

Senior Instructor

Digital Media and Composition Institute at The Ohio State University. 2013.

Writing Center Consultant

University of Louisville. 2010-2011.

\section{SCHOLARLY PUBLICATIONS}

Ferris, Harley. "Making the Case: DMAC as Professional Activism." CIWIC, DMAC, and Technology Professional Development in Rhetoric and Composition. Spec. issue of Computers and Composition Online. (Spring 2015): n. pag. Web. 24 August 2015.

\section{CREATIVE FICTION AND NONFICTION PUBLICATIONS}

Ferris, Harley. "Spring Summer Fall Winter Spring.” Word Riot (May 2009): n. pag. Web. 24 August 2015. 
Ferris, Harley. “Lorrell Lake.” Aquarian. (2010): 85-93. Print.

Ferris, Harley. "This Above All: A Personal History of a Writing Student." Florida English Journal 43.1 (Spring 2008): 10-12. Print.

DIGITAL PRODUCTION (Projects and links available at harleyferris.com)

KairosCast

Official podcast for the journal Kairos. Ongoing.

Finding Voices: The Art as Memory Project

Documentary for the Council on Developmental Disabilities. 2015.

"Leaving Nashville"

Creative non-fiction video for the Center for Digital Storytelling. 2015

Conference Program

Forty-page program for the International Association of the Study of Popular Music conference. 2015

Conference Website

Program and registration website for the Thomas R. Watson Conference in Rhetoric \& Composition. 2014.

Aktion T-4 Website

Archival research website with video and audio production for Brenda Brueggemann. 2012-2013.

\section{CONFERENCE PRESENTATIONS}

"Before and Beyond Web 2.0: Music, Technology, and Collective Action" Rhetoric Society of America Conference. Atlanta, GA. May 2016.

"Re-sounding Feedback: The Role of the Voice in Assessment" Conference on College Composition and Communication. Houston, TX. May 2016.

"Podcasting Together: Recording, Editing, and Sharing Sound" (half-day workshop)

Computers and Writing Conference. Menomonie, WI. June 2015.

"Talk to the Talkers: What Is Academic Podcasting All About?"

Computers and Writing Conference. Menomonie, WI. June 2015.

"Beyond Publics 2.0: Responding to the Digital Frontier" 
Watson Conference on Rhetoric and Composition. Louisville, KY. October 2014.

"Composing Revolution: The Body Rhetoric of Protest Music"

Computers and Writing Conference. Pullman, WA. June 2014.

"It Is What It Does: Music-making as Non-violent Resistance in the Civil Rights Movement"

Conference on College Composition and Communication. Indianapolis, IN. April 2014.

"Ways of (Sonic) Being: Composing and Performing Sonic Rhetorics" Computers and Writing Conference. Raleigh, NC. May 2012.

"To Sound American: Perceptions of Accent and Error across the Disciplines" Penn State Conference of Rhetoric and Composition. State College, PA. July 2011.

"From Humor to Horror: How Shirley Jackson Changed American Gothic" Alabama Regional Graduate Conference. Florence, AL. October 2010.

"Flannery O'Connor Is Hard to Find: A Biographical Criticism of O'Connor's Portrayal of the South"

National Conference on Undergraduate Research. Missoula, MT. April 2010.

"Between the Lines: The Visual Rhetoric of Comics"

National Council of Teachers of English Conference. Philadelphia, PA.

November 2009.

"Are We There Yet? A Study in Dystopian Fiction"

National Conference on Undergraduate Research. Salisbury, MD. April 2008.

\section{ADMINISTRATION}

Assistant Director of the University Writing Center

University of Louisville. 2014-2015.

Assistant Director

Digital Media and Composition Institute at The Ohio State University. 2014.

Assistant Coordinator of Creative Writing

University of Louisville. 2012-2013. 


\section{PROFESSIONAL SERVICE}

Section Editor

Kairos: A Journal of Rhetoric, Technology, and Pedagogy. 2014-present.

Assistant Editor

Kairos: A Journal of Rhetoric, Technology, and Pedagogy. 2011-2014.

Blog Editor

Computers and Composition Digital Press. 2013-present.

Workshop Leader

School of Interdisciplinary Graduate Studies, University of Louisville. 20112013.

\section{AWARDS AND HONORS}

Kairos Award for Research

Computers and Writing Conference. June 2014.

Sarah-Jean McDowell Award for Fiction

University of Louisville. May 2014.

University Fellowship

University of Louisville. 2012 and 2014

College of Arts \& Sciences Student of the Year

Jacksonville University. May 2010.

Division of Humanities Student of the Year

Jacksonville University. May 2010.

English Department Student of the Year

Jacksonville University. May 2010.

Writing Awards: 1st in Fiction, 1st in Poetry, 3rd in Critical Thinking

Florida Collegiate Honors Conference. February 2009.

\section{MEMBERSHIPS}

Modern Languages Association

National Council of Teachers of English

Sigma Tau Delta

Omicron Delta Kappa 